\title{
Free can catch me : empirical studies on the effects of premium and free-trial promotions on consumer behavior
}

Citation for published version (APA):

Rolef, C. (2012). Free can catch me : empirical studies on the effects of premium and free-trial promotions on consumer behavior. [Doctoral Thesis, Maastricht University]. Datawyse / Universitaire Pers Maastricht. https://doi.org/10.26481/dis.20121218cr

Document status and date:

Published: 01/01/2012

DOI:

10.26481/dis.20121218cr

Document Version:

Publisher's PDF, also known as Version of record

Please check the document version of this publication:

- A submitted manuscript is the version of the article upon submission and before peer-review. There can be important differences between the submitted version and the official published version of record.

People interested in the research are advised to contact the author for the final version of the publication, or visit the DOI to the publisher's website.

- The final author version and the galley proof are versions of the publication after peer review.

- The final published version features the final layout of the paper including the volume, issue and page numbers.

Link to publication

\footnotetext{
General rights rights.

- You may freely distribute the URL identifying the publication in the public portal. please follow below link for the End User Agreement:

www.umlib.nl/taverne-license

Take down policy

If you believe that this document breaches copyright please contact us at:

repository@maastrichtuniversity.nl

providing details and we will investigate your claim.
}

Copyright and moral rights for the publications made accessible in the public portal are retained by the authors and/or other copyright owners and it is a condition of accessing publications that users recognise and abide by the legal requirements associated with these

- Users may download and print one copy of any publication from the public portal for the purpose of private study or research.

- You may not further distribute the material or use it for any profit-making activity or commercial gain

If the publication is distributed under the terms of Article $25 \mathrm{fa}$ of the Dutch Copyright Act, indicated by the "Taverne" license above, 


\section{Free Can Catch Me}

Empirical Studies on the Effects of Premium and Free-trial Promotions on Consumer Behavior 
Free Can Catch Me - Empirical Studies on the Effects of Premium and Free-trial Promotions on Consumer Behavior

(C) 2012 Charlotte Rolef, Bonn

All rights reserved. No part of this publication may be reprinted or utilized in any form or by any electronic, mechanical or other means, now known, or hereafter invented, including photocopying and recording, or in any information storage or retrieval system, without permission from the copyright owner.

ISBN 9789461591999

Cover Design: Janina Schmitz

Layout and Printing by: Datawyse Maastricht 


\title{
Free Can Catch Me
}

\section{Empirical Studies on the Effects of Premium and Free-trial Promotions on Consumer Behavior}

\author{
PROEFSCHRIFT \\ ter verkrijging van de graad van doctor \\ aan de Universiteit Maastricht, \\ op gezag van de Rector Magnificus, prof. dr. L.L.G. Soete \\ volgens het besluit van het College van Decanen, \\ in het openbaar te verdedigen \\ op dinsdag 18 december 2012 om 12:00 uur \\ door
}

Charlotte Rolef

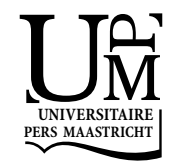




\section{Promotor}

Prof. dr. M. Wetzels

\section{Copromotor}

Dr. B. Foubert

\section{Beoordelingscommissie}

Prof. dr. K. de Ruyter (voorzitter)

Prof. dr. M. Carree

Prof. dr. K. Gedenk (Universität Hamburg) 
Für meine Familie 


\section{Acknowledgements}

Finally, I managed to finish this dissertation and am really happy. The last years were very busy and I need to thank a number of people that joined me on this journey:

My first thanks goes to Dr. Elizabeth Bruggen because I would not have started my $\mathrm{PhD}$ position at Maastricht University without her. She gave me the 'final push' and a couple of weeks later I was welcomed in the department. I was given the opportunity to work together with Prof. Dr. Martin Wetzels and Dr. Bram Foubert, which I am extremely thankful for.

Martin Wetzels became my promoter and always had an open ear for problems, questions or other issues. Martin, thanks a lot for your feedback and your support in all types of organizational matters. Your opinion on my research as well as your hints on how to proceed proved very valuable. On top, you always took a couple of minutes after having discussed the research for a relaxed talk about this and that.

Bram Foubert became my daily supervisor and was an enormous help. I was always welcome to ask for feedback and drop by his office. Bram, thank you so much for all your support and your motivation. Your feedback was extremely helpful and always very timely, even though you tended to apologize for being late. I am impressed by your work attitude and the effort you put into doing research. Furthermore, I enjoyed our talks about family life and the up and downs there are when combining work and family.

Together, the two of you made up a team that successfully supported me in all directions during the process of writing my dissertation. The combination of your two personalities was constructive and worked very well for me.

But the department had even more to give: I enjoyed sharing thoughts, ideas, successes, and drawbacks with my fellow PhD students and colleagues. Ingrid Beckers, Nina Gros, and Linda Lichel turned from office mates to dear friends. Vera Blazevic and I had fruitful talks while commuting together and Pascalle, Eefje, and Nicole took care of all types of administrative matters. I liked being a part of the department and benefited from all the different personalities, their insights, and ideas.

A special thanks goes to Prof. Dr. Karen Gedenk, Prof. Dr. Els Gijsbrechts, and Dr. Els Breugelmans, who gave valuable and very interesting comments on 
my research projects. I appreciate that each of you took time to support me and helped me to look at my research from always different angles.

However, not only my dissertation has kept me busy, but also my personal life. My marriage with Ralf and giving birth to Frederik and Greta were outstanding and unforgettable moments! These three persons have become the center of my life and it was not always easy to hide in my office and work on this dissertation while these three were waiting for me. Ralf, I really much appreciate your patience and your endless support. I love you and am excited for the things to come.

My parents have supported me my entire life. I can always rely on them, my sister Leonie, and my brother Jan. Whatever decision I take in my life, my family is with me and there is never any doubt. I have experienced this as outstanding and noteworthy and am now trying to act in a similar way. Mama und Papa, vielen lieben Dank!

And now some last acknowledgments: Since I have started another job while still working on my dissertation, I need to thank the IAL for its flexibility in stressful moments. Moreover, there are numerous friends, relatives, and acquaintances that I have not mentioned yet. This is the place to thank you for your company up to this point and for everything that will still happen in the future!

Charlotte Rolef, Bonn 2012 



\section{Table of Contents}

Chapter 1: Introduction $\quad 11$

1.1. Motivation 12

1.2. Review of Research on Free Promotions 13

1.3. Objectives 22

1.4. Dissertation Outline 23

Chapter 2: The Effects of Premium Promotions on Consumers' Incidence, Choice, and Quantity Decisions 25

2.1. Introduction 26

2.2. Contribution to the Literature 28

2.3. Hypotheses and Conceptual Framework 32

2.4. Experimental Design and Data Collection 36

2.5. Model Description 46

2.6. Results 51

2.7. Simulation Study 62

2.8. Conclusions and Managerial Implications 67

Chapter 3: The Effects of Free Trials on Consumers' Adoption Decisions of Contractual Services $\quad 71$

$\begin{array}{ll}\text { 3.1. Introduction } & 72\end{array}$

3.2. Literature Review 73

3.3. Conceptual Framework for the Effects of Free Trials 82

3.4. Empirical Study 85

3.5. Model and Variable Description 87

3.6. Results and Discussion $\quad 91$

3.7. Conclusion and Managerial Implications 94

Chapter 4: Conclusion $\quad 99$

4.1. Introduction 100

4.2. Discussion 100

4.3. Directions for Further Research 102

$\begin{array}{ll}\text { Appendix Pre-Purchase Questionnaire } & 104\end{array}$

$\begin{array}{ll}\text { References } & 107\end{array}$

$\begin{array}{ll}\text { Curriculum Vitae } & 115\end{array}$ 

Chapter 1

\section{Introduction}




\subsection{Motivation}

Free is a very intriguing concept that is of importance in many different situations: The entrance to a museum may be free, consumers may receive a free guarantee, or public transport may be offered for free. The fact that a certain service or product is offered at no cost makes the offer particularly interesting by suggesting that 'normally' a price had to be charged. Yet, can the desired and wished for responses ever be accomplished by giving out free things? What motivates individuals and firms to provide certain offers at no cost?

Gift giving is common practice in our society. However, its rules are manifold and depend strongly on the specific situations. If you unwrap your partner's present and find 100 Euros, you will be disappointed, because you rather expected a present with some symbolic meaning. Gift giving among partners is thus subject to the social exchange model, in which gifts have a symbolic meaning and are meant to build up social bonding such that reciprocity is not expected to take place immediately (Belk and Coon 1993). In other situations, the economic exchange model applies (Belk and Coon 1993). If a neighbor invites you for dinner, you will invite her for dinner at your house in response and take care that you put comparable effort in preparing the meal. In the economic exchange model gifts are valued based on economic attributes and immediately reciprocated with gifts of comparable monetary value to avoid dependence among the parties. Thus, the relationship among the parties involved determines the motivation of giving a gift, how a gift should be selected, and the expectations of the giver and receiver. Apart from situations of individual gift giving, free affects consumers' mindsets and behavior in many more circumstances.

Academic research on compensation and rewards also studies the role of free. In general, rewards, which are provided closely after a certain behavior, increase the chance of reoccurrence of this behavior (Deci, Koestner, and Ryan 1999). However, if an individual is intrinsically motivated to perform an activity, a reward is counterproductive, because extrinsic rewards may undermine intrinsic motivation and decrease performance (Deci et al. 1999; Gneezy and Rustichini 2000b). Gneezy and Rustichini (2000a) illustrate that introducing a fine for late coming parents increased the number of parents that came late to pick up their children (Gneezy and Rustichini 2000a). As long as parents did not have to pay a fine, they considered the service of the teacher to stay with their children as goodwill and tried to avoid being late. However, as soon as a fine was introduced, the teacher's behavior of staying with the children was perceived as a service parents pay for if needed. Heyman and Ariely (2004) argue that the character of a compensation determines whether consumers think in terms of monetary or social markets. If individuals receive a monetary compen- 
sation, they think in terms of market norms and according to reciprocation motives. Their performance is sensitive to the level of monetary rewards. However, if there is no or some non-monetary incentive, individuals behave in line with social norms, which are based on altruistic motives.

In product markets, zero price leads to surprising effects (Shampanier, Mazar, and Ariely 2007). Shampanier et al. (2007) report that consumers choose a product significantly more often, if it is offered for free than if it is offered at some cost. The findings provide empirical evidence that affect acts as a decisional cue and steers consumers' choices for the free product. Offering a product for free affects consumers' cost-benefit analysis. Instead of solely decreasing costs, free adds to the benefits and increases the product's attractiveness. Social norms have also been found to be at play in that they influence the amount of free products taken by a consumer. The majority merely takes one unit, if it is free, but takes multiple units when paying some positive price.

Free influences consumers' mindsets and behavior in that it determines a consumer's situational evaluation routines. Consumers' seem to perceive a free offer as a gift and evaluate the situation as a social exchange rather than a market exchange. However, even in gift giving among acquaintances reciprocity and monetary equality play a role. This triggers the question, what the effects of free offers as an incentive to promote products and services will be? Particularly, how do consumers react and can the use of free offers in promotions catch consumers and thus increase sales? To help answering these questions, this dissertation studies two promotions that involve a free offer-namely premiums, which are free gifts offered with the purchase of a product at its regular price and free trial promotions, which offer consumers the chance to try a service at no costs over a limited time period. Examples of premium promotions are toy-trucks with the purchase of washing powder and toys or glasses with McDonald's Happy Meals. Free trials are predominantly used for contractual services such as AOL, which offered free internet hours, and Microsoft, which offers free software trials via internet.

Free offers have already received attention in academic research. The next section reviews these studies and their findings to provide an overview of free offers in promotions and their effects.

\subsection{Review of Research on Free Promotions}

Firms regularly use promotions that involve free offers, such as bonus packs or 'Buy one get one free' promotions, free samples, premium promotions, and free trial promotions. In this section, we first discuss the relevant research sorted by promotion type and second evaluate what has in general been found on the role 
of free in promotional research. Table 1.1 presents an overview of the studied relationships and effects of promotions that involve a free offer.

Studies on premium promotions (Chandran and Morwitz 2006; D'Astous and Jacob 2002; Darke and Chung 2005; Shimp, Dyer, and Divita 1976) report inconsistent findings with regard to the promotion's effects on choice (Nunes and Park 2003; Simonson, Carmon, and O'Curry 1994). While Nunes and Park (2003) find positive sales effects, Simonson et al. (1994) show that premiums have no or even a negative impact. In a recent study with panel data on multiple premiums, Gedenk et al. (2010) report that some premiums positively affect sales while some have no or even a negative impact. Important factors that determine a premium's effectiveness have either not been studied or have not been sufficiently understood and require further attention.

The reviewed literature on free offers as incentives shows a lack of studies on the effects of free-trial promotions. Laochumnanvanit and Bednall (2005) formulate propositions on the evaluation of the trial, but neither empirically test these propositions nor consider behavioral effects or sales. Thus, there exists no empirical evidence on how free trials affect either evaluative or behavioral outcomes.

Contrary to free trials, there exist multiple studies on the effects of free product samples. Free samples are distinct from free service trials, because the former offers a fixed consumption amount whereas the latter provides a fixed consumption period. During this consumption period, the consumer can freely decide on the extent to which she uses the service. Thus, investigating usage becomes necessary. The findings of the reviewed studies reveal that samples exert positive effects on attitudinal measures and lead to immediate sales increases (Bawa and Shoemaker 2004; Heiman et al. 2001; Manchanda, Ying, and Youn 2008). Moreover, Gedenk and Neslin (1999) report that samples can lead to more positive purchase event feedback - a higher likelihood of future brand purchases - than monetary promotions.

Bonus pack promotions involve promotional packages of a product with free extra content (Chen et al. 2012; Diamond 1992; Hardesty and Bearden 2003). A variation is the 'Buy one get one free' promotion, which offers a second unit of the product for free (Sinha and Smith 2000). Of the reviewed studies on bonus pack promotions, none examines behavioral effects. Moreover, the comparison of bonus packs and price cuts has barely received any attention (Ong et al. 1997). Apparently, the focus so far has been on the investigation of different moderators of the relative performance of bonus packs and price cuts. For instance, Mishra and Mishra (2011) find that a price cut is preferred over a bonus pack for unhealthy food, because consumers look for justification of the purchase. The relationship reverses for healthy food because no monetary justification to buy more healthy food is necessary. 
Generally, research on free offers as incentives to purchase has investigated a variety of different product categories and factors that were expected to have an influence such as type of brand or framing of the promotion. The findings suggest that promotions involving a free offer can be effective tools to improve consumers' attitudes and perceptions (Bettinger, Dawson, and Wales 1979; D'Astous and Jacob 2002) as well as their purchase behavior (Heiman et al. 2001; Nunes and Park 2003). Noticeably, the different presentations of the free offer, for example as a free gift or as free extra content, influence consumers reactions. The investigated moderators vary across the reviewed studies. For example, consumer skepticism is an issue in research on premium promotions (Brown and Carpenter 2000; Simonson 1999), but much less in research on samples or bonus packs. Moreover, the depth of the promotion is recognized as a crucial factor in studies on the effectiveness of bonus packs and premium promotions, but not in research on sample promotions. While each promotion type has its own peculiarities and effects that deserve separate attention, some mechanisms are shared by most promotions that involve a free offer.

\subsubsection{Theoretical Considerations of Free}

The reviewed studies on promotions involving a free offer indicate that free requires particular attention. Indeed, free triggers a number of different mechanisms.

Interestingly, the mere mentioning of free causes consumers to process information differently: Shampanier et al. (2007) show that free not only reduces costs, but also increases the product's benefits, which leads to an overvaluation of the free product's value. Similarly, Gaeth et al. (1991) report that consumers tend to value free gifts higher than their actual retail value.

Moreover, promotions involving a free offer are less likely incorporated into the product's price, because these promotions are perceived by consumers as very salient (Chandran and Morwitz 2006) and deemphasize price arguments. According to mental accounting theory, free-offer promotions are perceived as a separated gain rather than a reduction of a loss (the price) (Kahneman and Tversky 1979; Thaler 2008). Free offers can easily become incommensurate resources (Nunes and Park 2003), if they are not framed in the same currency as the product's price, but focus on 'free'. That means consumers cannot easily compare the value of the free offer to the underlying product's price and have to base their evaluation of the promotion on other grounds. The results of such evaluations are often favorable for a promotion's perceived value. Free offers move consumers' focus away from price and thus avoid that consumers' perceptions of quality, deal value, and brand equity are negatively affected as may be the case with regular price discounts (Darke and Chung 2005; 
Palazón-Vidal and Delgado-Ballester 2005; Sprott and Shimp 2004). The salience of free offers can be very advantageous, because free offers may serve as a heuristic to solve complex choice tasks (Brown and Carpenter 2000). 


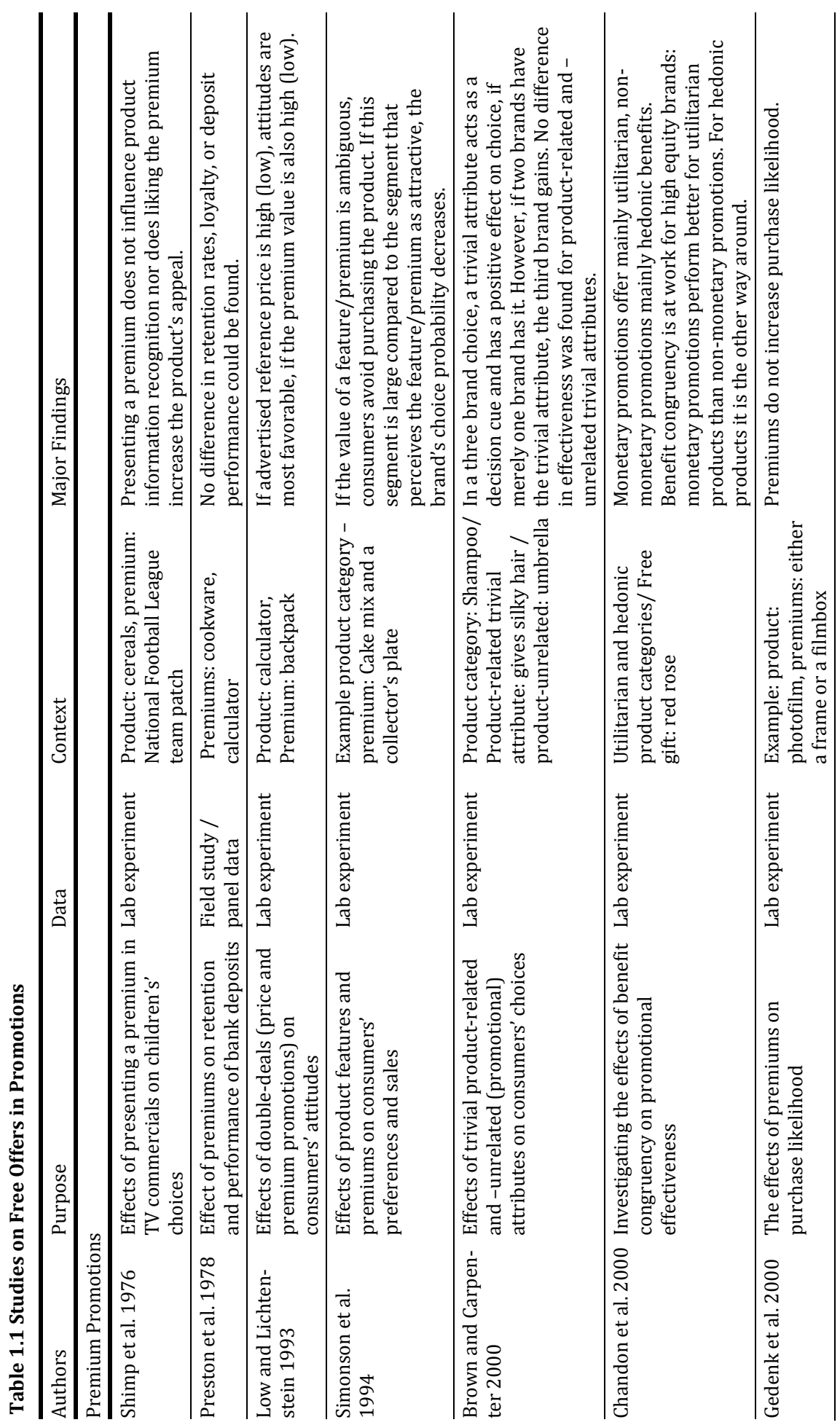




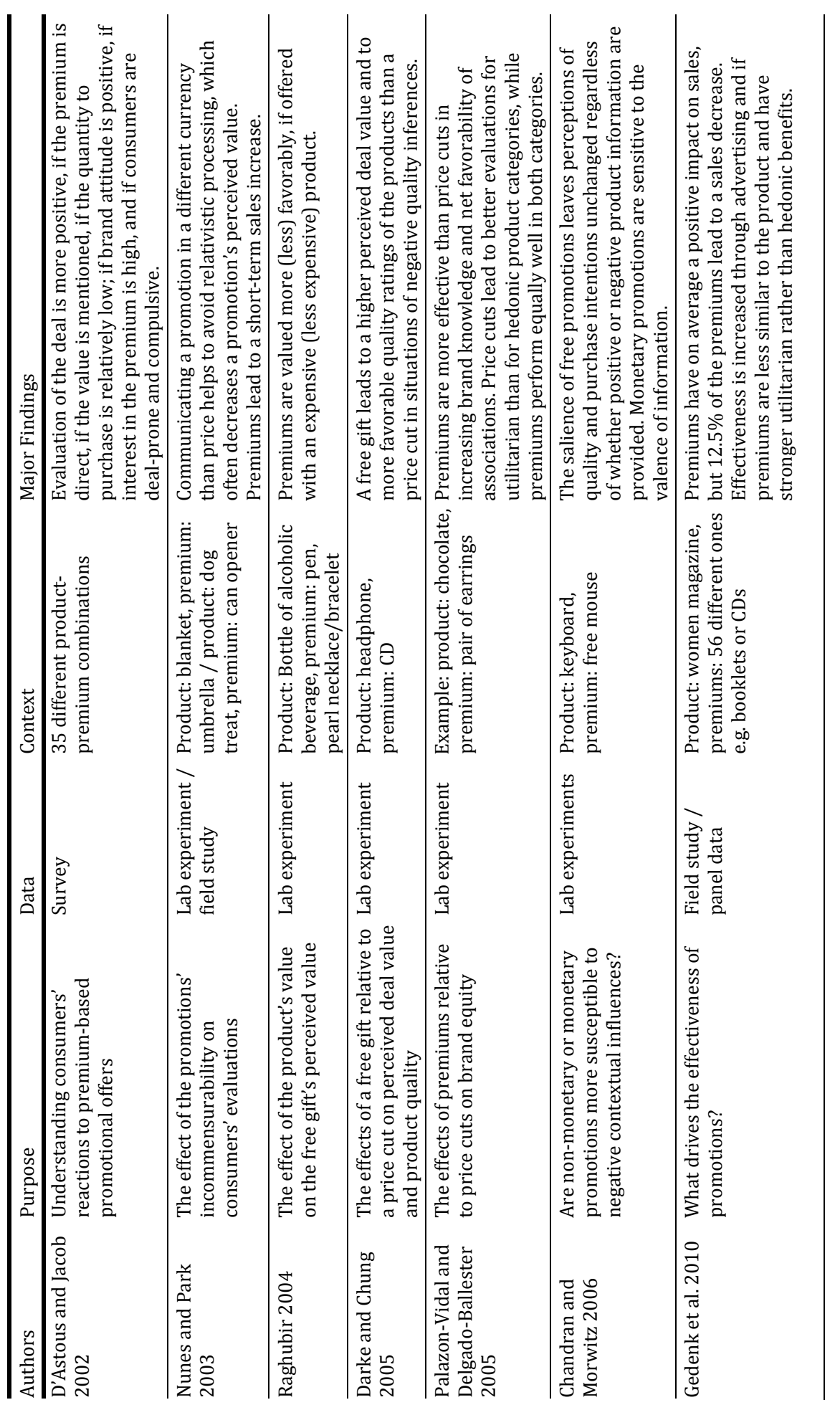



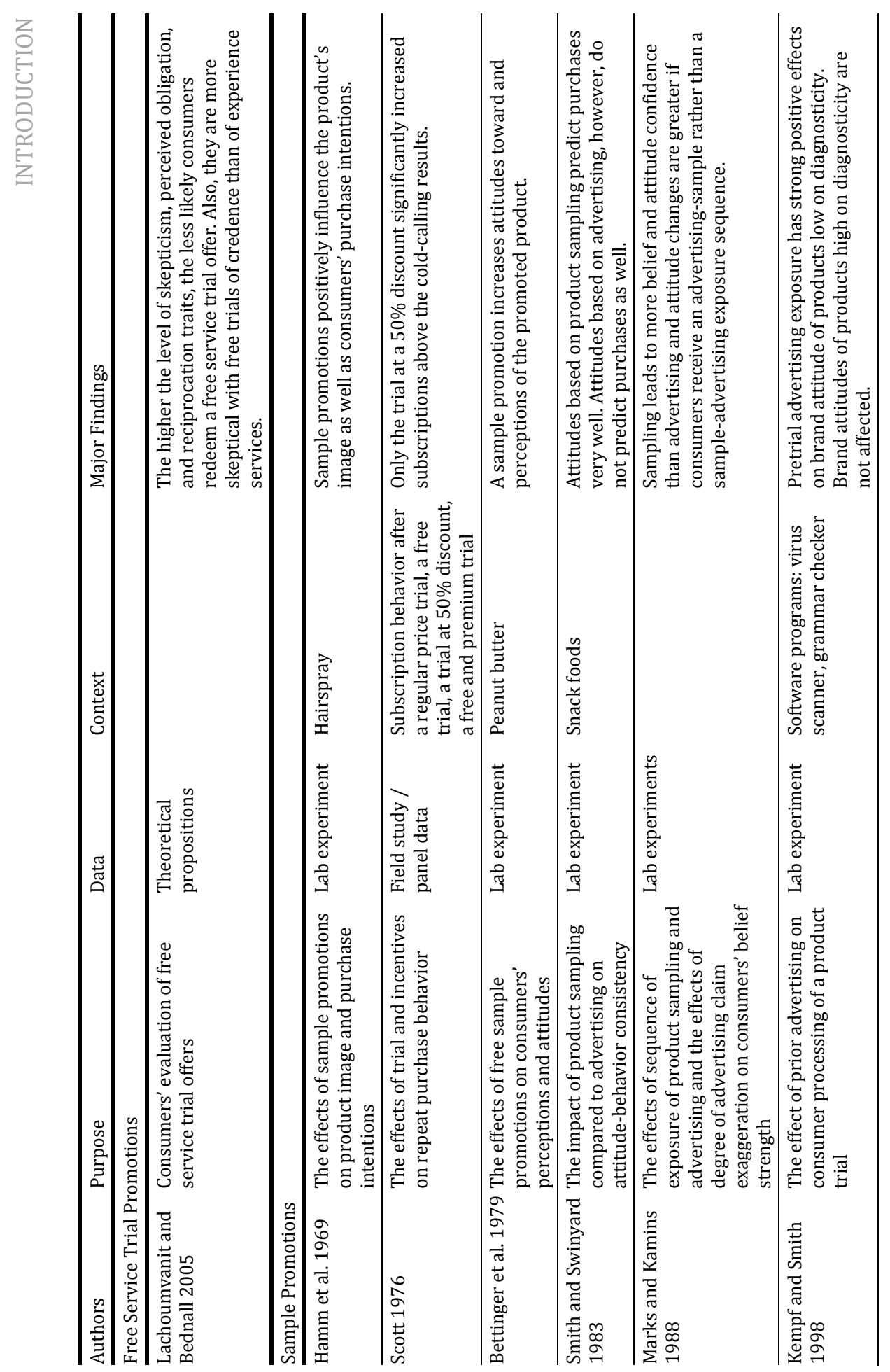


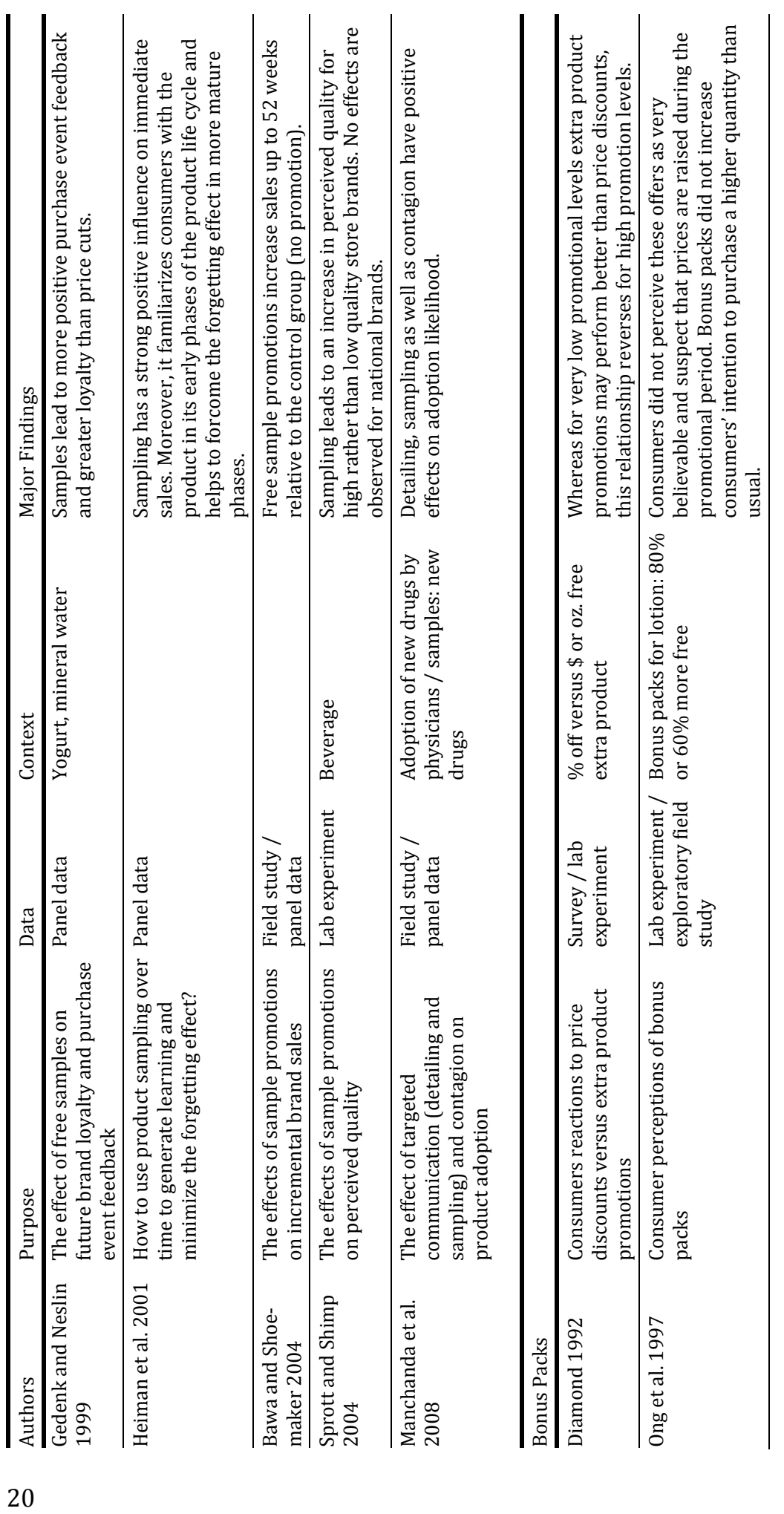




\begin{tabular}{|c|c|c|c|}
\hline 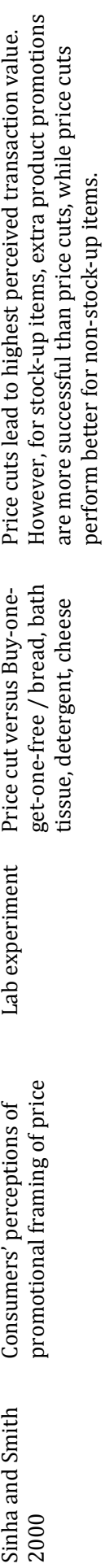 & 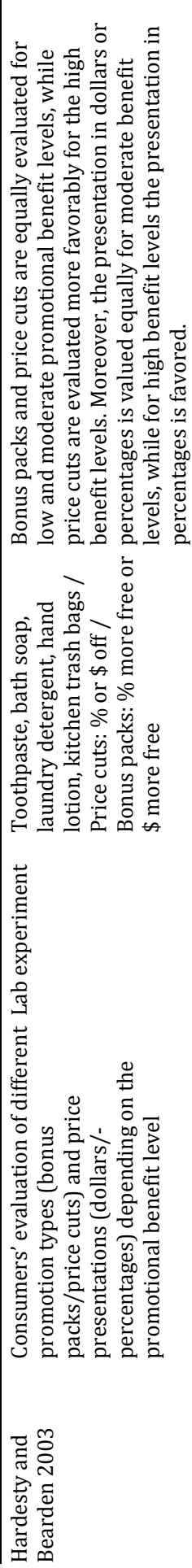 & 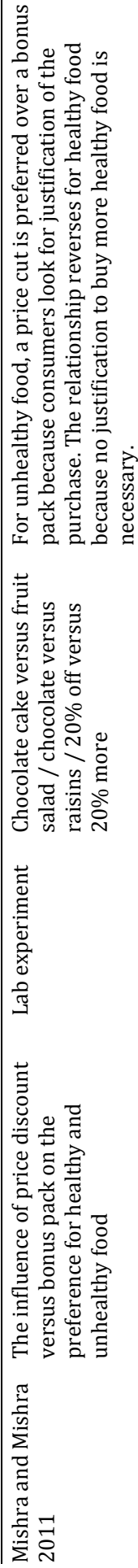 & 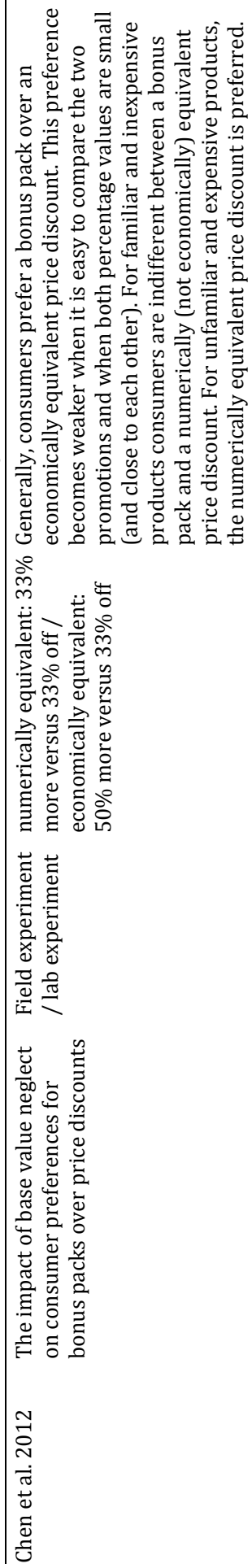 \\
\hline
\end{tabular}




\subsection{Objectives}

Free is an intriguing concept and its use as incentive to catch consumers has received some attention in literature. There seem to be general mechanisms at work, which are affected by the promotions' individual characteristics. To shed further light on how free offers affect promotional effectiveness, we investigate two research questions:

\section{What are the immediate effects of premium promotions on consumers' incidence, choice and quantity decisions and how do these effects com- pare with those of price cuts?}

\section{How do free trials influence consumers' adoption decisions of contrac- tual services?}

\subsubsection{Premium Promotions}

The second chapter explores the immediate effects of premium promotions on consumers' actual behavior and how premium effects compare to those of price cuts. Most research so far has investigated evaluative outcomes (D'Astous and Jacob 2002; D'Astous and Landreville 2003; Shimp et al. 1976) and consumer choice (e.g. Chandon, Wansink, and Laurent 2000; Gedenk, Hartmann, and Schulze 2000; Gedenk, Hoffmann, and Fantapié Altobelli 2008; Simonson et al. 1994), but neglected consumers' incidence and quantity decisions. Moreover, the studies on the effects on choice have reported inconsistent results, which require further attention. Another important contribution of our research is that we compare premium promotions to price cuts. Premium promotions are commonly used in the fast-moving consumer goods sector and thus form an alternative to price cuts. Yet, it is unclear how premiums compare to price cuts with regard to their effects on consumers' behavioral decisions, namely incidence, choice, and quantity.

We collect data via an online shopping experiment with seven consecutive weeks in which purchases of fast-moving-consumer-goods could be made. We build upon multiple theories to formulate expectations and hypotheses. In particular, we examine (1) how a premium promotion influences a consumer's incidence, choice, and quantity decisions, (2) how a premium promotion compares to a price cut, and (3) how this relative performance is influenced by three crucial moderators, namely category type - hedonism versus utilitarianism, brand type - national brand versus private label, and premium-product 
relatedness. We use a simultaneously estimated nested multinomial Logit model and a zero-truncated Poisson model with unobserved consumer heterogeneity to analyze the data.

\subsubsection{Free-Trial Promotions}

The objective of Chapter 3 is to examine whether (1) consumers choose free trials instead of the regular paid contract, whether (2) they adopt the regular paid contract more likely after using the trial, and (3) the extent to which usage intensity moderates the effect on adoption of the paid offer. Although companies regularly use free trials for innovative contractual services, academic research has to the best of our knowledge not yet studied this relationship. Empirical evidence on the influence of sales promotions on innovation adoption is limited and focuses mainly on products (Manchanda et al. 2008; Steenkamp and Gielens 2003). Prins and Verhoef (2007) and Nam et al. (2010) investigate actual adoption behavior of a new contractual service, but concentrate on marketing variables other than sales promotions.

We use data on the introduction of digital TV from a major European telecommunication provider that includes consumer-specific information, marketing-related variables, and behavioral data. We develop a framework that describes how a free trial affects acquisition and transaction utility (Thaler 1985) and triggers a set of specific utility premiums. This framework enables us to predict how a free trial influences consumers' adoption likelihood. We use a multinomial Logit model to estimate our model.

\subsection{Dissertation Outline}

This dissertation is divided into four chapters of which Chapters 2 and 3 are the empirical studies. Chapter 4 concludes on the theoretical findings of the empirical studies, discusses the managerial implications, and provides suggestions for further research.

The study of Chapter 2 investigates the immediate effects of premium promotions on incidence, choice, and quantity, compares these effects to those of price cuts and examines three crucial moderators of this relationship. The study of Chapter 3 examines the effects of a free-trial promotion on adoption likelihood of a contractual service. Both studies rely on insights from promotional literature, but differ in their set-up. On the one hand, we consider a free trial in a service setting and rely on panel data from a large company that we analyze using a multinomial Logit model. On the other hand, we study the effect of a premium attached to a product, collect data via an experiment and use a 
nested multinomial Logit model and a zero-truncated Poisson model with unobserved consumer heterogeneity. Moreover, the way the free offer is provided differs. Premiums are conditional on purchasing a product at its regular price and thus dependent on purchase. Free-trial promotions are offered unconditionally of any purchase. Here, the purchase decision takes place after the trial period. 


\section{Chapter 2}

\section{The Effects of Premium Promotions on Consumers' Incidence, Choice, and Quantity Decisions}

Firms often use premium promotions-free gifts offered with products purchased at their original prices, although academic research has not sufficiently studied their effects on consumers purchase decisions. To shed light on this relationship, we use data from an online shopping experiment and model a premium's effects on consumers' incidence, choice, and quantity decisions with a simultaneously estimated nested multinomial Logit model and a zerotruncated Poisson model with unobserved consumer heterogeneity. The results are in line with our expectations that premiums increase the likelihood of category purchases and induce brand switching, but leave consumers' quantity decisions unaffected. The comparison of premium and price cut effects reveals that a price cut in general outperforms a premium promotion. However, two of three studied moderators improve a premium's position and a simulation study illustrates that managers may prefer premiums depending on the pass-through rates. 


\subsection{Introduction}

A premium, or a product consumers receive for free with the purchase of another product at its regular price (D'Astous and Jacob 2002), is a wellestablished promotion regularly used by manufacturers in the marketplace. For example, McDonald's, as well as many fast-moving consumer goods companies, including Henkel and Procter \& Gamble, frequently give away premiums, such as free toys with the purchase of McDonald's Happy Meals or free toy trucks with the purchase of washing powder. Because premiums are gifts to consumers, they are expected to be perceived positively and as attractive. However, premium effects are not well understood. Extant literature suggests that carefully selected premiums can lead to favorable perceptions of the premium and the promoted product (D'Astous and Jacob 2002; D'Astous and Landreville 2003; Shimp et al. 1976), but studies investigating the effect of premiums on sales report positive as well as negative effects and even no effect at all (e.g. Chandon et al. 2000; Gedenk et al. 2000; Simonson et al. 1994). Furthermore, it remains unclear when firms should choose a premium over a traditional price cut. Even when a premium and a price cut have the same perceived value to end consumers, their different nature may lead to different outcomes. We acknowledge a need for a more systematic analysis of premium effectiveness. Thus, we investigate the immediate effects of premium promotions on consumers' incidence, choice, and quantity decisions and compare this performance with that of price cuts. In addition, we analyze whether a premium's performance compared with that of a price cut is moderated by three crucial factors namely premium-product relatedness, brand type, and category type. Our research adds to academic literature in three ways.

First, research on premium promotions has focused on consumers' evaluative responses (D'Astous and Jacob 2002; D'Astous and Landreville 2003; Shimp et al. 1976). The few studies that do investigate objective outcomes concentrate on brand choice or aggregate sales and neglect the quantity and incidence decisions (e.g. Chandon et al. 2000; Gedenk et al. 2000; Gedenk et al. 2010; Simonson et al. 1994). Thus, further research on all three decision levels is necessary because previous research reveals that a sales promotion may perform differently on the three decision levels (e.g. Foubert and Gijsbrechts 2007; Van Heerde, Gupta, and Wittink 2003).

Second, we compare the performance of premium promotions on all three decision levels with that of price cuts and systematically ensure that the different promotions have comparable perceived values. Although some studies include premiums as well as price cuts in their analyses, perceived values do not match, which impedes a direct comparison of the two promotion types (Chandon et al. 2000; Gedenk et al. 2000; Nunes and Park 2003). 
Third, research on sales promotions has identified several unique characteristics of premiums (e.g. Nunes and Park 2003; Raghubir 2004), but it has not systematically manipulated these characteristics to understand their impact on relative premium effectiveness. We choose three important moderators: a product category's degree of hedonism/utilitarianism, whether a product is a private label or national brand, and the degree of premium-product relatedness. Doing so enables us to gain insights into how and when the promotions' performances differ and the circumstances in which a premium can be used as an alternative to the popular price promotion.

This study is based on an online shopping experiment that simulated seven consecutive shopping trips during which participants were exposed to different promotions. The data set contains (fictitious) purchase decisions from 1930 respondents who are responsible for grocery shopping in their household and regularly purchase in at least one of the four product categories: margarine, orange juice, milk, and cereals. We use a nested multinomial logit (MNL) model to model incidence and choice and a zero-truncated Poisson model to model purchase quantity. We estimate the two models simultaneously using simulated maximum likelihood estimation with quasi-random Halton draws in SAS/IML. To capture unobserved heterogeneity, the parameters are normally distributed across households.

The results show that premiums have a positive effect on consumers' incidence and choice decisions but tend to leave the quantity decision unaffected. In general, premiums perform worse than equivalent price cuts on all decision levels. However, a premium's relative impact on choice and incidence increases if the premium comes with a private label rather than a national brand. This effect is strengthened in hedonic rather than utilitarian categories. Of interest, relatedness of the premium and the promoted product is not important. Although the findings in general suggest that a price cut is better able to increase product sales than an equivalent premium, the comparison is more favorable for premiums when costs are taken into account. Because premiums may cost the manufacturer considerably less than price cuts, a premium promotion may be the preferred strategy, particularly in hedonic categories.

In the remainder of the chapter, we provide an overview of the literature and present the conceptual framework and hypotheses. Next, we describe the experimental design, explain how we model the premium effects, and discuss the results. Then, we use the estimated coefficients to conduct a simulation study and compare the impact of alternative price and premium promotions on brand sales. A discussion of the results and their theoretical and managerial implications concludes the chapter. 


\subsection{Contribution to the Literature}

This study investigates the effectiveness of premium promotions and contributes to the extant sales promotion literature in three ways: It (1) examines the effects of premium promotions on consumers' incidence, choice, and quantity decisions; (2) compares these effects with those of traditional price cuts; and (3) investigates three moderators of the performance of premiums compared with price promotions. We next discuss these contributions in greater detail.

\subsubsection{Impact on Consumers' Purchase Decisions}

Rather than focusing on objective purchase decisions, most studies on premium effectiveness measure consumers' subjective evaluation of the promoted product (e.g. Darke and Chung 2005; Low and Lichtenstein 1993; Palazón-Vidal and Delgado-Ballester 2005) or the promotional offer as a whole (product plus premium) (D'Astous and Jacob 2002). For example, research has shown that premiums improve brand preference for (Shimp et al. 1976) and attitudes toward (Low and Lichtenstein 1993) the promoted product. Palazón-Vidal and Delgado-Ballester (2005) find that premiums generate more favorable associations with the promoted product, and Darke and Chung (2005) present evidence that premiums increase the perceived value of an offer.

Although most research focuses on evaluative responses to premium promotions, some studies have investigated consumers' actual behavior. However, this research falls short in providing a thorough understanding of the possible purchase effects for three reasons. First, some studies have focused on consumers' actual choice but used rather artificial choice settings in which respondents chose from small choice sets of two to three items (Chandon et al. 2000; Gedenk et al. 2000; Simonson et al. 1994) or in which the premiums involved unattractive items (Simonson et al. 1994). This research has found both positive (Chandon et al. 2000) and negative (Gedenk et al. 2000; Simonson et al. 1994) effects of premium promotions on brand choice.

Second, although field studies have investigated premium effectiveness, their focus is on only one product category and on aggregate sales (Esteban-Bravo, Múgica, and Vidal-Sanz 2009; Gedenk et al. 2010; Nunes and Park 2003; Preston, Dwyer, and Rudelius 1978). In addition, Esteban-Bravo et al. (2009) and Preston et al. (1978) do not state the promoted products' sales but rather focus on sales of a non-promoted version and a comparison of promotionally and non-promotionally-acquired customers, respectively. Gedenk et al. (2010) and Nunes and Park (2003) merely report the promoted products' average shortterm sales, which increase as a result of the premium. 
Third, choice represents only one step in the purchase process: Incidence and quantity decisions have been neglected. Because studies have focused on either choice or aggregate sales, how premiums perform at the individual purchase level cannot be generalized. However, previous research has shown that a sales promotion can be highly effective on one decision level and ineffective on another (e.g. Foubert and Gijsbrechts 2007; Van Heerde et al. 2003). Given their characteristics, we expect this to be true for premium promotions as well. Premiums are considered hedonic items (Chandon et al. 2000) and as valuable gifts that hold some economic value (Gaeth et al. 1991; Gedenk et al. 2000), which makes them effective at the incidence and choice levels. At the quantity level, we expect lower premium effectiveness. Premiums must be carried and stored by the consumer after product purchase. These costs increase with additional units of a premium, whereas the hedonic experience does not increase. While the effect at the quantity level is questionable, it might be positive at the incidence and choice levels. Thus, this study contributes to existing literature by examining the effects of premium promotions at all three consumer purchase decision levels in a more realistic purchase context than that in prior studies.

\subsubsection{Comparison with Price Cuts}

With the increase in competition, both manufacturers and retailers have searched for alternatives to price promotions. In response, marketing researchers have studied the purchase effects of these alternative promotional techniques in comparison with price cuts. For example, research has shown that price cuts trigger stronger brand switching effects than either product features and displays (Kumar and Leone 1988) or charity promotions that promise a contribution to a social cause per unit sold (Arora and Henderson 2007). Compared with coupons, price cuts yield stronger quantity and incidence acceleration effects (Neslin, Henderson, and Quelch 1985). Other studies have identified promotion techniques that outperform regular price cuts. For example, Walters and Rinne (1986) find that sales are more strongly affected by double coupons than by price cuts. Furthermore, carefully designed bundle promotions can outperform price cuts because of their strong positive effects on consumers' choice decisions (Foubert and Gijsbrechts 2007).

Surprisingly, no research to date has systematically pitted the purchase effects of premium promotions against those of equivalent price cuts. Although Nunes and Park (2003), Chandon et al. (2000), and Gedenk et al. (2000) include both premiums and price cuts in their analyses, they do not match the perceived values of the promotions, which hinders a direct comparison. However, comparing these two types of promotions systematically is worthwhile because 
premium characteristics generally trigger different mechanisms than price cuts. A premium promotion is a non-monetary promotion with predominantly hedonic benefits (Chandon et al. 2000). Typically, a premium is free to consumers, and its monetary value is not communicated. Thus, consumers may perceive a premium's value as higher than its actual cost (Gaeth et al. 1991). A price cut's value is unambiguous, because it is clearly communicated. Mental accounting theory predicts that a premium, because of its non-monetary nature, is perceived as a separate gain, while a price cut is integrated in the product's price and is considered a decrease of loss (Nunes and Park 2003; Thaler 1985). Moreover, premium promotions might be more salient than price cuts because they involve some gift attached to a product, which catches consumers' attention (Chandran and Morwitz 2006). Another consequence of the non-monetary nature of premiums is that they do not suffer from reference price effects to the same extent as price cuts do. A premium is perceived as a separate gain, which is not integrated in the product's price and thus does not influence a consumer's quality or deal value perceptions (Darke and Chung 2005). Thus, premiums might perform better than price cuts at the incidence and choice levels and might lead to increased short-term sales. However, a premium needs to be carried, stored, and eventually disposed of, and its salience can lead to reactance and justification problems (Low and Lichtenstein 1993; Simonson et al. 1994). Therefore, premiums might be relatively less effective at the quantity level.

In this study, we examine the performance of premiums compared with that of price cuts while controlling for these promotions' perceived value. From here on, we use the term "relative premium effectiveness" to refer to the effectiveness of a premium relative to the corresponding price cut.

\subsubsection{Moderators of Relative Effectiveness}

Relative premium effectiveness should not be examined in isolation but hinges on several moderating factors. Extant research indicates that branding the premium (Raghubir 2004), stating a premium's monetary value (D'Astous and Jacob 2002; Nunes and Park 2003; Raghubir 2004), varying the necessary purchase quantity to receive the premium (D'Astous and Jacob 2002), and varying the promoted product's price (Raghubir 2004) all affect consumers' evaluations of the premium or the promotional offer as a whole. This study examines three factors that deserve specific attention because of their possible impact on the performance of premium promotions compared with that of price cuts: premium-specific, product-specific, and category-specific factors. Because our selection of moderators includes variations within the two product-level categories and brands as well as variations of the premium, we are able to gain a comprehensive view of relative premium effectiveness. 
First, the premium-specific variable is the premium's relatedness to the promoted product. We consider a premium and a product related if they can be used together in typical product usage situations (Gaeth et al. 1991; Martin and Stewart 2001). Previous promotional literature has recognized the importance of relatedness in consumer decision making. Kivetz (2005) observes that consumers choose a reward that is related to the performed effort. Gaeth et al. (1991) find that a bundle of two related products is perceived more valuable as the sum of its parts, except if the main product is of high quality. Recently, Gedenk et al. (2010) report that the premium's relatedness to the product decreases a premium's effectiveness in enhancing short-term sales. However, they define relatedness differently: Using a magazine as the main product, they consider an informational booklet a similar and a CD a dissimilar premium. Thus, the research to date has generated mixed results for the effects of relatedness and overall has not investigated how relatedness affects relative premium performance.

Second, we investigate the impact of the product-specific moderator brand type: We distinguish between national brands and private labels. In general, a private label is lower priced and has lower perceived quality than national brands (Sethuraman, Srinivasan, and Kim 1999). Previous work has demonstrated that consumers' out-of-stock reactions (Schary and Christopher 1979) and sales promotion responses (Sprott and Shimp 2004) differ between private labels and national brands. In this study, we argue that the effectiveness of a premium relative to a price cut depends on whether the promoted product is a private label or a national brand, such that private label and national brand managers may have different interests in premium promotions.

The third moderator involves the product category's degree of hedonism versus utilitarianism. Ample research has documented the importance of this factor throughout the consumer decision-making process (e.g. Dhar and Wertenbroch 2000; Okada 2005; Sloot, Verhoef, and Franses 2005). The promotional literature also accounts for the effects of hedonism and utilitarianism. For example, Park and Mowen (2007) report that in a hedonic purchase situation, non-monetary promotions are more effective than monetary ones, while these promotions seem equally effective in a utilitarian purchase situation. Similarly, Chandon et al. (2000) find that in contrast with price cuts, premiums are more effective when offered with a hedonic rather than a utilitarian brand. Thus, although the moderating impact of hedonism/utilitarianism on the performance of premiums has been addressed, we also include it in our study to obtain a more comprehensive overview of the promotions' effects on purchase decisions. 


\subsection{Hypotheses and Conceptual Framework}

In this section, we develop hypotheses about the effects of premium promotions on consumers' purchase decisions and the role of three moderating variables on the performance of premiums compared with that of price cuts. To provide a more sound comparison of premium and price cuts, we consider promotions whose economic value is perceived as equivalent by the average consumer. That is, we assume that the average consumer's willingness to pay for the premium equals the price reduction.

\subsubsection{The Impact of Premium Promotions on Consumers' Purchase Decisions}

In what follows, we develop hypotheses and expectations regarding the impact of premium promotions on incidence, choice, and quantity. We begin by discussing premium promotion effects at the incidence and choice levels and then continue with the quantity effects. We discuss the incidence and choice effects together because they are governed by the same principles (e.g. Bucklin and Gupta 1992; Bucklin and Lattin 1992).

\subsubsection{Choice and Incidence Effects}

We expect that premium promotions increase product and category attractiveness and base our argumentation on three principles. First and most obvious, consumers perceive premiums as having positive economic value (Gaeth et al. 1991; Gedenk et al. 2000), such that offers that include a premium are considered of greater value than offers without. Second, premiums can serve as a simple heuristic to solve complex choice tasks. Brown and Carpenter (2000) find that trivial attributes that are unimportant to the functioning of the product, such as product features, sweepstakes, or add-ons, can successfully distinguish a product from similar alternatives. Premiums can also be such attributes and thus work in a similar manner. Third, the mere hedonic experience of receiving a gift may appeal to consumers regardless of the premium's economic value (Chandon et al. 2000). In a similar vein, the so-called zero-price effect suggests that an item (the premium in our case) is particularly attractive when it is for free (Shampanier et al. 2007).

Admittedly, the promotional literature offers some theories that imply negative premium effects on product and category attractiveness. Attribution theory holds that a prominent promotion, such as a premium, may lead consumers to attribute their purchase to the promotion instead of the product itself and, as a consequence, make negative quality inferences about the product (Blattberg and Neslin 1990). Furthermore, in line with reactance theory, 
consumers may perceive a premium as a blunt manipulation that limits their choices and in response refrain from buying the promoted product (Brehm 1966, 1989). Finally, according to justification theory, consumers may find it difficult to justify the purchase of products with premiums whose benefits may not always be clear (Brehm 1966; Gedenk et al. 2000; Simonson et al. 1994).

We recognize that some consumers may perceive a product with a premium as unattractive, especially those who attach little or no value to the premium (Simonson et al. 1994). However, because we study premiums whose average value is non-negligible (we match the premiums' value with non-zero price discounts), we expect the premium's impact on the incidence and choice probabilities to be positive overall.

\section{H1: A premium promotion has a positive impact on consumers' incidence and choice decisions.}

\subsubsection{Quantity Effects}

Research shows that to fully reap the benefits of price cuts, consumers increase their purchase quantities; that is, they "accelerate" purchase (e.g. Ailawadi et al. 2007; Bell, Chiang, and Padmanabhan 1999; Gupta 1988). We expect that this phenomenon is unlikely to occur with premium promotions, and we support our reasoning with several principles. First, premium promotions mainly offer hedonic benefits, and an additional unit of the premium does not necessarily increase a consumer's hedonic experience (Chandon et al. 2000). Second, if extra units of a premium entail only carrying, storage, and disposal costs, consumers may even decide to buy less than they would without the promotion, to avoid these costs (Gedenk et al. 2000). No or negative quantity effects can also occur when consumers apply social rather than market norms: That is, when a product is distributed for free, consumers are likely to take only one unit out of fairness (e.g. Heyman and Ariely 2004).

Such mechanisms imply that consumers are unlikely to accelerate in response to premiums. Instead, we expect premiums to trigger no or even negative quantity effects. Because it is impossible to formally test this statement (it includes the null effect), we formulate only the following expectation:

\section{E1: A premium promotion has no or even a negative impact on consumers' quantity decisions.}

\subsubsection{Moderators of Relative Premium Effectiveness}

As argued previously, to compare premiums with equivalent price cuts, the moderating role of premium-, product-, and category-related factors should be 
taken into account. More specifically, we examine the impact of three moderators - namely, premium-product relatedness, private label versus national brands, and the category's degree of hedonism/utilitarianism.

\subsubsection{Premium-Product Relatedness}

Consumers display a greater willingness to pay for related than non-related items (Venkatesh and Kamakura 2003). Thus, the premium's relatedness to the product increases the value consumers attach to the combined offer, a principle that may influence premium effectiveness at all decision levels. In addition, at the incidence and choice levels, a premium's role as a heuristic that facilitates decision making may be more prominent when it is related rather than unrelated to the promoted product. Indeed, Brown and Carpenter (2000) demonstrate that trivial attributes are more likely to induce an increase in choice probability if they are product related, such as product features, rather than unrelated, such as sweepstakes or add-ons. Relatedness between the premium and the product also may temper any negative attribution, reactance, or justification effects (e.g. Aaker and Keller 1990; Kivetz 2005; Martin and Stewart 2001). In other words, consumers are less likely to perceive a related premium as manipulative, which helps them justify the purchase. Thus, we hypothesize that relatedness between a premium and the main product strengthens the premium's performance relative to price cuts at the incidence, choice, and quantity levels.

H2a: At the incidence and choice levels, relatedness has a positive impact on a premium promotion's relative performance.

\section{H2b: At the quantity level, relatedness has a positive impact on a premium promotion's relative performance.}

\subsubsection{Private Label versus National Brand}

Although sales promotions can be more effective for national brands than for private labels for many reasons, other principles imply the opposite. On the one hand, because of their strong brand image, national brands can better resist negative inference effects when consumers treat sales promotions as signals of low quality (Raghubir and Corfman 1999). On the other hand, because private labels focus on affordability (Ailawadi, Neslin, and Gedenk 2001), they arguably have less to lose from negative quality inferences than national brands.

Although these arguments are relevant for both premiums and price cuts, one principle holds in particular for price promotions and less for premiumsnamely, asymmetric switching. Research shows that price cuts for national brands induce more switching than price cuts for private labels (e.g. Blattberg 
and Wisniewski 1989; Sethuraman et al. 1999; Sivakumar and Raj 1997). That is, a lower price makes national brands affordable to price-sensitive consumers, who otherwise purchase the cheaper private labels. In contrast, a price cut for the private label does not lead to the same amount of consumer switching because many buyers of national brands do not want to give up quality to switch to the discounted private label.

Unlike price cuts, premium promotions do not offer a monetary incentive and therefore are less likely to make national brands attractive to pricesensitive consumers. As a result, in the shift from a private label to a national brand, premium promotions do not benefit to the same extent from asymmetric switching, and thus their relative effectiveness decreases.

\section{H3: At the incidence and choice levels, the relative performance level of premium promotions is lower for national brands than for private la- bels.}

By definition, asymmetric switching does not affect a consumer's quantity decision. Furthermore, extant literature does not provide any other principles that suggest that brand type moderates the relative performance of premiums at the quantity level. Therefore, we leave this as an empirical question.

\subsubsection{Hedonism/Utilitarianism}

Chandon et al.'s (2000) benefit congruency framework predicts that consumers prefer promotions that offer similar benefits as the underlying product. Thus, price cuts, which mainly offer utilitarian benefits, should have relatively stronger choice effects in utilitarian categories, whereas premiums, which mainly provide hedonic benefits, should be relatively more effective in hedonic categories. However, Chandon et al. can validate their framework only for highequity brands: High-equity brands offer stronger utilitarian and hedonic benefits than low-equity brands, which are mainly bought for their low price.

These findings regarding the role of hedonism and utilitarianism enable us to fine-tune our expectations of the impact of private labels and national brands. Specifically, we expect that the decrease in a premium's relative performance when moving from a private label to a national brand (see H3) is more pronounced for utilitarian than for hedonic product categories. In hedonic categories, the benefit congruency effect mitigates the decrease in relative premium performance in the switch from a private label to a national brand. In contrast, in utilitarian categories, the congruency effect reinforces the relative performance of price cuts for national brands. 
H4: At the incidence and choice levels, the decrease in relative premium effectiveness in the switch from a private label to a national brand is greater in utilitarian than in hedonic product categories.

Again, we do not formulate any hypothesis for the effects at the quantity level: $\mathrm{H} 3$, of which $\mathrm{H} 4$ is a refinement, only pertains to the incidence and choice levels, and Chandon et al. (2000) developed their framework to explain switching patterns. Nonetheless, we also empirically explore the role of hedonism versus utilitarianism at the quantity level.

\subsection{Experimental Design and Data Collection}

The data for this study were collected through an online purchase experiment in which we replicated a realistic shopping environment. Respondents, all members of a research panel in a Western European country, made fictitious purchases in different hedonic and utilitarian product categories with varying promotions during a seven-week period. Evidence indicates that computersimulated shopping experiments provide highly realistic buying behavior data, especially when decision cues mimic those of a real store environment (Burke et al. 1992). Moreover, shopping experiments enable the researcher to increase the variance of the explanatory variables and investigate less common scenarios. In this study, we manipulate four factors: the premium's relatedness to the product category (related/unrelated), the category's level of hedonism and utilitarianism (hedonic/utilitarian), the type of brand on promotion (national brand/private label), and the depth of price cuts (low/medium/high). The latter manipulation enables us to estimate a linear discount effect and compare the premium impact with that of equivalent and non-equivalent discounts.

Subsequently, we discuss the results of the pre-tests and manipulation checks conducted to determine the product categories, assortment composition, premiums, price-cut levels, and brands on promotion. Furthermore, we address the survey design and the experimental setup.

\subsubsection{Selection of Product Categories}

We generated an initial list of hedonic and utilitarian product categories on the basis of previous research (e.g. Breugelmans, Campo, and Gijsbrechts 2006; Campo 1997) and used up-to-date consumer purchase data from GFK to narrow the selection down to four categories with sufficiently high penetration. We retained two utilitarian categories (i.e. milk and margarine) and two hedonic categories (i.e. orange juice and cereals). At the end of the main study, we 
asked respondents how utilitarian and hedonic they perceived the product categories on a two-item six-point Likert scale adopted from Okada (2005). Table 2.1 displays the means and standard deviations of these items. Independent t-tests ${ }^{1}$ revealed that respondents perceived orange juice and cereals as significantly $(p<.01)$ more hedonic and milk and margarine as significantly $(p$ $<.0005$ ) more utilitarian (see Table 2.1).

Table 2.1 Descriptive Statistics for Utilitarianism and Hedonism Measures

\begin{tabular}{lll}
\hline Category & Mean & Standard Deviation \\
\hline Utilitarianism & & \\
\hline Milk & $5.36^{\mathrm{a}}$ & .95 \\
Margarine & $4.79^{\mathrm{a}}$ & 1.16 \\
Orange juice & $4.44^{\mathrm{a}}$ & 1.21 \\
Cereals & $4.31^{\mathrm{a}}$ & 1.20 \\
\hline Hedonism & & \\
\hline Cereals & $3.55^{\mathrm{b}}$ & 1.43 \\
Orange juice & $3.26^{\mathrm{b}}$ & 1.48 \\
Milk & $2.56^{\mathrm{b}}$ & 1.50 \\
Margarine & $2.19^{\mathrm{b}}$ & 1.34 \\
\hline
\end{tabular}

a All means differ at $p<.05$

b All means differ at $p<.05$

\subsubsection{Selection of Assortment and Promoted Brands}

To ensure that the simulated shopping trips appeared realistic and allowed respondents to behave as they normally do, we composed assortments that represented a high market share in the respective categories (see Table 2.2). With the GFK market share data, we generated assortments of the most popular stock-keeping units (SKUs) and selected the most prominent package size per category (see Table 2.2, third column) while ensuring that the brand lines did not appear incomplete or unbalanced. The chosen SKUs either were national brand SKUs or belonged to the house brand of a major supermarket chain. ${ }^{2}$ The regular prices of the national brand items in the assortment were determined as rounded averages of non-promoted prices in three major supermarket chains in the studied country. The regular prices of the private label items

\footnotetext{
${ }^{1}$ Respondents evaluated only the categories in which they made purchases during the shopping simulation. As a result, for a given pair of product categories, some respondents evaluated both categories and some evaluated only one category. We conducted independent $t$-tests and, for each pair of categories, disregarded respondents who assessed both categories.

2 In 2008, the chain had a market share of $25.1 \%$ in the studied country Delhaize Group (2009), "Annual Report 2008," http://www.delhaizegroup.com/Portals/0/html/AnnualReport/2008/html\%20nl/index.htm.
} 
were based only on prices in the relevant supermarket chain. We selected two sets of items in each category that were promoted alternately during the experiment. The first set contained SKUs of a major national brand, and the second consisted of private label SKUs. The sets matched in number of items and product characteristics. A manipulation check at the end of the main study indicated that in all categories, respondents perceived the private label as of significantly lower quality than the national brand $(p<.0001$, see Table 2.3$)$.

Table 2.2 Information about Product Assortments

\begin{tabular}{lllll}
\hline Category & $\begin{array}{l}\text { Market Share } \\
\text { Assortment }(\%)\end{array}$ & $\begin{array}{l}\text { Total Nr } \\
\text { of Items }\end{array}$ & $\begin{array}{l}\text { Package } \\
\text { Size }\end{array}$ & $\begin{array}{l}\text { Nr of Items in } \\
\text { Promotional Sets }\end{array}$ \\
\hline Orange juice & 83 & 10 & $1 \mathrm{l}$ & 2 \\
Cereals & 93 & 42 & $500 \mathrm{~g}$ & 3 \\
Margarine & 98 & 18 & $250 \mathrm{~g}$ & 2 \\
Milk & 75 & 18 & $1 \mathrm{l}$ & 3 \\
\hline
\end{tabular}

Table 2.3 Perceived Quality Scores

\begin{tabular}{lllll}
\hline \multirow{2}{*}{ Category } & \multicolumn{2}{l}{ Private Label } & \multicolumn{2}{l}{ National Brand } \\
\cline { 2 - 5 } & Mean $^{\mathrm{a}}$ & $\begin{array}{l}\text { Standard } \\
\text { Deviation }\end{array}$ & Mean $^{\mathrm{a}}$ & $\begin{array}{l}\text { Standard } \\
\text { Deviation }\end{array}$ \\
\hline Orange juice $^{\mathrm{b}}$ & 3.27 & 1.48 & 4.44 & 1.21 \\
Cereals $^{\mathrm{b}}$ & 3.55 & 1.43 & 4.31 & 1.20 \\
Margarine $^{\mathrm{b}}$ & 2.19 & 1.34 & 4.80 & 1.16 \\
Milk $^{\mathrm{b}}$ & 2.56 & 1.48 & 5.36 & .95 \\
\hline
\end{tabular}

${ }^{a}$ Measured on a seven-point scale .

${ }^{\mathrm{b}}$ Difference is significant at $p<.0001$.

\subsubsection{Selection of Premiums}

In view of our hypotheses, we need to select related and unrelated premiums for each product category. Furthermore, to be able to compare premium effects with those of price cuts, we need to match the values of both promotions. Therefore, we proceeded as follows: We generated an extensive list of possible (related and unrelated) premiums. Respondents in a first pre-test saw pictures and read brief descriptions of these different premiums and then indicated how much they would maximally pay for each product if they found it on the shelves of their regular supermarket. We chose willingness to pay because we wanted to obtain consumers' subjective evaluations of the product in a specified situation (Ajzen and Driver 1992; Wertenbroch and Skiera 2002). The sample consisted of 175 consumers who were reached online through snowball sampling 
and had a similar socio-demographic profile to that of the participants in the main study. We discarded premiums with an excessively high or low average perceived value as well as premiums that showed a large variance in perceived value. In the second pre-test, 219 randomly selected members of an online research panel at the university of one of the authors rated the retained premiums' relatedness to the four product categories on a seven-point scale adapted from Martin and Stewart (2001). For each category, we selected one clearly related and one clearly unrelated premium with similar perceived values. Table 3.4 provides an overview of the selected premiums and their average perceived values and relatedness scores. According to the scores, the related premium was always significantly $(p<.0001$, see Table 2.4$)$ more related than the unrelated premium.

Table 2.4 Selection of Premium Promotions

\begin{tabular}{|c|c|c|c|}
\hline Category & $\begin{array}{l}\text { Related Premium } \\
\text { Unrelated Premium }\end{array}$ & $\begin{array}{l}\text { Average Perceived } \\
\text { Value (€) }\end{array}$ & $\begin{array}{l}\text { Relatedness }^{\mathrm{a}} \\
\text { Mean Score } \\
\mathrm{b}\end{array}$ \\
\hline \multirow[t]{2}{*}{ Orange juice } & Glass & .40 & 6.33 \\
\hline & Keychain & .35 & 1.76 \\
\hline \multirow[t]{2}{*}{ Cereals } & Bowl & .62 & 6.44 \\
\hline & Key tag & .62 & 2.16 \\
\hline \multirow[t]{2}{*}{ Margarine } & Spreading knife & .59 & 6.14 \\
\hline & Pen & .55 & 1.86 \\
\hline \multirow[t]{2}{*}{$\overline{\text { Milk }}$} & Carton/bottle holder & .29 & 5.15 \\
\hline & Set of red magnets & .28 & 2.14 \\
\hline
\end{tabular}

a Difference between mean scores of related and unrelated premium is always significant at $p<.0001$.

$\mathrm{b}$ Measured on a seven-point scale.

\subsubsection{Determination of Price Cuts}

Because this study compares the effects of premiums with those of equivalent price cuts, we needed to ensure that the perceived premium value falls in the range of possible price cuts. For each category, we determined three absolute price-cut levels, one of which, usually the middle one, approximated the premiums' perceived value. We derived the other two levels by adding or subtracting an amount approximately equal to $10 \%$ of the average regular price in the category. ${ }^{3}$ The last three columns of Table 2.5 list the price-cut levels for all four

\footnotetext{
${ }^{3}$ Only for margarine, it is the highest (rather than medium) price cut that corresponds to the premiums' perceived value. In that category, the perceived premium value is already high relative to the regular price of the private label, such that an even higher price cut would seem unrealistic. We
} 
categories. In the shopping experiment, price cuts were always presented as absolute amounts.

Table 2.5 Price-Cut Levels

\begin{tabular}{lllll}
\hline \multirow{2}{*}{ Category } & \multirow{2}{*}{ Average SKU Price $(€)$} & \multicolumn{3}{l}{ Price Cut $(€)$} \\
\cline { 3 - 5 } & & Low & Medium & High \\
\hline Orange juice & 1.50 & .20 & .35 & .50 \\
Cereals & 3.25 & .30 & .60 & .90 \\
Margarine & 2.09 & .15 & .35 & .55 \\
Milk & 1.11 & .15 & .25 & .35 \\
\hline
\end{tabular}

\subsubsection{Survey Design}

The online survey consisted of three parts: the initialization stage, the actual purchase simulation, and a concluding section. The purpose of the initialization stage was to screen respondents and gather the data needed to generate an individualized questionnaire. To qualify, respondents needed to be actively involved in buying groceries for their household and to regularly shop in at least one of the four selected product categories. If these pre-requisites were met, we assigned respondents to at least one and at most two product categories. Whenever a respondent indicated to regularly shop in more than two product categories, we assigned him or her to one hedonic and one utilitarian category. Respondents then provided more detailed information about their consumption behavior in the product categories to which they were assigned (see Appendix A1 for a list of scales). The consumption information collected in the initialization phase contained usual package size consumed, average weekly consumption, and number of open and closed packages currently in stock. The information on usual package size and packages in stock helped us calculate a respondent's initial volume in stock. We used average weekly consumption to update the respondent's inventory during the shopping simulation. The simulation covered a fictitious period of seven consecutive weeks during which the respondent purchased in at most two product categories. Figures 2.1 and 2.2 represent screenshots of two shopping situations with a price cut and a premium, respectively.

took $10 \%$ and $20 \%$ of the average regular price and subtracted these amounts from the high price cut to find the medium and low price cuts, respectively. 
Figure 2.1 Example Screenshot of a Price Cut

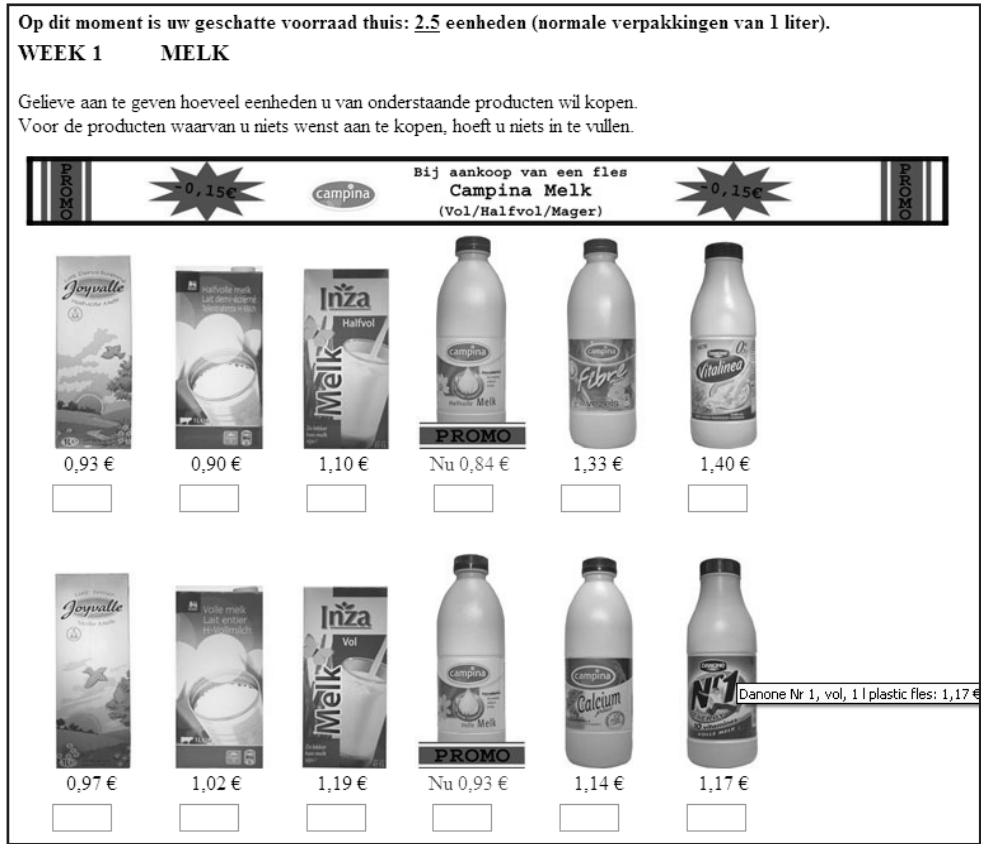

Figure 2.2 Example Screenshot of a Premium Promotion

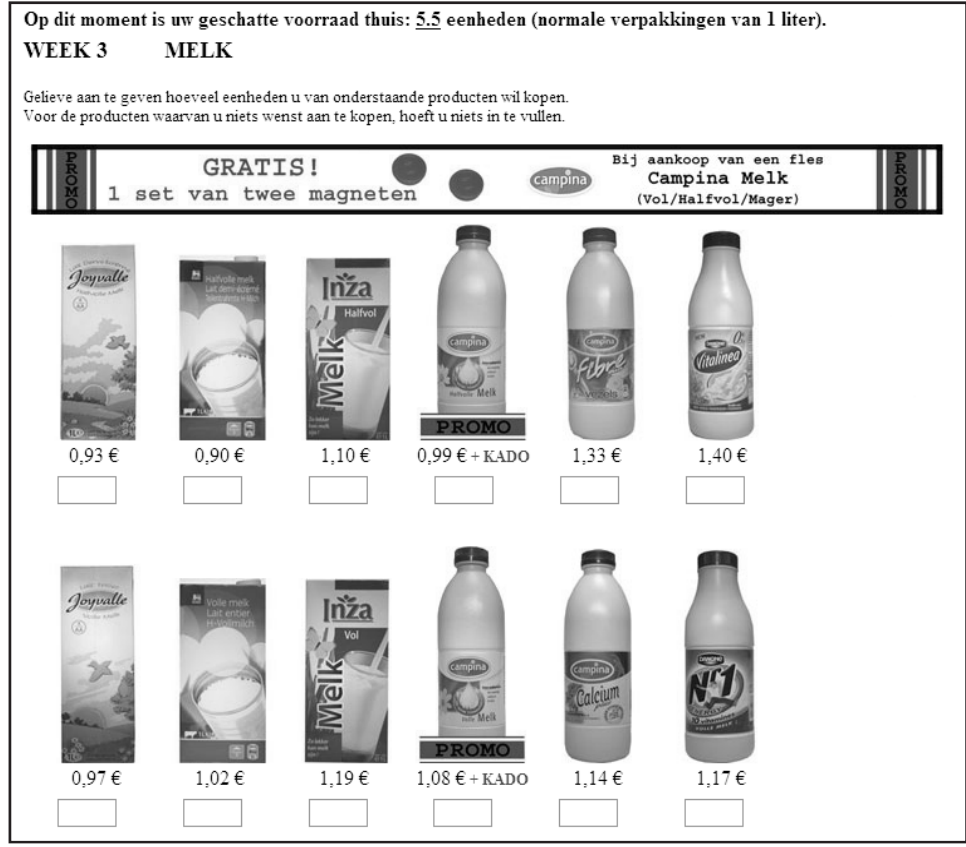


We considered the first week a warm-up week during which respondents got acquainted with the shopping experiment and excluded it from our analysis. As in actual purchase situations, the respondent was not obliged to buy. In the beginning of each shopping week, we showed respondents their current inventory. We calculated this inventory by adding the purchase quantity in the previous week to each respondent's previous inventory and subtracting average weekly consumption. Next, we provided instructions on how to proceed with the purchase simulation, followed by a planogram with pictures of the brands making up the assortment. The product's price appeared below each picture. Respondents could receive more information by holding the mouse on the picture, which opened up a pop-up window with further details on the product's brand name, form, flavor, and size. In the boxes below the products, consumers indicated their purchase quantity, if non-zero.

In the weeks in which products were on promotion, we displayed a promotional banner above the assortment to reflect the realistic shopping environment in which promotions are typically accompanied by displays. Again, a popup window with additional information about the promotion opened up when respondents held the mouse on the banner. At the same time, we attached a promotional sign to the pictures of promoted products.

We used a full factorial design to study the effects of the different promotions. During the seven-week simulation, we selected one promotion-free week per category, and we alternately attached a promotion to either the national brand or the private label SKUs during the remaining six weeks. Respondents saw neither the same promotion nor the same promoted SKUs in consecutive weeks. We also varied the order of the promotions across respondents to avoid order effects.

In the last part of the survey, we collected information on respondents' usual purchase behavior and socio-demographics and included two manipulation checks. The questions on usual purchase behavior covered average purchase frequency, usual purchase quantity, and choice shares of the different SKUs during the last 12 months. We asked these questions after the shopping simulation to avoid interference with the respondents' fictitious purchase decisions. The socio-demographics included gender, age, nationality, family situation, number and age of children, education, and profession. Finally, for each category in which they purchased during the simulation, respondents evaluated the perceived quality of the promoted national and private label brands and the category's level of hedonism and utilitarianism. The results of these manipulation checks were provided previously. 


\subsubsection{Sample Characteristics}

A cooperating marketing research company sent approximately 11,700 randomly selected members of its research panel an invitation to participate in our online experiment. Of these, 2,468 panelists (approximately 21\%) completed the survey. We removed consumers who were not (entirely or partly) responsible for their household's grocery purchases or did not usually buy in any of the four product categories. After also deleting respondents with inconsistent or implausible answers, we retained a sample of 1,930 consumers. Table 2.6 summarizes the distribution of the final sample over the socio-demographic characteristics. In their study on stock-out reactions, Sloot et al. (2005) use a sample with similar characteristics they view as representative of Western European shoppers. 
Table 2.6 Sample Demographics

\begin{tabular}{|c|c|c|}
\hline Variable & Levels & Percentage (\%) \\
\hline \multirow[t]{2}{*}{ Gender } & Male & 20 \\
\hline & Female & 80 \\
\hline \multirow[t]{7}{*}{ Age } & $\leq 18$ years & 1 \\
\hline & 19-25 years & 7 \\
\hline & 26-35 years & 22 \\
\hline & $36-45$ years & 24 \\
\hline & 46-55 years & 22 \\
\hline & $56-65$ years & 20 \\
\hline & $\geq 66$ & 4 \\
\hline \multirow[t]{7}{*}{ Family situation } & Living with parents & 3 \\
\hline & Single & 16 \\
\hline & Widow & 3 \\
\hline & Married & 53 \\
\hline & Living together & 20 \\
\hline & Divorced & 4 \\
\hline & Other & 1 \\
\hline \multirow[t]{2}{*}{ Children } & Yes & 48 \\
\hline & No & 52 \\
\hline \multirow{5}{*}{$\begin{array}{l}\text { Children in certain age groups } \\
\text { (children = yes) }\end{array}$} & $<3$ years & 14 \\
\hline & $3-6$ years & 16 \\
\hline & $7-14$ years & 26 \\
\hline & $15-18$ years & 16 \\
\hline & $>18$ years & 28 \\
\hline \multirow[t]{6}{*}{ Highest level of education } & Primary school & 4 \\
\hline & Secundary school & 36 \\
\hline & College, short type & 34 \\
\hline & College, long type & 13 \\
\hline & University & 12 \\
\hline & Other & 1 \\
\hline \multirow[t]{7}{*}{ Profession } & Student & 4 \\
\hline & Homemaker & 9 \\
\hline & Part-time worker & 19 \\
\hline & Full-time worker & 45 \\
\hline & Unemployed & 4 \\
\hline & Retired & 15 \\
\hline & Other & 4 \\
\hline
\end{tabular}


Table 2.7 lists for each category the number of households, purchase occasion, average number of purchase incidences, and average purchase quantity. In the final sample, 974 households shopped in the orange juice category, 671 in the cereals category, 898 in the margarine category, and 1,175 in the milk category. These households purchased on average 3.52, 3.99, 2.83, and 3.62 times in the orange juice, cereals, margarine, and milk category, respectively. The average purchase quantity varies largely from 17.31 units of milk to 4.14 units of margarine and from 10.19 units of orange juice to 4.64 units of cereals, which is a result of the products' differing storability.

Table 2.7 Description of Data

\begin{tabular}{lclll}
\hline Category & $\begin{array}{l}\text { Number of House- } \\
\text { holds (HH) }\end{array}$ & $\begin{array}{l}\text { Purchase } \\
\text { Occasions }\end{array}$ & $\begin{array}{l}\text { Average Number of } \\
\text { Incidences (per HH) }\end{array}$ & $\begin{array}{l}\text { Average Purchase } \\
\text { Quantity (per HH) }\end{array}$ \\
\hline Orange juice & 974 & 6122 & 3.52 & 10.19 \\
Cereals & 671 & 4819 & 3.99 & 4.64 \\
Margarine & 898 & 5600 & 2.83 & 4.14 \\
Milk & 1175 & 7359 & 3.62 & 17.31 \\
\hline
\end{tabular}

As a first tentative impression of the promotions' effects, Table 2.8 presents the choice shares of the national brand and the private label in the weeks in which a premium, a price cut, or no promotion was offered. The results indicate that premiums and price cuts strongly increase the choice shares of the promoted brands. Table 2.9 lists the category purchase incidences as shares of the total number of shopping trips in the weeks in which a premium, a price cut, or no promotion was offered. Higher incidence shares occur in the weeks with price cuts than in the weeks without a promotion. A premium increases incidence shares only when it is attached to a private label. Table 2.10 summarizes the average purchase quantities per household within the four product categories when a premium, a price cut, or no promotion was offered for a national brand or a private label. In general, the average units purchased within a category increase from no-promotion to price-cut scenarios. However, the numbers suggest that premiums do not increase, but rather decrease, quantity if national brands are on promotion. When premiums are offered with private labels, the average quantity purchased slightly increases. 
Table 2.8 Choice Shares (\%) with and without Promotions

\begin{tabular}{lllllll}
\hline \multirow{2}{*}{ Category } & \multicolumn{2}{l}{ National Brand } & \multicolumn{4}{l}{ Private Label } \\
\cline { 2 - 7 } & Premium & Price Cut & No Promotion & Premium & Price Cut & No Promotion \\
\hline Orange juice & 41.61 & 61.10 & 28.60 & 40.82 & 53.58 & 23.99 \\
Cereals & 27.52 & 28.04 & 13.00 & 14.29 & 18.17 & 5.67 \\
Margarine & 32.89 & 43.64 & 18.68 & 24.80 & 27.36 & 11.84 \\
Milk & 47.62 & 69.18 & 30.00 & 50.71 & 57.51 & 41.17 \\
\hline
\end{tabular}

Table 2.9 Category Purchase Incidences (\%) with and without Promotions

\begin{tabular}{llllll}
\hline \multirow{2}{*}{ Category } & \multicolumn{2}{l}{ National Brand } & \multicolumn{2}{l}{ Private Label } & \multirow{2}{*}{ No Promotion } \\
\cline { 2 - 5 } & Premium & Price Cut & Premium & Price Cut & \\
\hline Orange juice & 57.38 & 57.79 & 55.19 & 56.60 & 53.14 \\
Cereals & 56.90 & 57.97 & 54.58 & 54.73 & 52.81 \\
Margarine & 51.02 & 49.78 & 44.79 & 42.66 & 41.08 \\
Milk & 60.60 & 59.96 & 57.85 & 59.50 & 49.42 \\
\hline
\end{tabular}

Table 2.10 Average Purchase Quantities (Units) with and without Promotions

\begin{tabular}{llllll}
\hline \multirow{2}{*}{ Category } & \multicolumn{4}{l}{ National Brand } & \multicolumn{2}{l}{ Private Label } & No Promotion \\
\cline { 2 - 5 } & Premium & Price Cut & Premium & Price Cut & \\
\hline Orange juice & 1.29 & 2.31 & 1.92 & 3.10 & 1.57 \\
Cereals & .65 & .99 & .91 & 1.38 & .72 \\
Margarine & .56 & 1 & .79 & 1.18 & .60 \\
Milk & 2.36 & 3.50 & 3.30 & 5.84 & 2.32 \\
\hline
\end{tabular}

\subsection{Model Description}

We formulate a joint model for the three consumer purchase decisionsincidence, choice, and quantity-in which choice is conditional on incidence and quantity on choice (Bell et al. 1999; Chiang 1991; Zhang and Krishnamurthi 2004; e.g Zhang and Wedel 2009). The probability that consumer $h$ buys q units of SKU i on shopping trip $t$ can be expressed as

$$
\mathrm{P}_{\mathrm{t}}^{\mathrm{h}}(\mathrm{i} \& q)=\mathrm{P}_{\mathrm{t}}^{\mathrm{h}}(\text { inc }) * \mathrm{P}_{\mathrm{t}}^{\mathrm{h}}(\mathrm{i} \mid \mathrm{inc}) * \mathrm{P}_{\mathrm{t}}^{\mathrm{h}}(\mathrm{q} \mid \text { inc } \& i),
$$

where

$\boldsymbol{P}_{t}^{h}(\boldsymbol{i n c})=$ the probability that consumer h purchases in the category on shopping trip $\mathrm{t}$, 
$P_{t}^{h}(\boldsymbol{i} \mid$ inc $)=$ the probability that consumer h purchases SKU i on shopping trip t conditional on buying in the category, and

$\boldsymbol{P}_{\boldsymbol{t}}^{\boldsymbol{h}}(\boldsymbol{q} \mid \boldsymbol{i n c} \& \boldsymbol{i})=$ consumer h's probability of buying quantity q on shopping trip t conditional on buying SKU i.

In what follows, we first discuss the modeling approaches for the incidence, choice, and quantity decisions and then explain the estimation procedure.

\subsubsection{Incidence and Choice Decisions}

We model the probability of buying SKU $i$ on shopping trip $t$ with a nested MNL model. This model incorporates the interdependence of the decision to buy in a category (incidence) and the decision to purchase a particular SKU (choice). Next, we first discuss the consumer's utility function and then derive the model formulation of the nested MNL model.

The decision to purchase a certain SKU is conditional on buying in the category. Thus, the utility a consumer $\mathrm{h}$ receives from buying SKU i involves utilities at the category level $\boldsymbol{U}_{\boldsymbol{t}}^{\boldsymbol{h}}$ and utilities specific to the SKU $\boldsymbol{Z}_{\boldsymbol{i} \boldsymbol{t}}^{\boldsymbol{h}}$. The utility consumer $\mathrm{h}$ receives from purchasing in a category, $\boldsymbol{U}_{\boldsymbol{t}}^{\boldsymbol{h}}$, is a function of the observed utility $\boldsymbol{W}_{t}^{\boldsymbol{h}}$, which is a linear function of observed variables, and an unobserved portion $\boldsymbol{\varepsilon}_{t}^{\boldsymbol{h}}$, which is treated as random from the researcher's perspective.

$$
U_{t}^{h}=W_{t}^{h}+\varepsilon_{t}^{h} .
$$

where $\varepsilon_{t}^{h}$ are independent and follow the same type I extreme value distribution (Train 2002). The observed utility function is as follows:

$$
\mathrm{W}_{\mathrm{t}}^{\mathrm{h}}=\tau_{0}+\tau_{\text {Inv }} \times \operatorname{Inv}_{\mathrm{t}}^{\mathrm{h}}+\tau_{\text {IPDUR }} \times \operatorname{IPDUR}_{\mathrm{t}}^{\mathrm{h}},
$$

where $\boldsymbol{I n} \boldsymbol{v}_{\boldsymbol{t}}^{\boldsymbol{h}}$ represents consumer h's mean-centered inventory on shopping trip t. We compute a consumer's inventory in the following manner: Max $(0$, inventory at shopping trip $\mathrm{t}-1+$ quantity bought at shopping trip $\mathrm{t}-1$ - consumer's average weekly consumption). We then mean-center the weekly inventory values using a consumer's average inventory. The next variable is the inter-purchase duration, IPDU $\boldsymbol{R}_{t}^{h}$, which is the average number of weeks between two consecutive purchase incidences of consumer $h$.

We again divide the utility $\boldsymbol{Z}_{\boldsymbol{i t}}^{\boldsymbol{h}}$ that a consumer derives from purchasing a particular SKU in a product category into an observed part $\boldsymbol{V}_{i t}^{\boldsymbol{h}}$ and an unobserved portion $\varepsilon_{i t}^{h}$.

$$
\mathrm{Z}_{\mathrm{it}}^{\mathrm{h}}=\mathrm{V}_{\mathrm{it}}^{\mathrm{h}}+\varepsilon_{\mathrm{it}}^{\mathrm{h}},
$$


where $\varepsilon_{i t}^{h}$ are again independent and type I extreme value distributed. The choice utility $\boldsymbol{V}_{\boldsymbol{i t}}^{\boldsymbol{h}}$ is a linear function:

$$
\begin{aligned}
& V_{\mathrm{it}}^{\mathrm{h}}=\sum_{\mathrm{K}} \sum_{\mathrm{l} \in \mathrm{L}_{\mathrm{K}}} \beta_{\mathrm{K}, \mathrm{l}} \times \mathrm{AT}_{\mathrm{K}, \mathrm{l}, \mathrm{i}}+\beta_{\mathrm{Loy}} \times \operatorname{Loy}_{\mathrm{i}}^{\mathrm{h}}+\beta_{\mathrm{LB}} \times \mathrm{LB}_{\mathrm{it}}^{\mathrm{h}}+\beta_{\text {Prem }} \times \text { Prem }_{\mathrm{it}}^{\mathrm{h}}+ \\
& \beta_{\text {RelPrem }} \times \text { RelPrem }_{\mathrm{it}}^{\mathrm{h}}+\beta_{\text {PremNB }} \times \text { PremNB }_{\mathrm{it}}^{\mathrm{h}}+\beta_{\mathrm{PC}} \times \mathrm{PC}_{\mathrm{it}}^{\mathrm{h}}+\beta_{\mathrm{DISC}} \times \\
& \operatorname{DISC}_{\mathrm{it}}^{\mathrm{h}}+\beta_{\mathrm{PCDNB}} \times \mathrm{PCNB}_{\mathrm{it}}^{\mathrm{h}} .
\end{aligned}
$$

To capture intrinsic SKU preferences, we include several attribute-specific constants in the choice utility function (e.g. Breugelmans, Campo, and Gijsbrechts 2007; Foubert and Gijsbrechts 2007). For each attribute $\mathrm{K}$, there is a set of levels $\mathrm{L}_{\mathrm{K}}$. The dummy variable $\boldsymbol{A} \boldsymbol{T}_{\boldsymbol{K}, \boldsymbol{l}, \boldsymbol{i}}$ takes the value of 1 if SKU i is characterized by level $\mathrm{l}$ of attribute $\mathrm{K}$ and 0 if otherwise. We also include a loyalty ble $\boldsymbol{L o y}_{\boldsymbol{i}}^{\boldsymbol{h}}$, which represents consumer h's self-stated overall choice share for SKU I in the 12 months before the study, and a purchase-feedback dummy variable $\boldsymbol{L} \boldsymbol{B}_{i t}^{\boldsymbol{h}}$, which equals 1 if consumer $\mathrm{h}$ bought the same SKU on the last purchase incidence.

Three variables capture the effects of a premium promotion on an SKU's utility. The first is $\boldsymbol{P r e m}_{i t}^{h}$, which is a dummy variable that takes the value of 1 when a premium is offered for SKU $i$ in week $t$ and 0 if otherwise. Its coefficient represents the effect of an unrelated premium on the utility of a store brand. To capture the incremental effect of a premium for a national brand, we include $\operatorname{PremN} B_{i t}^{h}$, which equals 1 if the premium is offered with an SKU that belongs to a national brand and 0 if otherwise. Its coefficient represents the change in utility if a premium comes with a national rather than a store brand. Finally, RelPrem $_{i t}^{h}$ is a dummy variable that indicates whether the premium is related to the category and thus represents the incremental effect of a related premium compared with an unrelated premium.

To account for the influence of price cuts, we incorporate three variables in the utility function. The dummy variable $\boldsymbol{P} \boldsymbol{C}_{\boldsymbol{i t}}$ is 1 whenever a price cut is offered, and $\boldsymbol{D I S \boldsymbol { C } _ { i t } ^ { h }}$ takes on the absolute values of the price cuts in euros. So, in addition to a linear discount effect, we include a constant feature effect; these effects pertain to store brands. We use the dummy variable $\boldsymbol{P C N} \boldsymbol{B}_{i t}^{\boldsymbol{h}}$ to capture the incremental effect of a price cut on a national rather than a store brand. Similar to $\operatorname{Prem}_{\mathbf{N}} \boldsymbol{B}_{i t}^{h}$ this variable equals 1 when the price cut applies to an SKU that belongs to a national brand.

Given the expressions for $\boldsymbol{U}_{\boldsymbol{t}}^{\boldsymbol{h}}$ and $\boldsymbol{Z}_{\boldsymbol{i t}}^{\boldsymbol{h}}$ and the distributions of the error terms, we can show that the probability of consumer h choosing SKU I on shopping trip $t$ can be split into two components: 


$$
\mathrm{P}_{\mathrm{t}}^{\mathrm{h}}(\mathrm{i})=\mathrm{P}_{\mathrm{t}}^{\mathrm{h}}(\mathrm{inc}) * \mathrm{P}_{\mathrm{t}}^{\mathrm{h}}(\mathrm{i} \mid \mathrm{inc})
$$

where $\boldsymbol{P}_{\boldsymbol{t}}^{\boldsymbol{h}}(\boldsymbol{i n c})$ represents the incidence probability (i.e. the probability that consumer h purchases in the category on shopping trip t) and $\boldsymbol{P}_{\boldsymbol{t}}^{\boldsymbol{h}}(\boldsymbol{i} \mid \mathbf{i n c} \boldsymbol{c})$ is the probability that consumer $h$ buys SKU $i$ on shopping trip $t$, given that the consumer purchases in the category. In addition, $\boldsymbol{P}_{\boldsymbol{t}}^{\boldsymbol{h}}(\boldsymbol{i n c})$ is a binary logit model, and $\boldsymbol{P}_{\boldsymbol{t}}^{\boldsymbol{h}}(\boldsymbol{i} \mid \mathbf{i n c})$ is an MNL model:

$$
\begin{aligned}
& P_{t}^{h}(\text { inc })=\frac{\exp \left(\mathrm{w}_{\mathrm{t}}^{\mathrm{h}}+\tau_{\mathrm{IV}} * \mathrm{IV}_{\mathrm{t}}^{\mathrm{h}}\right)}{1+\exp \left(\mathrm{w}_{\mathrm{t}}^{\mathrm{h}}+\tau_{\mathrm{IV}} * \mathrm{IV}_{\mathrm{t}}^{\mathrm{h}}\right)} \\
& \mathrm{P}_{\mathrm{t}}^{\mathrm{h}}(\mathrm{i} \mid \text { inc })=\frac{\exp \left(\mathrm{V}_{\mathrm{it}}^{\mathrm{h}}\right)}{\sum_{\mathrm{j}} \exp \left(\mathrm{V}_{\mathrm{jt}}^{\mathrm{h}}\right)^{\prime}}
\end{aligned}
$$

where $\boldsymbol{I} \boldsymbol{V}_{\boldsymbol{t}}^{\boldsymbol{h}}$ is the inclusive value for consumer h on shopping trip $\mathrm{t}$ and captures the attractiveness of the category assortment. We derived this inclusive value by taking the logarithm of the denominator of the choice model:

$$
I V_{t}^{h}=\log \left(\sum_{j} \exp \left(V_{j t}^{h}\right)\right)
$$

The term $\boldsymbol{\tau}_{\boldsymbol{I V}}$ is the so-called scale parameter, which measures the extent to which the attractiveness of the SKUs affects the customer's decision of whether to buy in the category.

\subsubsection{Quantity Decision}

The decision of how many units of SKU $\mathrm{i}$ to buy on shopping trip $\mathrm{t}$ is conditional on SKU i being chosen. Therefore, we model the probability that consumer $h$ purchases quantity q of SKU i, $\boldsymbol{P}_{\boldsymbol{t}}^{\boldsymbol{h}}(\boldsymbol{q} \mid \boldsymbol{i n} \boldsymbol{c} \& \boldsymbol{i})$, with a zero-truncated Poisson model (e.g. Ailawadi et al. 2007; Foubert and Gijsbrechts 2007):

$$
\mathrm{P}_{\mathrm{t}}^{\mathrm{h}}(\mathrm{q} \mid \text { inc } \& i)=\frac{\exp \left(-\lambda_{\mathrm{it}}^{\mathrm{h}}\right)\left(\lambda_{\mathrm{it}}^{\mathrm{h}}\right)^{\mathrm{q}_{\mathrm{it}}^{\mathrm{h}}}}{\mathrm{q}_{\mathrm{it}}^{\mathrm{h} !}\left(1-\exp \left(-\lambda_{\mathrm{it}}^{\mathrm{h}}\right)\right)^{\prime}}
$$

where $\boldsymbol{\lambda}_{\mathbf{i t}}^{\mathbf{h}}$ is the purchase rate for which we use an exponential function to ensure that $\boldsymbol{\lambda}_{\mathbf{i t}}^{\mathbf{h}}$ is always positive: 


$$
\begin{aligned}
\lambda_{\mathrm{it}}^{\mathrm{h}}= & \exp \left(\gamma_{0}+\gamma_{\text {Loy }} \times \text { Loy }_{\mathrm{i}}^{\mathrm{h}}+\gamma_{\text {Inv }} \times \operatorname{Inv}_{\mathrm{t}}^{\mathrm{h}}+\gamma_{\text {Avquan }} \times \text { Avquan }^{\mathrm{h}}+\gamma_{\text {Prem }} \times\right. \\
& \text { Prem }_{\mathrm{it}}^{\mathrm{h}}+\gamma_{\text {RelPrem }} \times \text { RelPrem }_{\mathrm{it}}^{\mathrm{h}}+\gamma_{\text {premNB }} \times \text { premNB }_{\mathrm{it}}^{\mathrm{h}}+\gamma_{\mathrm{PC}} \times \mathrm{PC}_{\mathrm{it}}^{\mathrm{h}}+ \\
& \left.\gamma_{\mathrm{DISC}} \times \operatorname{DISC}_{\mathrm{it}}^{\mathrm{h}}+\gamma_{\mathrm{PCDNB}} \times \text { PCNB }_{\mathrm{it}}^{\mathrm{h}}\right),
\end{aligned}
$$

where $\boldsymbol{A v q u a n}^{h}$ represents consumer h's self-stated average purchase quantity and $\boldsymbol{L o y} \boldsymbol{y}_{i}^{h}$, as previously, reflects consumer h's overall choice share for SKU i. Together, Avquan ${ }^{\boldsymbol{h}}$ and $\boldsymbol{L o y}_{\boldsymbol{i}}^{\boldsymbol{h}}$ capture observed differences in the 'baseline' purchase quantity across consumers and/or SKUs. As in the incidence model, we include $\boldsymbol{I n} \boldsymbol{v}_{\boldsymbol{t}}^{h}$ to account for the cross-time fluctuations in the consumer's inventory level. Finally, we use the same variables as previously to assess the promotion effects on the quantity decision.

\subsubsection{Estimation}

To capture unobserved heterogeneity, the parameters of our model are normally distributed parameters across households (Park and Gupta 2009; Roy, Chintagunta, and Haldar 1996; Train 2003). Therefore, the likelihood function that results from combining the three models explained previously does not have a closed form. Thus, we estimate the three consumer decisions of incidence, choice, and quantity simultaneously using simulated maximum likelihood with quasi-random Halton draws. The use of Halton sequences to estimate the parameters' means and standard deviations leads to better coverage, lower root mean square errors (Sándor and Train 2004; Train 2003), and a lower number of draws needed (Bhat 2001) and thus outperforms independent random draws. In this study, we draw 100 values for each coefficient and respondent (McFadden and Train 2000; Revelt and Train 1998).

Accordingly, the simulated log-likelihood function to be optimized is as follows:

$$
\begin{aligned}
& \operatorname{SLL}=\sum_{\mathrm{h}} \ln \left(\frac { 1 } { \mathrm { R } } \sum _ { \mathrm { r } } \left(\prod _ { \mathrm { t } } \left\{\left(\left(\mathrm{P}_{\mathrm{tr}}^{\mathrm{h}}(\text { inc })\right)^{\mathrm{y}_{\mathrm{t}}^{\mathrm{h}}} \times\left(1-\mathrm{P}_{\mathrm{tr}}^{\mathrm{h}}(\mathrm{inc})\right)^{\left(1-\mathrm{y}_{\mathrm{t}}^{\mathrm{h}}\right)}\right) \times\right.\right.\right. \\
& \left.\left.\left.\left.\prod_{\mathrm{i}}\left(\left(\mathrm{P}_{\mathrm{tr}}^{\mathrm{h}} \mathrm{i} \mid \mathrm{inc}\right)\right)^{\mathrm{y}_{\mathrm{it}}^{\mathrm{h}}} \times\left(\mathrm{P}_{\mathrm{tr}}^{\mathrm{h}}(\mathrm{q} \mid \text { inc } \& i)\right)^{\mathrm{y}_{\mathrm{it}}^{\mathrm{h}}}\right)\right\}\right)\right)
\end{aligned}
$$

where

$\boldsymbol{R}=$ the number of draws,

$\boldsymbol{P}_{\boldsymbol{t r}}^{h}(\boldsymbol{i n c})=$ the probability for the $\mathrm{r}^{\text {th }}$ draw of parameters that consumer $\mathrm{h}$ purchases in the category on shopping trip $t$, 
$\boldsymbol{y}_{\boldsymbol{t}}^{\boldsymbol{h}}=$ the category purchase indicator (1 if consumer h purchases in the category on shopping trip $t$ and 0 if otherwise),

$\boldsymbol{P}_{\boldsymbol{t r}}^{\boldsymbol{h}}(\boldsymbol{i} \mid \boldsymbol{i n c})=$ the probability for the $\mathrm{r}^{\text {th }}$ draw of parameters that consumer $\mathrm{h}$ purchases SKU i on shopping trip $t$ conditional on buying in the category,

$\boldsymbol{y}_{i t}^{\boldsymbol{h}}=$ the SKU purchase indicator (1 if consumer h purchases SKU i on shopping trip $t$ and 0 if otherwise), and

$\boldsymbol{P}_{t r}^{h}(\boldsymbol{q} \mid \boldsymbol{i n} \boldsymbol{c} \& \boldsymbol{i})=$ consumer h's probability of buying quantity q on shopping trip t conditional on buying SKU i for the $\mathrm{r}^{\text {th }}$ draw of parameters.

We performed all estimations and computations with SAS/IML.

\subsection{Results}

In this section, we report the results of our model estimation and hypotheses tests. We discuss the parameter estimates of the control variables and attribute-specific intercepts and proceed with the assessment of the absolute impact of premium promotions on consumers' purchase decisions (H1, E1) and the moderators of premium effectiveness relative to price cuts $(\mathrm{H} 2-\mathrm{H} 4)$.

\subsubsection{Control Variables and Attribute-Specific Intercepts}

\subsubsection{Choice and Incidence}

Tables 2.11 and 2.12 display the parameter estimates of our simultaneously estimated mixed nested MNL and truncated Poisson models. For each parameter's distribution, we report the population mean, the standard deviation, and the corresponding standard errors. We first discuss the estimates for the attribute-specific intercepts at the choice level, which appear in Table 2.11. For each attribute, we determine one reference level that is excluded in the analysis and constitutes the benchmark for the remaining levels of the same attribute. The baseline of a specific SKU corresponds to the sum of the parameter estimates of the attribute levels describing the SKU. As the brand intercepts (see Table 2.11) of the promoted brands show, in the orange juice category the national brand (benchmark level) and the private label ( $\mathrm{M}_{\mathrm{PLO}}=.05, p>.7$ ) are equally attractive, while the private label is more attractive in the margarine and milk categories ( $\mathrm{M}_{\mathrm{PLMA}}=.5, p<.1 ; \mathrm{M}_{\mathrm{PLM}}=.9, p<.01$ ) and less attractive in the cereals category $\left(\mathrm{M}_{\mathrm{PLC}}=-1.21, p<.01\right)$ than the respective national brands (benchmark levels). Although our manipulation checks indicated that in all four categories, the selected national brands have a greater perceived quality than the private label, apparently the latter sometimes has greater baseline attractiveness because of its lower price. 
Table 2.11 Parameter Estimates of Attribute-Specific Constants

\begin{tabular}{|c|c|c|c|c|c|}
\hline & Mean & $\begin{array}{l}\text { Standard } \\
\text { Deviation }\end{array}$ & & Mean & $\begin{array}{l}\text { Standard } \\
\text { Deviation }\end{array}$ \\
\hline \multicolumn{3}{|l|}{ Orange Juice } & \multicolumn{3}{|l|}{ Margarine } \\
\hline \multicolumn{3}{|c|}{ Brand Intercepts } & \multicolumn{3}{|l|}{ Brand Intercepts } \\
\hline Minute Maid & .00 & .00 & Becel & .00 & .00 \\
\hline Delhaize & .05 (.15) & $.94^{* * *}(.12)$ & BecelOmega & $-.86(.63)$ & $-1.30^{* * *}(.44)$ \\
\hline Granini & $-.46^{* *}(.20)$ & $-.75^{* * *}(.19)$ & Becelproactiv & $-.66^{* *}(.27)$ & $-.96^{* * *}(.25)$ \\
\hline Looza & $-.67^{* * *}(.19)$ & $-.06(.23)$ & Delhaize & $.50^{*}(.30)$ & $-1.11^{* * * *}(.20)$ \\
\hline Appelsientje & $.91^{* * *}(.11)$ & $.47^{* * *}(.12)$ & Belolive & $.89^{* * *}(.23)$ & $-.01(.58)$ \\
\hline Oxfam & $.04(.17)$ & $.46^{* *}(.19)$ & Bertolli & $.28(.26)$ & $.36(.33)$ \\
\hline \multicolumn{3}{|c|}{ Flavor Intercepts } & Effi & $.19(.34)$ & $-.39(.31)$ \\
\hline Normal & .00 & .00 & Planta & $.55^{* *}(.26)$ & $-.91^{* * *}(.20)$ \\
\hline Pulp & $-1.60^{* * *}(.12)$ & $-1.57^{* * *}(.14)$ & Vitelma & $.46^{* *}(.23)$ & $-.45^{* * *}(.17)$ \\
\hline \multirow[t]{6}{*}{ Breakfast } & $-1.77^{* * * *}(.38)$ & $-.99(.30)$ & AlproSoja & $.53^{* *}(.21)$ & $-.10(.30)$ \\
\hline & & & Benecol & $-.63(.47)$ & $-.84^{* *}(.34)$ \\
\hline & & & \multicolumn{3}{|l|}{$\underline{\text { Flavor Intercepts }}$} \\
\hline & & & Normal & .00 & .00 \\
\hline & & & Light & $-.08(.08)$ & $.28(.23)$ \\
\hline & & & Oliveoil & $-.05(.41)$ & $-.75(.51)$ \\
\hline \multicolumn{3}{|l|}{ Cereals } & \multicolumn{3}{|l|}{ Milk } \\
\hline \multicolumn{3}{|c|}{ Brand Intercepts } & \multicolumn{3}{|l|}{ Brand Intercepts } \\
\hline Kelloggs & .00 & .00 & Campina & .00 & .00 \\
\hline Delhaize & $-1.21^{* * *}(.17)$ & $-2.26^{* * *}(.19)$ & Delhaize & $.90^{* * *}(.16)$ & $1.83^{* * *}(.15)$ \\
\hline Nestlé & $-.23^{* *}(.10)$ & $-.29^{* * *}(.11)$ & Inza & $-.85^{* *}(.38)$ & $-1.33^{* * *}(.34)$ \\
\hline \multicolumn{3}{|c|}{ Type Intercepts } & Joyvalle & $.98^{* * *}(.14)$ & $.69^{* * *}(.19)$ \\
\hline Rice & .00 & .00 & Danone & $-1.53^{* * *}(.45)$ & $-1.88^{* * *}(.27)$ \\
\hline Corn & $-.06(.27)$ & $-.05(.20)$ & Type Intercepts & & \\
\hline Wheat & $-.44^{* *}(.19)$ & $.21^{* *}(.08)$ & Halffull $1-2 \%$ fat & .00 & .00 \\
\hline Mixed & $-.37^{*}(.20)$ & $-.20^{* *}(.08)$ & Full $3-4 \%$ fat & $-1.35^{* * *}(.12)$ & $-1.55^{* * *}(.15)$ \\
\hline \multicolumn{3}{|c|}{ Form Intercepts } & Lowfat.1-.5\% fat & $-.99^{* * *}(.11)$ & $.68^{* * *}(.15)$ \\
\hline Flakes & .00 & .00 & Skim $0 \%$ fat & $-1.42^{* * *}(.15)$ & $.56^{* *}(.23)$ \\
\hline Balls & $.02(.17)$ & $.16(.17)$ & Flavor Intercepts & & \\
\hline Loops & $.19(.16)$ & $-.01(.20)$ & Normal & .00 & .00 \\
\hline Puffies & $-.33^{*}(.19)$ & $.11(.11)$ & Lactosefree & $-2.01^{* * *}(.42)$ & $-1.50^{* * * *}(.31)$ \\
\hline Cups & $-.12(.16)$ & $.12(.15)$ & Fibre & $-2.39^{* * *}(.61)$ & $.12(.76)$ \\
\hline Package & $-.56^{* * *}(.16)$ & $.36^{* *}(.17)$ & Children & $-1.12^{* *}(.50)$ & $-.83^{* *}(.35)$ \\
\hline Specialform & $-.97^{* * *}(.15)$ & $-.27^{*}(.15)$ & Vitamins & $-.14(.19)$ & $.07(.23)$ \\
\hline
\end{tabular}




\begin{tabular}{lllll}
\hline & Mean & $\begin{array}{l}\text { Standard } \\
\text { Deviation }\end{array}$ & Mean & $\begin{array}{l}\text { Standard } \\
\text { Deviation }\end{array}$ \\
\hline Flavor Intercepts & & & \\
Darkchoco & .00 & .00 & & \\
Health & $-.39^{* * *}(.13)$ & $1.28^{* * *}(.11)$ & \\
Milkchoco & $-.16(.12)$ & $-.05(.13)$ & \\
Natural & $-.10(.11)$ & $.63^{* * *}(.14)$ & \\
Honeysugar & $-.08(.14)$ & $-.32^{* * *}(.10)$ & \\
Fruit & $-.43^{* * *}(.13)$ & $-.57^{* * *}(.15)$ & \\
Special & $-.04(.16)$ & $.49^{* * * *}(.15)$ &
\end{tabular}

${ }^{*} p<.1 .^{* *} p<.05 .{ }^{* * *} p<.01$.

Notes: Standard errors are in parentheses.

Table 2.12 presents the parameter estimates for the control and promotional variables. At the incidence level, the estimated mean parameters for the control variables show the expected signs. The coefficients of the mean-centered inventory (INV) coefficients are negative and significant $(p<.01)$ across all categories. As expected, the fewer units consumers have in stock, the more likely they make a purchase. The parameter estimates of the average inter-purchase duration (IPDUR) variable are also negative and significant $(p<.01)$. The higher the respondent's usual inter-purchase time, the less likely he or she purchases in the category. Finally, in line with our expectations and previous research (e.g. Train 2003), the means of the coefficients of the inclusive value (IV) are between 0 and 1 . As the standard deviations of the parameters' distributions show, at the incidence level all but two standard deviations are highly significant, indicating considerable consumer heterogeneity. Yet a large majority of consumers still react in the direction of the mean effect. For example, the standard deviations of the distributions for the coefficient of INV indicate that in all four categories, more than $90 \%$ of the consumers have a negative coefficient for INV. At the choice level, we observe that loyalty (Loy) and the purchase-feedback indicator (LB) on average exert a significantly $(p<.01)$ positive influence on utility in all categories. Considerable consumer heterogeneity also exists at this decision level, but when we take into account the magnitude of the standard deviation, a large majority of consumers have a coefficient that shows the same sign as the mean effect. For example, for Loy, although consumer heterogeneity is substantial, at least $99 \%$ of consumers have a positive coefficient.

\subsubsection{Quantity}

Next, we examine the impact of control variables on consumers' quantity decisions. The effect of loyalty (Loy) is positive and significant $(p<.01)$, except for the margarine category, in which it is only weakly significant $(p<.1)$. For two of 
the four categories, the results indicate a significantly $(p<.01)$ negative mean effect of inventory (INV) on the quantity decision. For cereals, the mean effect is not significantly different from zero, while it is positive and significant $(p<.01)$ for the orange juice category, which may be due to cyclic buying behavior. That is, consumers purchase large amounts in a certain period and nothing or much less in other periods. The last control variable in the quantity model is a consumer's usual average quantity bought per shopping trip (Avquan). The mean effect is significant $(p<.01)$ and positive for all four categories. At the quantity level, we also find unobserved consumer heterogeneity, which is particularly evident in the milk category. Here, $29 \%$ of consumers have a positive INV coefficient, signaling cyclic purchase behavior, and 23\% have a negative Loy coefficient. In summary, the estimated coefficients of the control variables indicate that the participants in our shopping simulation on average behaved in line with purchase behavior observed in similar shopping experiments and in reallife purchase data (Ailawadi et al. 2007; Breugelmans et al. 2006; Foubert and Gijsbrechts 2007). 


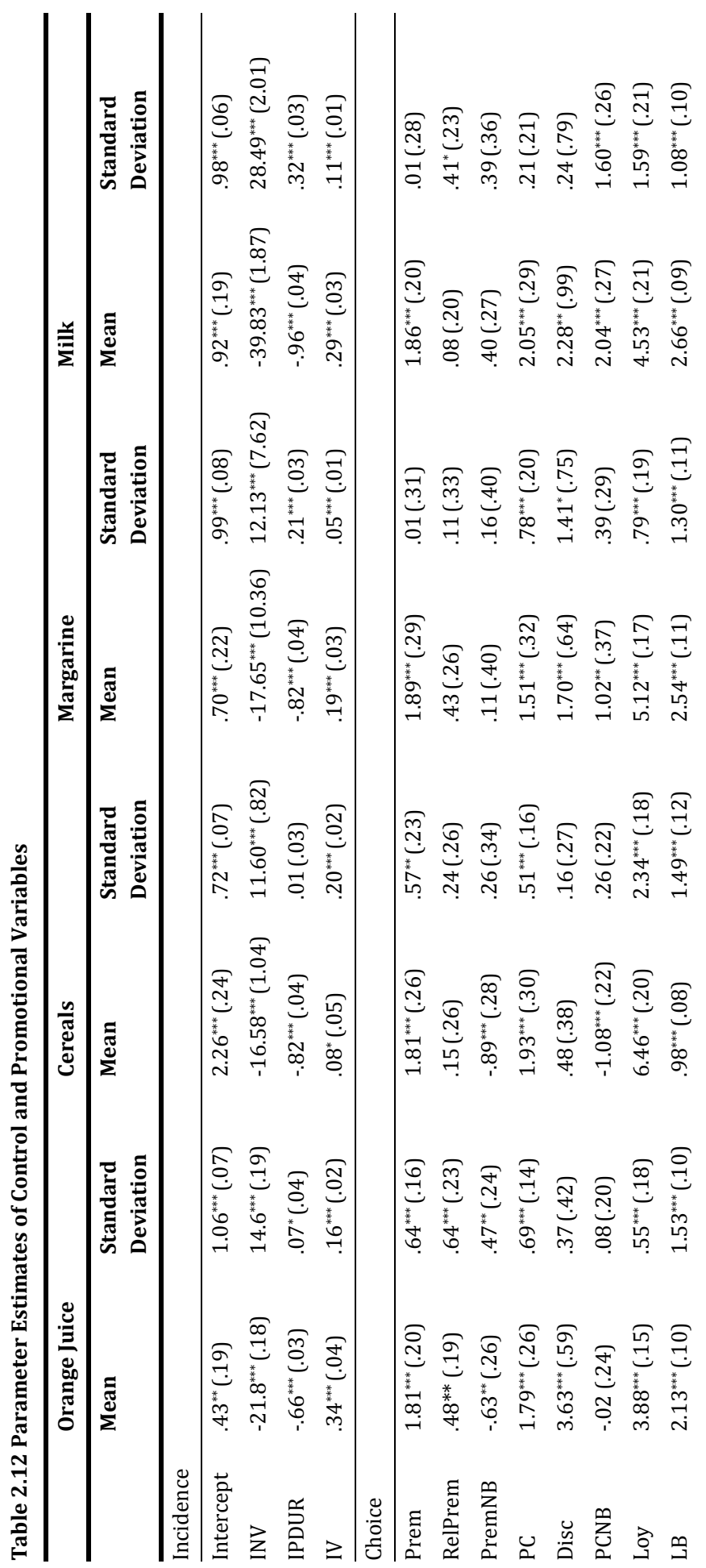




\section{CHAPTER 2}

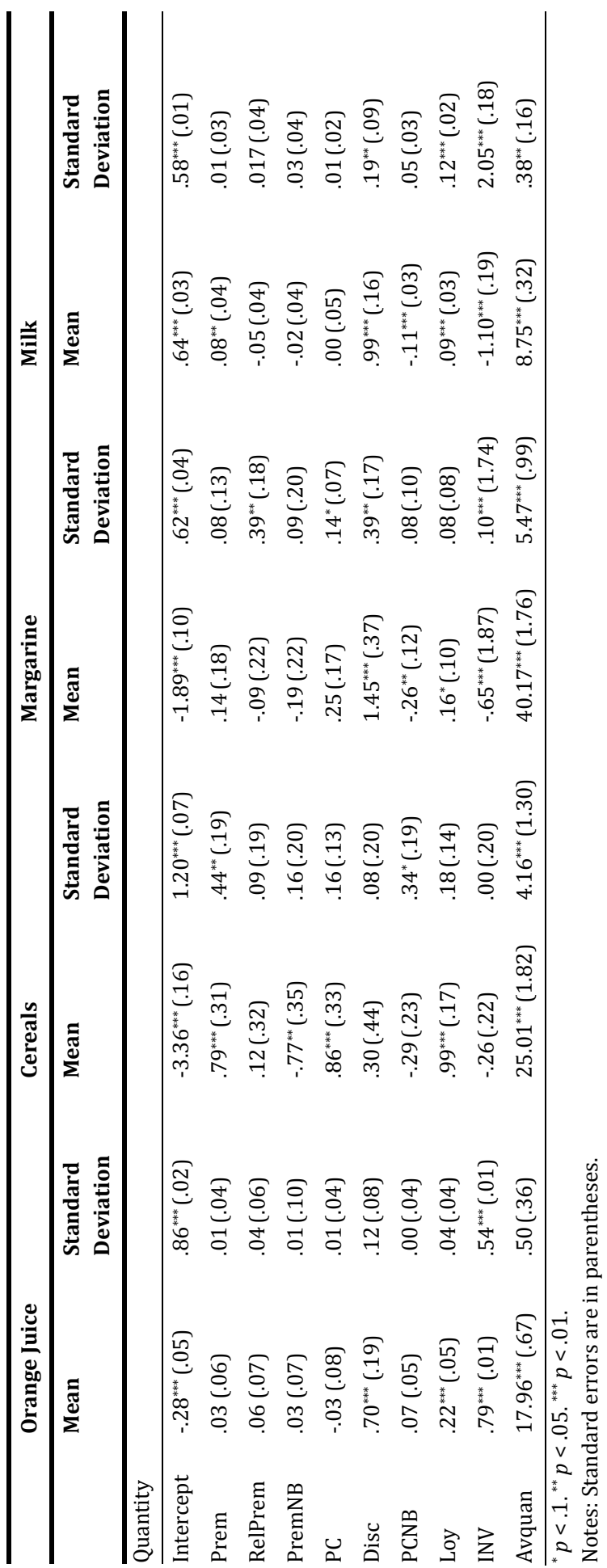




\subsubsection{The Impact of Premium Promotions on Purchase Decisions}

We examine the hypotheses for and expectation of the absolute impact of premium promotions on incidence, choice, and quantity (H1 and E1, Table 2.13).

\subsubsection{Choice and Incidence Effects}

As explained previously, the effects of promotions on the incidence and choice decisions are governed by the same principles. Specifically, at the incidence level, a promotion's impact manifests through the inclusive value, which captures the changes in the SKU's utility as a result of the promotion. In line with random utility maximization theory (Train 2003), the mean coefficients of IV are between 0 and 1 . Thus, on average, a positive promotion effect on an item's utility will also translate into a positive effect on incidence. Table 2.12 shows that in the choice model, the coefficient of Prem, a dummy that equals 1 for every premium, is on average positive and significant $(p<.01)$ in all categories. However, to evaluate the total effect of each premium, we should also consider the coefficients of RelPrem, which captures the change in effectiveness when a premium is related (rather than unrelated) to the product, and PremNB, which captures the change in effectiveness when a premium comes with a national brand (rather than a private label). Specifically, we add up the mean coefficients as shown in the first row of Table 2.13 and conduct $t$-tests to test whether the mean effects differ from zero. As Table 2.14 shows, the results reveal that premiums - unrelated or related and national brands or private labels-exert a significant and positive influence on consumers' incidence and choice decisions. With the exception of premiums that come with national brands in the cereals category $(p<.1)$, all coefficients are significant at the .01 level. To investigate the unobserved consumer heterogeneity of the total premium effects, we add up the variances of the parameters' distributions and take the square root to derive the standard deviations (Table 2.14). The results indicate that the majority of respondents, always greater than $93 \%$, react positively to premiums. These results lend support to $\mathrm{H} 1$. 
Table 2.13 Summary of Hypotheses

\section{Purchase Level Relationship}

\begin{tabular}{|c|c|c|c|}
\hline H1 & $\begin{array}{l}\text { Incidence and } \\
\text { choice }\end{array}$ & Premium effects are positive. & $\begin{array}{l}0<\tau_{\text {IV }}<1 \\
\beta_{\text {Prem }}>0 \\
\beta_{\text {Prem }}+\beta_{\text {RelPrem }}>0 \\
\beta_{\text {Prem }}+\beta_{\text {PremNB }}>0 \\
\beta_{\text {Prem }}+\beta_{\text {RelPrem }}+\beta_{\text {PremNB }}>0\end{array}$ \\
\hline E1 & Quantity & $\begin{array}{l}\text { Premiums have no or } \\
\text { negative effects. }\end{array}$ & $\begin{array}{l}\gamma_{\text {Prem }} \leq 0 \\
\gamma_{\text {Prem }}+\gamma_{\text {RelPrem }} \leq 0 \\
\gamma_{\text {Prem }}+\gamma_{\text {PremNB }} \leq 0 \\
\gamma_{\text {Prem }}+\gamma_{\text {RelPrem }}+\gamma_{\text {PremNB }} \leq 0\end{array}$ \\
\hline $\begin{array}{l}\mathrm{H} 2 \mathrm{a} \\
\mathrm{H} 2 \mathrm{~b}\end{array}$ & $\begin{array}{l}\text { Incidence and } \\
\text { choice } \\
\text { Quantity }\end{array}$ & $\begin{array}{l}\text { Relatedness increases the } \\
\text { relative performance of } \\
\text { premiums. }\end{array}$ & $\begin{array}{l}\beta_{\text {RelPrem }}>0 \\
\gamma_{\text {RelPrem }}>0\end{array}$ \\
\hline H3 & $\begin{array}{l}\text { Incidence and } \\
\text { choice }\end{array}$ & $\begin{array}{l}\text { Relative performance of } \\
\text { premiums decreases when } \\
\text { moving from a private label } \\
\text { to a national brand. }\end{array}$ & $\beta_{\text {PremNB }}<\beta_{\text {PCNB }}$ \\
\hline$\overline{\mathrm{H} 4}$ & $\begin{array}{l}\text { Incidence and } \\
\text { choice }\end{array}$ & $\begin{array}{l}\text { H3 is particularly true for } \\
\text { utilitarian product categories. }\end{array}$ & 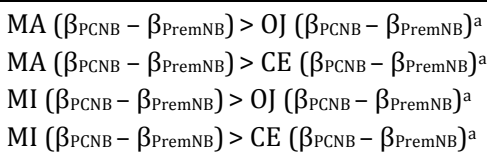 \\
\hline
\end{tabular}

a $\mathrm{MA}=$ margarine, $\mathrm{MI}=$ milk, $\mathrm{OJ}=$ orange juice, and $\mathrm{CE}=$ cereals. 
Table 2.14 Total Premium Effects (TPE)

\begin{tabular}{|c|c|c|c|c|c|c|c|c|}
\hline \multirow{3}{*}{$\begin{array}{l}\text { Type of } \\
\text { Premium }\end{array}$} & \multicolumn{4}{|c|}{ Orange Juice } & \multicolumn{4}{|c|}{ Cereals } \\
\hline & \multicolumn{2}{|c|}{ Private Label } & \multicolumn{2}{|c|}{ National Brand } & \multicolumn{2}{|c|}{ Private Label } & \multicolumn{2}{|c|}{ National Brand } \\
\hline & TPE & $\begin{array}{l}\text { Standard } \\
\text { Deviation }\end{array}$ & TPE & $\begin{array}{l}\text { Standard } \\
\text { Deviation }\end{array}$ & TPE & $\begin{array}{l}\text { Standard } \\
\text { Deviation }\end{array}$ & TPE & $\begin{array}{l}\text { Standard } \\
\text { Deviation }\end{array}$ \\
\hline \multicolumn{9}{|l|}{ Choice } \\
\hline Unrelated & $\begin{array}{l}1.81^{* * *} \\
(8.90)\end{array}$ & .64 & $\begin{array}{l}1.18^{* * *} \\
(2.78)\end{array}$ & .79 & $\begin{array}{l}1.81^{* * *} \\
(7.01)\end{array}$ & .57 & \begin{tabular}{|l|}
$.92^{*}$ \\
$(1.89)$
\end{tabular} & .62 \\
\hline Related & $\begin{array}{l}2.29^{* * *} \\
(6.68)\end{array}$ & .91 & $\begin{array}{l}1.66^{* * *} \\
(3.32)\end{array}$ & 1.02 & $\begin{array}{l}1.96^{* * *} \\
(4.25)\end{array}$ & .61 & $\begin{array}{l}1.07^{*} \\
(1.76)\end{array}$ & .67 \\
\hline \multicolumn{9}{|l|}{ Quantity } \\
\hline Unrelated & $\begin{array}{l}.03 \\
(.56)\end{array}$ & .01 & $\begin{array}{l}.06 \\
(.53)\end{array}$ & .01 & $\begin{array}{l}.79^{* * *} \\
(2.60)\end{array}$ & .44 & $\begin{array}{l}.02 \\
(.04)\end{array}$ & .47 \\
\hline Related & $\begin{array}{l}.09 \\
(.29)\end{array}$ & .04 & $\begin{array}{l}.12 \\
(.35)\end{array}$ & .04 & $\begin{array}{l}.91^{*} \\
(1.68)\end{array}$ & .45 & $\begin{array}{l}.14 \\
(.19)\end{array}$ & .48 \\
\hline \multirow{3}{*}{$\begin{array}{l}\text { Type of } \\
\text { Premium }\end{array}$} & \multicolumn{4}{|c|}{ Margarine } & \multicolumn{4}{|l|}{ Milk } \\
\hline & \multicolumn{2}{|c|}{ Private Label } & \multicolumn{2}{|c|}{ National Brand } & \multicolumn{2}{|c|}{ Private Label } & \multicolumn{2}{|c|}{ National Brand } \\
\hline & TPE & $\begin{array}{l}\text { Standard } \\
\text { Deviation }\end{array}$ & TPE & $\begin{array}{l}\text { Standard } \\
\text { Deviation }\end{array}$ & TPE & $\begin{array}{l}\text { Standard } \\
\text { Deviation }\end{array}$ & TPE & $\begin{array}{l}\text { Standard } \\
\text { Deviation }\end{array}$ \\
\hline \multicolumn{9}{|l|}{ Choice } \\
\hline Unrelated & $\begin{array}{l}1.89^{* * *} \\
(6.60)\end{array}$ & .01 & $\begin{array}{l}2.00^{* * *} \\
(3.19)\end{array}$ & .15 & $\begin{array}{l}1.86^{* * *} \\
(9.21)\end{array}$ & .01 & $\begin{array}{l}2.26^{* * *} \\
(5.27)\end{array}$ & .39 \\
\hline Related & $\begin{array}{l}2.32^{* * *} \\
(4.94)\end{array}$ & .11 & $\begin{array}{l}2.43^{* * *} \\
(3.32)\end{array}$ & .19 & $\begin{array}{l}1.94^{* * *} \\
(5.60)\end{array}$ & .41 & $\begin{array}{l}2.34^{* * *} \\
(4.57)\end{array}$ & .57 \\
\hline \multicolumn{9}{|l|}{ Quantity } \\
\hline Unrelated & $\begin{array}{l}.14 \\
(.78)\end{array}$ & .08 & $\begin{array}{l}-.05 \\
(.09)\end{array}$ & .12 & $\begin{array}{l}.08^{* * *} \\
(2.23)\end{array}$ & .01 & $\begin{array}{l}.06 \\
(.24)\end{array}$ & .03 \\
\hline Related & $\begin{array}{l}.05 \\
(.14)\end{array}$ & .4 & \begin{tabular}{|l}
-.14 \\
$(.30)$
\end{tabular} & .41 & $\begin{array}{l}.03 \\
(.46)\end{array}$ & .02 & $\begin{array}{l}.01 \\
(.17)\end{array}$ & .03 \\
\hline
\end{tabular}

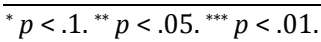

Notes: $\mathrm{t}$-values are in parentheses.

The standard deviations of the total premium effects are calculated by adding up the variances (in the computation of the total premium effect included) of the parameters' distributions and taking the square root of this sum.

\subsubsection{Quantity Effects}

Table 2.12 reports population means and standard deviations of the coefficients of the variables Prem, RelPrem, and PremNB. As previously, we need to combine the coefficients as summarized in Table 2.13 and conduct t-tests to determine whether the various premiums have a mean effect that is different 
from zero. The results displayed in Table 2.14 show that, on average, premiums have no effect on consumers' quantity decisions; only three of the 16 mean effects are significant. To assess the 'strength' of these non-significant results, we conduct a power analysis (Murphy and Myors 1998). For the non-significant effects to become significant at the .05 level with a power of .8 (the traditional standard for adequate power), the sample must consist of at least 23,800 consumers in the orange juice category, 134,500 in the cereals category, 11,100 in the margarine category, and 44,800 consumers in the milk category. As in the choice level, we also examine the unobserved consumer heterogeneity of the total premium effects at the quantity level. The mean effects of the orange juice category, the milk category, and the private margarine labels do not suffer from heterogeneity and are true for approximately $90 \%$ of the consumers. However, for the cereals brands and the national margarine brands, the calculated standard deviations of the parameter estimates' distributions reveal strong consumer heterogeneity. Approximately $35 \%$ of consumers in the cereals category react negatively, and $35 \%$ of consumers of national margarine brands react positively and, thus, in the opposite direction of the estimated mean effect. Therefore, 13 of the 16 mean effects in Table 2.14 are non-significant, and two of the three significant mean effects are subject to strong heterogeneity. Thus, we find at least partial support for our expectation that premium promotions have no (or a negative) impact on customers' quantity decisions.

\subsubsection{Moderating Effects of Relative Premium Effectiveness}

In $\mathrm{H} 2-\mathrm{H} 4$, we compare the effects of premiums and equivalent price cuts and investigate the moderating impact of three factors on these promotions' relative performance. Before we reflect on the results of our hypotheses tests, note that in our model, the price-cut effects are captured by the variables PC, Disc, and PCNB (see Table 2.12). The mean effect of PC, a dummy that indicates the mere presence of a price cut, is systematically positive and significant $(p<.01)$ at the incidence and choice levels and typically non-significant at the quantity level, with the exception of the cereals category $(p<.01)$. The mean effect of Disc, which measures the actual discount, is positive and significant $(p<.05)$ at all decision levels in all categories, except for cereals. We discuss the effects of the dummy variable PCNB, which captures the incremental impact of price promoting a national rather than a store brand, subsequently. Finally, although consumer heterogeneity in price promotion response at the different decision levels is substantial, at least $80 \%$ of consumers react in the same direction as the mean effects. 


\subsubsection{The Moderating Impact of Premium-Product Relatedness}

$\mathrm{H} 2 \mathrm{a}$ and $\mathrm{H} 2 \mathrm{~b}$ hypothesize that relatedness strengthens the relative effectiveness of premiums on incidence, choice, and quantity. As Table 2.12 shows, the mean effect of RelPrem in the incidence and choice model is significantly positive $(p<.01)$ only for the orange juice category. For the other three categories, on average RelPrem does not have a significant impact. Thus, H2a receives only limited support. At the quantity level, the mean effects of RelPrem are all nonsignificant; thus, H2b also is not supported. Surprisingly, across the three purchase decision levels, premiums tend to have the same effect regardless of their relatedness to the product. This finding suggests that consumers tend to evaluate the premium on its own and pay less attention to its functional compatibility with the category. In the context of fast-moving consumer goods, premiums are usually simple and mundane items whose functionality is obvious even without a clear link with the category.

\subsubsection{Moderating Impact of Private Label versus National Brand}

At the incidence and choice levels, we expect that the performance of premiums decreases relative to price cuts in the shift from a private label to a national brand (see H3). To test this hypothesis, we focus on the coefficients of PremNB and PCNB in the incidence and choice model (Table 2.12). Though not always significant, the mean coefficients of PremNB and PCNB follow a similar pattern across product categories. That is, they are positive in utilitarian categories and negative in hedonic ones. One reason may be that in hedonic categories, national brands are bought especially because of their intrinsic image, making promotional incentives less effective. In contrast, in utilitarian categories, a promotion may be a trigger that attracts customers to the more expensive national brand.

To study changes in relative promotion effectiveness when going from a private label to a national brand, we compute $\left(\beta_{\mathrm{PCNB}}-\beta_{\text {PremNB }}\right)$ for each category. This mean difference (MD) is positive and significant in the orange juice $\left(\mathrm{MD}_{0}\right.$ $=.61, p<.05)$, margarine $\left(\mathrm{MD}_{\mathrm{Ma}}=.91, p<.01\right)$, and milk $\left(\mathrm{MD}_{\mathrm{M}}=1.64, p<.01\right)$ categories but non-significant in the cereals category $\left(\mathrm{MD}_{\mathrm{C}}=-.19, p>.5\right)$. Thus, in the switch from a private label to a national brand, the effectiveness of a premium tends to increase less or decrease more than that of a price cut. This finding offers support for $\mathrm{H} 3$ and suggests that a price cut induces more asymmetric switching effects than a premium. At the quantity level, we find no impact of brand type on relative premium effectiveness: None of the differences between the coefficients of PCNB and PremNB are significant.

\subsubsection{Moderating Impact of Category Type}

We hypothesize in $\mathrm{H} 4$ that the lower relative premium effectiveness for national brands compared with private labels is most prominent in utilitarian catego- 
ries. Therefore, we compare the MD values across categories. ${ }^{4}$ We find that the mean differences in the utilitarian categories are systematically greater than those in the hedonic categories. These results are statistically significant $(p<$ .01 ), except for the comparison between the utilitarian margarine category and the hedonic orange juice category $(p>.5)$. Overall, these comparisons across categories support our expectation that at the incidence and choice levels, the lower relative premium effectiveness for national brands is most problematic in utilitarian categories. We also compare the MD values across categories at the quantity level but find no differences. This result at the quantity level is not surprising, because relative promotion effectiveness between private labels and national brands does not vary in the first place.

\subsection{Simulation Study}

To translate our results into managerially relevant insights, we conduct a simulation study in which we use the parameter estimates to calculate the percentage changes in brand line sales in response to different promotions. Thus, in this analysis, we take the perspective of the manufacturer, be it a national brand or a private label manufacturer. ${ }^{5}$ Specifically, we examine the circumstances under which a premium is more effective than price cuts, taking into account the promotions' effects on consumers' incidence, choice, and quantity decisions. Throughout the simulation, we also consider our moderators of relative premium effectiveness: premium-product relatedness, private label versus national brand, and hedonism/utilitarianism.

\subsubsection{Approach}

To simulate brand line sales in a given scenario, we compute the expected purchase quantity $E\left(Q_{i}^{h}\right)$ for each SKU i in the relevant brand line and for each consumer $h$ in our sample:

$$
E\left(Q_{i}^{h}\right)=P^{h}(\text { inc }) * P^{h}(i \mid \text { inc }) * E\left(q_{i}^{h} \mid \text { inc \& } i\right) .
$$

\footnotetext{
${ }^{4}$ We compute the standard deviations of, for example, $\mathrm{MD}_{\mathrm{M}}-\mathrm{MD}_{\text {oj }}$ as the square root of the sum of the variances of $\mathrm{MD}_{\mathrm{M}}$ and $\mathrm{MD}_{\mathrm{oj}}$. In other words, we ignore the covariance between $\mathrm{MD}_{\mathrm{M}}$ and $\mathrm{MD}_{0 \mathrm{j}}$ because this would require the simultaneous estimation of our model in both categories (milk and orange juice). We believe our approach is rather conservative because the covariance between the MD values in two categories is likely to be positive, such that in reality the standard deviation of $\mathrm{MD}_{\mathrm{M}}$ and $\mathrm{MD}_{\mathrm{o}}$ may be smaller than the value we use to compute our t-statistic.

${ }^{5}$ Retailers often outsource the production of their private labels (Ailawadi and Harlam 2009).
} 
As previously, $P^{h}($ inc $)$ is the purchase incidence probability, and $P^{h}(i \mid$ inc $)$ is the choice probability for SKU i conditional on purchase incidence. The term $E\left(q_{i}^{h} \mid\right.$ inc \& $\left.i\right)$ represents the expected purchase quantity conditional on incidence and choice, as follows:

$$
\mathrm{E}\left(\mathrm{q}_{\mathrm{i}}^{\mathrm{h}} \mid \mathrm{i} \& \text { inc }\right)^{\mathrm{h}}=\frac{\left(\lambda_{\mathrm{i}}^{\mathrm{h}}\right)}{\left(1-\exp \left(-\lambda_{\mathrm{i}}^{\mathrm{h}}\right)\right)^{\prime}}
$$

where $\lambda_{i}^{h}$ is the purchase rate.

In our computations, we use the estimated mean coefficients and manipulate our marketing variables such that they reflect the scenario of interest. The other variables (e.g. SKU loyalty, usual purchase quantity) receive consumerspecific constant values; for variables that, in principle, vary across time (the inventory and purchase-feedback dummy variable), we use consumer-specific average values. We obtain brand line sales by aggregating the expected purchase quantities across consumers and the relevant SKUs. Finally, we assess a promotion's impact by computing the percentage change in brand line sales relative to the sales in a scenario without any promotions.

\subsubsection{Simulation Results}

The results of our simulation study reveal that though premiums have a positive effect on consumers' incidence and choice decisions, their overall impact on brand line sales is always considerably smaller than that of an equivalent price cut, regardless of the type of promoted brand (private/national) and the nature of the premium (related/unrelated) (see Table 2.15).

Table 2.15 Percentage Change in Brand Line Sales

\begin{tabular}{lllll}
\hline Category & Brand Type & Price Cut & Related Premium & Unrelated Premium \\
\hline Orange juice & Private label & $279.14 \%$ & $172.39 \%$ & $118.89 \%$ \\
& National brand & $205.60 \%$ & $87.48 \%$ & $54.03 \%$ \\
\hline Cereals & Private label & $323.69 \%$ & $247.25 \%$ & $211.50 \%$ \\
& National brand & $60.57 \%$ & $46.09 \%$ & $37.78 \%$ \\
\hline Margarine & Private label & $360.47 \%$ & $188.43 \%$ & $147.87 \%$ \\
& National brand & $236.87 \%$ & $82.81 \%$ & $66.93 \%$ \\
\hline Milk & Private label & $150.05 \%$ & $76.30 \%$ & $81.07 \%$ \\
& National brand & $239.18 \%$ & $89.22 \%$ & $93.87 \%$ \\
\hline
\end{tabular}


The main driver of this difference is the promotions' impact at the quantity level. Whereas price cuts have a strong positive impact on consumers' quantity decisions, this is not the case for premium promotions. However, for a fair assessment of the promotions' relative effectiveness, we also take into account the cost of both deal types. Specifically, a premium may cost the manufacturer far less than the value consumers ascribe to it. Furthermore, to support a price promotion, manufacturers often must grant the retailer a reduction in the wholesale price that is greater than the discount to the end consumer. That is, retailer pass-through rates are typically lower than 100\% (Besanko, Dubé, and Gupta 2005; Tyagi 1999). Besanko et al. (2005) report an average pass-through rate of $60 \%$, implying that the reduction in the wholesale price is on average $1 / 0.6=1.67$ times greater than the retail discount. Ailawadi and Harlam (2009) find a median pass-through rate of merely $20 \%$, with individual rates varying between $1.5 \%$ and $130 \%$. To account for these concerns, we investigate how much the studied premiums should maximally cost per unit for the manufacturer to prefer the premium to a price cut with the same cost. We call this amount the premium's "indifference cost" - that is, the promotional cost per unit sold of the promoted product that leaves the manufacturer indifferent between the premium promotion and a price discount. We compute the premium's indifference cost for retailer pass-through rates ranging between $5 \%$ and $120 \%$. Figure 2.3 illustrates how the indifference cost arises for the private label in the orange juice category. The horizontal curve marks the percentage sales impact of the related premium, and the sloped curves represent the percentage sales impact of increasing reductions in the wholesale price and alternative pass-through rates: The impact of a given reduction in the wholesale price on brand line sales shifts upward when the pass-through rate increases. The intersections of the premium and discount curves determine the premium's indifference cost. For example, for a pass-through rate (PTR) of $35 \%$, the premium, as long as it does not cost more than 42.9 cents, is more effective than a price cut with the same per unit cost. For higher premium costs, the manufacturer would be better off (in terms of sales) offering a reduction in the wholesale price that equals the premium cost. 


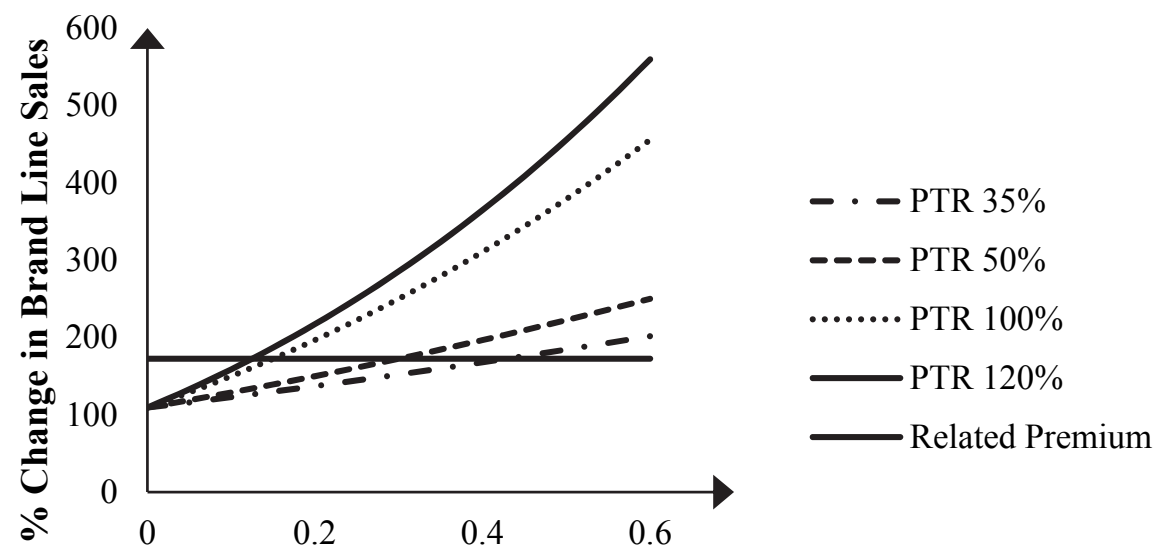

\section{Reduction in Wholesale Price (Euro)}

Figure 2.4 presents the premiums' indifference cost as a function of the retail pass-through rates. To increase the generalizability of our findings, the vertical axis presents the indifference costs relative to the premium's value (we discuss the absolute indifference costs subsequently). We show the results for related and unrelated premiums and for one hedonic (orange juice) and one utilitarian (margarine) product category. Unless otherwise indicated, the results of the two remaining categories, cereals and milk, also support our conclusions. In the graphs of Figure 2.4, the black lines refer to the premium indifference cost for the private label, and the red line represents the indifference cost for the national brand. Note that only Panel A includes results for the national brand because in the other settings, a national brand could never benefit more from the premium promotion than from a price cut: Regardless of the size of the discount, the price cut triggered a fixed sales effect that largely exceeded the premium impact. We now discuss the insights emerging from these graphs.

First, the curves are negatively sloped, implying that the premium indifference cost decreases when the pass-through rate increases. Consider, for example, the private label in the (hedonic) orange juice category (solid line in Figure 2.4 , Panel A). For a pass-through rate of $25 \%$, manufacturers can afford to spend up to 60 cents for the related premium, or $150 \%$ of the premium's value. However, for a pass-through rate of $75 \%$, the related premium's indifference cost drops to 20 cents, or $50 \%$ of the premium's value.

Second, although we did not find support for $\mathrm{H} 2 \mathrm{a}$ and $\mathrm{H} 2 \mathrm{~b}$ that related premiums are more effective than unrelated premiums, a comparison of Panel A with Panels B-D reveals that the indifference cost tends to be greater for related than for unrelated premiums. For example, for the private label in the 
(utilitarian) margarine category (Figure 2.4, Panels C and D) and a passthrough rate of $40 \%$, the indifference cost for the related premium amounts to 55.85 cents, or $94.65 \%$ of the premium's value, whereas the indifference cost for the unrelated premium is only 26.85 cents, or $48.77 \%$ of the premium's value. 6

Third, although premiums are likely to generate positive sales effects for national brands as well as private labels (see Table 2.15), the willingness to pay for a premium may be substantially lower for a national brand manufacturer than for a private label manufacturer. As demonstrated previously, a premium's relative impact at the incidence and choice levels improves when the premium is attached to a private label rather than a national brand (see H3). As Figure 2.4, Panel A shows, for the related premium in the orange juice category, the indifference cost is systematically lower for the national brand than for the private label. For example, with a pass-through rate of $30 \%$, the indifference cost is 50.11 cents (or $125 \%$ of the premium's value) for the private label, but only 6.34 cents (or $15.84 \%$ of the premium's value) for the national brand. In the other panels of Figure 2.4, national brand manufacturers should not pay at all for the premium, regardless of the pass-through rate, because they are always better off offering a wholesale discount equivalent to the premium cost. ${ }^{7}$

\footnotetext{
${ }^{6}$ The milk category is an exception because the unrelated premium performs slightly better than the related premium (though here too the differences in performance are not based on significant coefficients). For example, for a private label at a pass-through rate of $25 \%$, the indifference cost for the unrelated premium is 3.63 cents, or $14.29 \%$ of the premium's value. In contrast, the manufacturer would not be willing to pay for the related premium, because a price discount with the same cost would always generate higher brand line sales.

${ }^{7}$ As an exception, in the cereals category, the relative performance of premiums appears stronger for national brands than for private labels. For example, for a related premium and a pass-through rate of $30 \%$, the indifference cost is 19.76 cents (or $31.87 \%$ of the premium's value) for the private label, but 63.25 cents (or $102.02 \%$ of the premium's value) for the national brand.
} 
FIGURE 2.4 Premium Indifference Costs as a Function of Pass-Through Rates
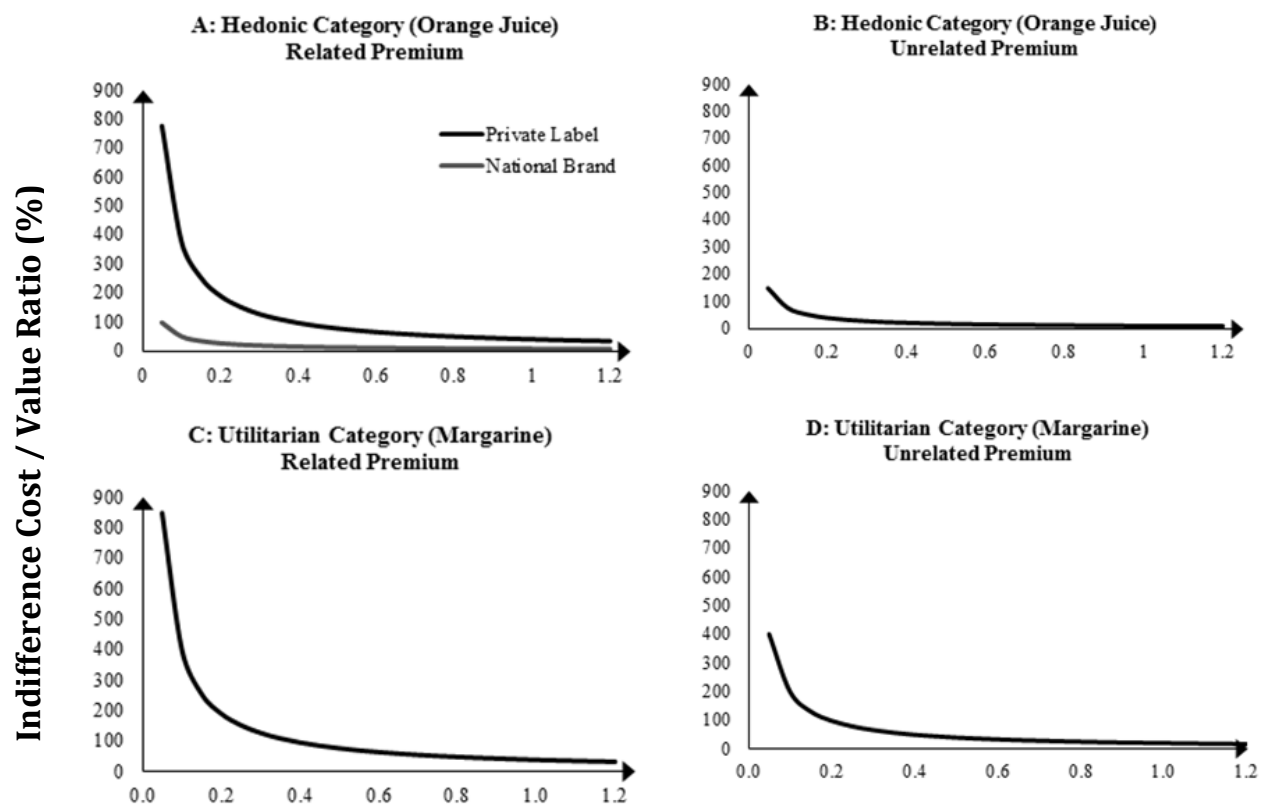

Pass-Through Rates (PTR)

Fourth, the difference between the premium indifference cost for private labels and national brands is most noticeable in utilitarian categories. Especially in utilitarian categories, national brands benefit more from price cuts than from premiums (see H4). As a result, the willingness to pay for a premium among national brand manufacturers tends to be particularly low in utilitarian categories. This becomes apparent from Figure 2.4. While for the hedonic category orange juice national brand manufacturers may still be willing to pay for a (related) premium, they are not interested in offering premiums in the utilitarian category of margarine because they will always benefit more from a price cut (with the same per unit cost).

\subsection{Conclusions and Managerial Implications}

This research contributes to the existing promotions literature by (1) investigating the immediate effects of premium promotions on the three consumer purchase decisions (i.e. incidence, choice, and quantity), (2) comparing these effects with those of price cuts, and (3) examining the impact of possible moderating variables on relative premium effectiveness. We rely on data from an 
online shopping experiment in four product categories-orange juice, milk, cereals, and margarine-and estimate MNL and Poisson models with unobserved consumer heterogeneity. In what follows, we discuss the main findings, the resultant managerial implications, and the limitations and future research directions.

\subsubsection{Main Findings}

This study sheds new light on how premiums perform at the three purchase levels and how their effectiveness in comparison with price cuts can change depending on the setting. Premiums have a positive effect on consumers' incidence and choice decisions but do not affect the quantity decision. The comparison of premiums and equivalent price cuts reveals that, in general, price cuts generate higher sales than premiums particularly because of their strong effect on quantity. However, the examination of the three moderators-premiumproduct relatedness, brand type, and category type-suggests that a premium's relative performance can improve. At the incidence and choice level, a premium promotion's relative effectiveness is enhanced if the premium comes with a private label rather than a national brand. This effect is intensified if the brand belongs to a hedonic rather than a utilitarian product category. Thus, benefit congruence (Chandon et al. 2000) increases relative premium performance in that a promotion with hedonic benefits (i.e. a premium) performs better in hedonic than in utilitarian categories. Surprisingly, we do not find the expected positive effect of premium-product relatedness on relative premium effectiveness. This result suggests that consumers value the premium itself and consider the functional compatibility with the category rather unimportant. Furthermore, premiums that are attached to fast-moving consumer goods tend to be simple items whose functionality is apparent even without a clear link with the category.

Although premiums generally generate lower sales than equivalent price cuts, we need to consider costs for a fair comparison. Premiums are often worth more than they actually cost to the manufacturer. Thus, we conduct a simulation study and account for costs by considering pass-through rates, which represent how much of a manufacturer's price reduction a retailer passes on to its customers (Ailawadi and Harlam 2009; Besanko et al. 2005). A premium gains attractiveness relative to a price cut the lower is the pass-through rate. At the same per unit cost, a premium can lead to higher brand line sales than a price cut. However, we find that regardless of the pass-through rate, premiums do not make sense for utilitarian national brands. Premiums are unable to compete with the strong effect of price cuts on incidence, choice, and quantity. 
However, for hedonic brands and utilitarian private labels, premiums can be successful.

\subsubsection{Managerial Implications}

This study's findings reveal how strategic objectives are associated with choosing the appropriate promotion type. Premiums can be effective depending on the promoter's objective. In general, managers that want to increase brand line sales might consider premiums because consumers, in response to premiums, switch to the promoted product. However, premium promotions do not affect consumers' quantity decisions. Managers focusing on increasing secondary demand should consider premiums, while managers aiming to increase primary demand should choose price cuts because of their strong quantity effects. The insights of this study lead to different implications and suggestions for manufacturers and retailers.

Increasing secondary demand is particularly important for product manufacturers, which typically initiate the use of premium promotions. Depending on the promotions' costs, which we account for in our simulation study, premiums can be an alternative to price cuts. Manufacturers are concerned with increasing their brands' market share. Primarily, they aim to attract sales from other brands and thus may consider using premium promotions. Increasing secondary demand can be a manufacturer's goal in different situations: First, when introducing a new product, it might make sense for the manufacturer to use a premium to induce trial of the product. Second, to enhance sales of one particular brand, the manufacturer could attach an attractive premium, which will reduce sales from other brands in the category.

Retailers are largely interested in enhancing primary demand in their stores. However, premiums do not affect primary demand, and thus price cuts should be chosen instead. Yet, if the focus is on increasing secondary demand, retailers should consider the use of premium promotions. Many retailers have begun producing and selling their own brands to increase revenues and bind consumers to their stores. Retailers that want to improve brand line sales of their private labels should choose a premium. After all, retailers must carefully consider promotional costs because price cuts for private labels are typically retailer initiated and not subject to pass-through rates.

Of particular interest to both manufacturers and retailers is that a premium is often worth more than its costs (Gaeth et al. 1991). Thus, managers should be aware of the value consumers attach to the premium because cheap products can serve as efficient premium promotions. While price cuts are always worth the pronounced discount, premiums can be worth much more than they cost and thus outperform price cuts. 


\subsubsection{Limitations}

This study has several limitations that offer opportunities for further research. First, although our computer-based shopping experiment enabled us to evoke a realistic purchase context and, at the same time, manipulate the factors of interest, it would be useful to study premium promotions with real-life panel data.

Second, we carefully designed our product portfolios by adding the most popular brands but, at the same time, decided to present merely one product size. Although this is the most frequently purchased product size, the inclusion of other product sizes might help gain additional insights into switching effects as a result of premium promotions.

Third, we concentrated on the immediate impact of premiums and did not make inferences about relative premium performance in the long run. However, it might be that the performance of premiums relative to price cuts improves when we also account for effects across time: While price cuts lower consumers' reference price (Lattin and Bucklin 1989), premiums deemphasize the product's price and thus might not lead to lower reference prices (Darke and Chung 2005).

Fourth, we limited our investigation of moderators to three crucial factors. Further research could also consider the impact of other factors, such as branding the premium, imposing a quantity requirement, or stating the value of the premium, on purchase behavior.

Fifth, we concentrated on the comparison of premiums and price cuts because the latter is a popular and well-researched promotion. However, further research could also compare premiums with other promotions, such as bonus pack promotions (Hardesty and Bearden 2003), which offer free additional content. Moreover, it would be particularly useful also to consider promotions in which a sample of another existing product is attached to the base product. Finally, research could broaden the scope of this study by including more product categories or studying other non-food fast-moving consumer goods. 


\section{Chapter 3}

\section{The Effects of Free Trials on Consumers' Adoption Decisions of Contractual Services}

This empirical study investigates (1) whether consumers choose a free trial and (2) whether using the free trial increases consumers' adoption likelihood of contractual services. We argue that a free trial influences acquisition utility through decreased fees and usage effects, transaction utility through negative reference price effects, and a set of utility premiums through an option premium and inertial effects. The analysis of panel data from a major European telecommunications firm with a multinomial Logit model shows that a free trial is chosen because it is offered for free. Moreover, its use increases adoption likelihood unless consumers' expected usage frequency by far exceeds their actual. The results also provide evidence of negative reference price effects and positive inertial effects, but cannot verify the expectation that consumers value a postponement of their adoption decision through trial use. 


\subsection{Introduction}

The successful introduction of innovations deeply influences a firm's performance (Bayus, Erickson, and Jacobson 2003; Pauwels et al. 2004) and is particularly crucial for innovations involving high investments in new technologies that must be earned back within a reasonable amount of time. To avoid failure, managers search for tools to accelerate the adoption process. One often-applied tool in practice is the free trial to promote new products or services. A free trial allows consumers to experience the product or service for free during a fixed time frame and, afterward, to decide whether to purchase. Companies that have relied on free trials include Internet providers, such as AOL, which has offered cost-free Internet hours to users, and Netflix, a US-based DVD rental site, which has used a free-trial subscription. In general, these services are contractual in nature and based on innovative technologies. Although free trials for such contractual services are common in practice, academic literature has thus far ignored their effects. Thus, this research examines the impact of free trials on consumers' adoption of a new contractual service.

First, only recently have studies begun investigating the role of marketing variables in consumers' adoption decisions (Prins and Verhoef 2007; Steenkamp and Gielens 2003). Most research has focused on perceived innovation characteristics and adopters' personal characteristics, such as sociodemographics and psychographics (Arts, Frambach, and Bijmolt 2011; Manning, Bearden, and Madden 1995; Meuter et al. 2005; Steenkamp and Burgess 2002). However, studies on the influence of sales promotions on innovation adoption remain rare (Manchanda et al. 2008; Prins and Verhoef 2007; Steenkamp and Gielens 2003). Research has explored product sampling (Bawa and Shoemaker 2004; Gedenk and Neslin 1999), but because the current study examines trial of a contractual service, the context differs fundamentally: A service trial involves a fixed consumption period rather than a fixed consumption amount, such that it is necessary to consider usage during the trial. Moreover, consumers tend to incur setup costs for a service trial and eventually termination costs at the end of the trial.

Second, academic research often ignores actual adoption behavior and instead focuses mainly on attitudes toward and intentions to try or purchase (Curran, Meuter, and Surprenant 2003; Dabholkar and Bagozzi 2002; Moreau, Lehmann, and Markman 2001). However, previous research has shown that, especially for innovations, intentions to adopt are poor predictors of actual adoption behavior (Arts et al. 2011).

Third, the studies that do consider actual consumer behavior are primarily concerned with products (Manchanda et al. 2008; Steenkamp and Gielens 2003), whereas studies on actual adoption behavior of new contractual services 
are rare (Nam et al. 2010; Prins and Verhoef 2007). From a consumer's perspective, new contractual services bear relatively high risks because they typically involve a long-term financial commitment.

Consequently, the question of how a free-trial promotion of a new contractual service affects consumers' adoption behavior remains unanswered. Therefore, this study strives to contribute to both the adoption and the sales promotion literature by (1) examining the effect of free trials on (2) consumers' actual adoption behavior of (3) a new contractual service.

This study uses panel data over a 24-month period to describe consumer adoption of digital television in a European country. The data set includes 10,040 consumers and contains detailed information on subscription and usage behavior, demographics, marketing communication variables, and relevant trial-related variables. For a limited time, consumers were offered a threemonth free trial as an alternative to the regular 12-month contract to experience the innovation without the usual costs (i.e., installation/activation and monthly fees). The findings show that the consumers accepted the free trial more often than the regular offer because of the absence of the regular fees. That is, the consumers focused on the fact that the trial is free of charge and unexpectedly did not value the option to opt out after the trial. In general, a trial promotion increases consumers' likelihood of adopting the regular paid offer after trial because they can avoid paying the installation and activation fees again; in addition, they tend to engage in inertial behavior and continue using the digital television. However, a free trial suffers from negative reference price effects because consumers tend to adjust their internal reference prices downward after the use of a free trial, which decreases adoption likelihood. Finally, usage during trial is an important factor: If actual usage is lower than expected, consumers are less likely to adopt.

The remainder of this chapter proceeds as follows: We first review extant literature, present the conceptual framework, and explain the empirical study. Then, we describe the mathematical model and the relevant variables and report the results. We conclude with a discussion of the main insights.

\subsection{Literature Review}

First, we review literature on consumers' responses to sample promotions to gain insight into how a trial influences consumers' purchase decisions. Second, we discuss the drivers of innovation adoption-namely, innovation characteristics, consumer characteristics, marketing communication variables, and social contagion/word of mouth. Third, we discuss the use of behavioral intention measures and actual behavior as outcome variables in innovation adoption 
literature. We conclude the chapter with a review of innovation adoption research.

\subsubsection{Responses to Product Trial}

Firms regularly employ free samples to boost product sales. Especially in the diffusion process of new products, the degree to which consumers try a product is a crucial determinant of success (Jain, Mahajan, and Muller 1995). The use of sampling promotions has become common practice in the industry and has also received attention in academic literature, which reports both evaluative and behavioral responses to sample promotions.

Using a sample promotion instead of purchasing the product at its regular price improves consumers' attitudes toward and perceptions of the promoted brand (Bettinger et al. 1979; Hamm, Perry, and Wynn 1969). The impact of samples on attitudes and belief confidence may even be stronger than that of advertising (Kempf and Smith 1998; Marks and Kamins 1988; Smith and Swinyard 1983). Throughout a product's life cycle, firms can effectively deploy sampling not only to teach consumers about the product and its true characteristics (Heiman et al. 2001; Sprott and Shimp 2004) but also to prevent consumers from forgetting the product (Heiman et al. 2001).

Several studies have documented the behavioral responses to sampling. Gedenk and Neslin (1999) demonstrate that samples lead to more positive purchase event feedback and greater loyalty than price cuts. Heiman et al. (2001) find that sampling can lead to immediate sales increases, and Bawa and Shoemaker (2004) show that free samples significantly increase sales of the promoted product through (1) greater customer retention after trial, (2) the samples' ability to accelerate purchases, and (3) an increased purchase probability of consumers who would not have tried the product without the sample. Scott (1976), however, shows that a free sample does not increase consumers' likelihood of accepting a regular subscription. Rather, a less strong incentive, such as a $50 \%$ discount on the sample, proved more effective.

The current context, free trials for subscription services, is quite different from the settings that have been considered thus far. First, a free trial involves a fixed consumption period rather than a fixed consumption amount. The extent to which a consumer uses the service during the trial period will clearly affect his or her subsequent adoption probability. Thus, this analysis explicitly accounts for usage intensity as a moderator of trial effectiveness. Second, free trials for subscription services trigger specific dynamics that also influence the adoption decision. For example, efforts to set up the service at the beginning of the trial period (e.g. installation) are sunk after the trial, thus encouraging consumers to continue the subscription. Similarly, a consumer's decision not to 
adopt at the end of the trial period involves (nonmonetary) opt-out costs (e.g. deinstallation), which might form another motivation to adopt the service.

\subsubsection{Drivers of Innovation Adoption}

Extant literature on innovation adoption has mainly focused on two sets of drivers: innovation and consumer characteristics (Arts et al. 2011; Manning et al. 1995; Meuter et al. 2005). However, research has also recognized the importance of social contagion (Goldenberg et al. 2009; Manchanda et al. 2008; Nam et al. 2010) and marketing-mix variables (Manchanda et al. 2008; Prins and Verhoef 2007; Steenkamp and Gielens 2003). In what follows, we discuss the four different groups of innovation adoption drivers.

\subsubsection{Innovation Characteristics}

In general, studies in the field of innovation adoption have employed Innovation Diffusion Theory (Rogers 2003) and the Technology Acceptance Model (Davis 1989). According to Innovation Diffusion Theory, relative advantage, complexity, trialability, observability, and the compatibility of the innovation with the adopter's values and needs all determine the rate of adoption. These variables have regularly been included in research on innovation adoption (Gatignon and Robertson 1991; Meuter et al. 2005). The Technology Acceptance Model suggests that the technology's perceived usefulness and ease of use are antecedents of consumers' attitudes toward an innovation, which in turn predict intentions to use the innovation (Adams, Nelson, and Todd 1992; Dabholkar and Bagozzi 2002; Davis 1989). In addition to these variables, uncertainty and perceived risk, which capture the degree to which an innovation's future utility is uncertain, are regularly included in models on innovation adoption (Hoeffler 2003; Ostlund 1974). Table 3.1 summarizes the innovation characteristics and their effects on innovation adoption.

\subsubsection{Consumer Characteristics}

Empirical research provides evidence that socio-demographics and psychographics predict innovation adoption to varying degrees (Arts et al. 2011; Meuter et al. 2005; Ostlund 1974). Although socio-demographics seem the least important antecedents (e.g. Arts et al. 2011), most studies still include them; the main variables are gender, age, education, and income (Dickerson and Gentry 1983; Gielens and Steenkamp 2007; Meuter et al. 2005; Prins and Verhoef 2007; Steenkamp and Burgess 2002; Steenkamp and Gielens 2003). Although psychographics predict innovation adoption better than demographics, researchers have only recently begun including them more frequently (Arts et al. 2011; Dabholkar and Bagozzi 2002; Meuter et al. 2005). Examples are product 
involvement (Arts et al. 2011; Moreau et al. 2001), innovativeness (Arts et al. 2011; Im, Bayus, and Mason 2003), self-efficacy, and self-consciousness (Dabholkar and Bagozzi 2002). Table 3.1 reports the descriptions and effects of the consumer characteristics.

\subsubsection{Social Contagion}

Research has identified social contagion as a determinant of innovation diffusion. At the aggregate level, the Bass (1969) model predicts that innovation diffusion is dependent not only on marketing communications but also on interactions between adopters and potential adopters. Only recently have studies at the disaggregate level begun also including social contagion as a determinant of consumers' innovation adoption (Iyengar, Van den Bulte, and Valente 2011; Manchanda et al. 2008; Nam et al. 2010). Even when marketing effects are controlled for (Iyengar et al. 2011; Manchanda et al. 2008), social contagion is at work through social ties; the more social ties a person has, the faster he or she adopts because knowledge spreads faster (Goldenberg et al. 2009). However, the downside is that the effects of negative word of mouth can be twice as strong as positive effects, which may be detrimental for firms (Nam et al. 2010).

\subsubsection{Marketing Variables}

The innovation adoption literature has also recognized the importance of marketing variables as antecedents of adoption (Prins and Verhoef 2007; Rogers 2003; Steenkamp and Gielens 2003). Specifically, trial of innovations may be affected by the focal firm's mass-marketing efforts as well as by its competitors' direct marketing efforts and sales promotions (see Table 3.1) (Manchanda et al. 2008; Prins and Verhoef 2007; Steenkamp and Gielens 2003). First, advertising positively affects innovation adoption by reaching a large amount of potential customers and informing them about the existence of the innovation (Prins and Verhoef 2007; Steenkamp and Gielens 2003). Competitive mass-marketing efforts exert the opposite effect; the more intensively a competitor advertises, the less likely consumers will purchase the focal company's offer (Prins and Verhoef 2007; Steenkamp and Gielens 2003). Although mass-marketing efforts of both the focal firm and its competitors strongly influence innovation adoption, they are outweighed by the impact of direct marketing efforts. Manchanda et al. (2008) and Prins and Verhoef (2007) find that consumers are particularly receptive to individually targeted marketing messages. Surprisingly, the effect of sales promotions on innovation adoption has received only limited attention. Steenkamp and Gielens (2003) report that feature and display promotions positively affect innovation adoption. Manchanda et al. (2008) examine the effect of sampling on innovation adoption and find that the more samples a potential adopter receives, the higher is his or her likelihood to adopt. The current study 
also investigates the impact of trial on subsequent adoption decisions, but as argued previously, the context substantially differs.

The results of these recent studies illustrate that marketing actions have an important impact on consumers' adoption decisions. However, only a limited number of marketing variables have been investigated, and particularly in the context of contractual services, popular promotions have been neglected. Rather, academics have concentrated on innovation and consumer characteristics. The current study contributes to the literature by focusing on the effects of a free-trial promotion on the adoption behavior of a contractual service while examining the effects of important marketing communication variables. In the following subsections, we provide a review of the innovation adoption literature on (1) intentions versus actual behavior and (2) products versus services. 


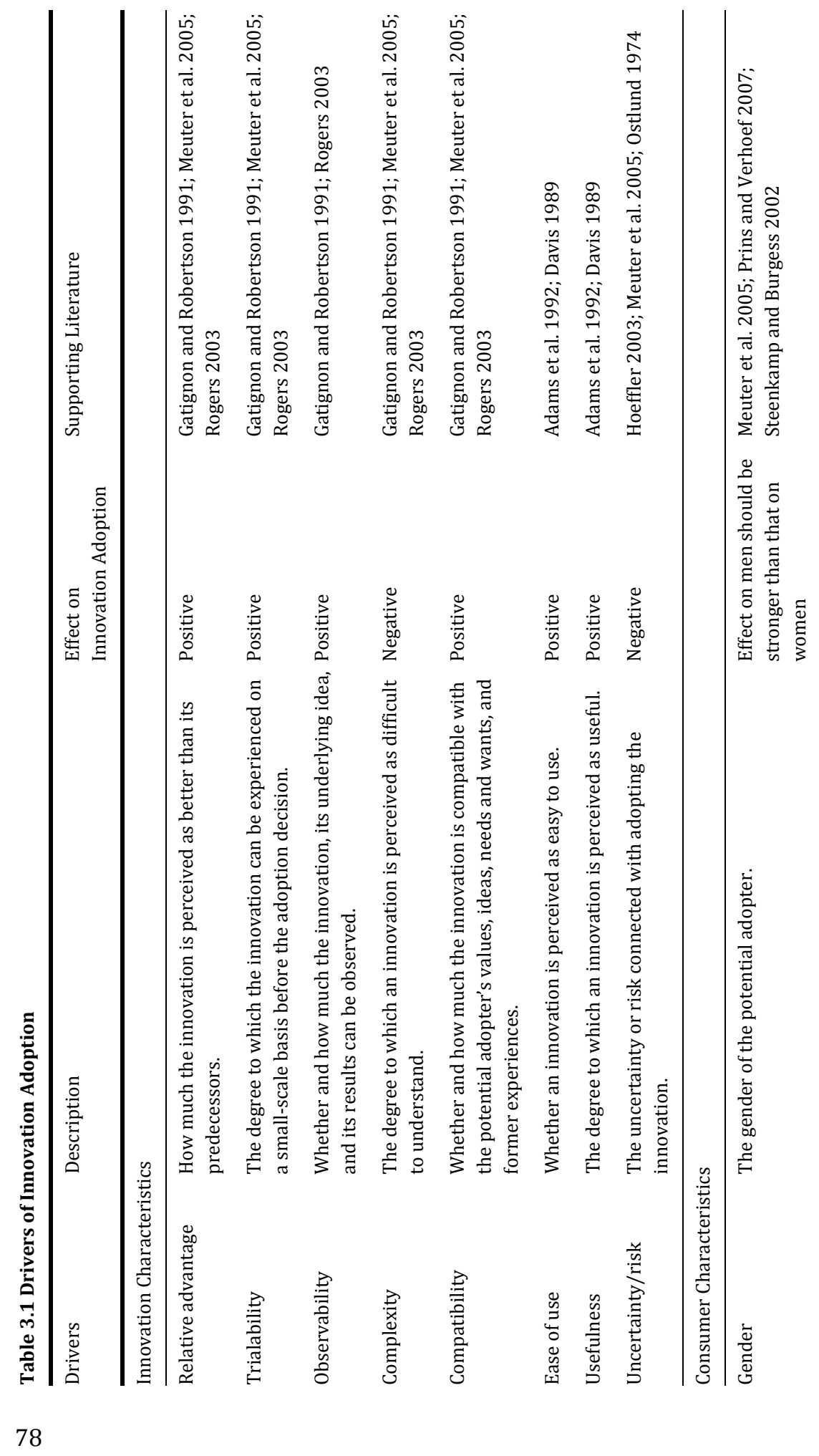




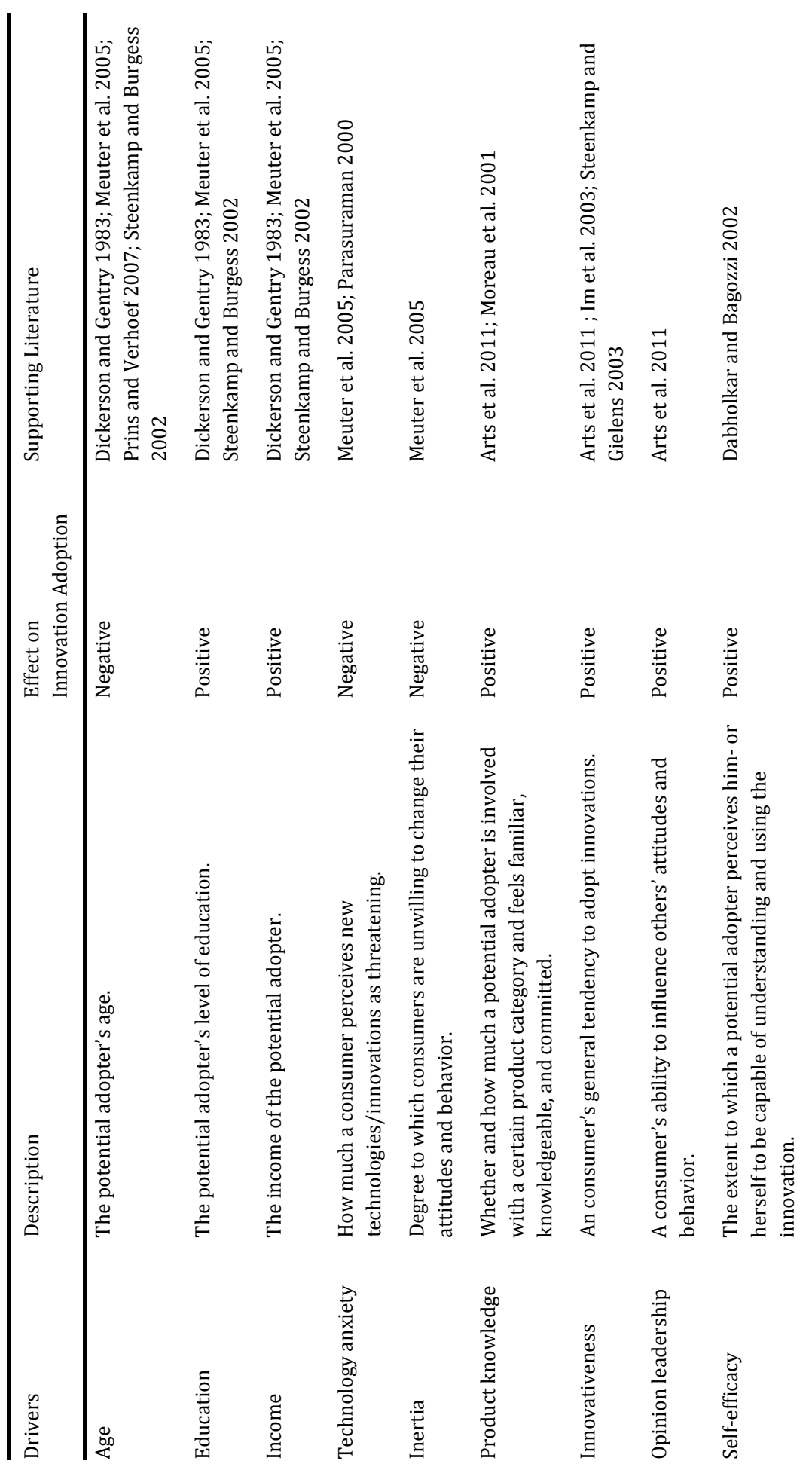




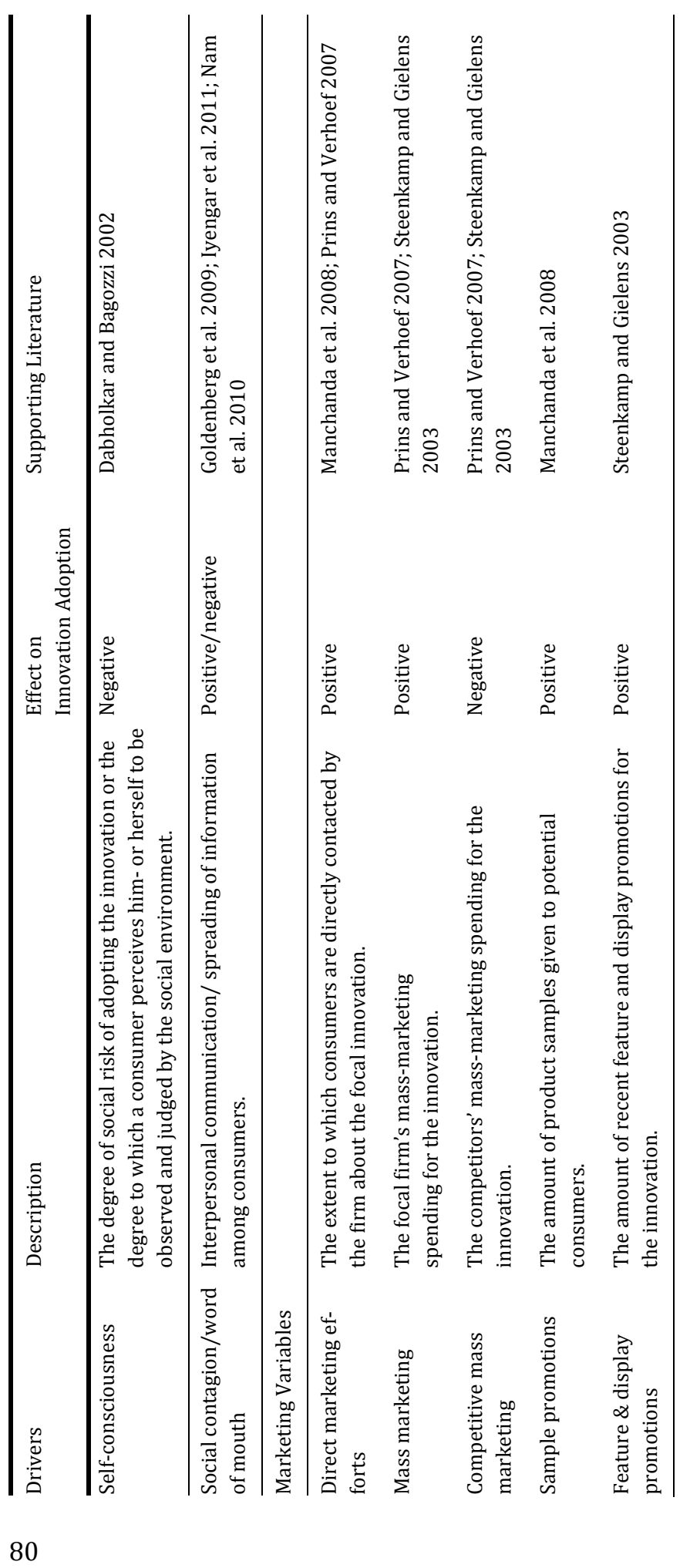




\subsubsection{Actual Adoption versus Intentions}

Extant literature on innovation adoption has concentrated on attitudes toward the innovation or intentions to try or purchase (Curran and Meuter 2007; Curran et al. 2003; Dabholkar and Bagozzi 2002; Meuter et al. 2000; Moreau et al. 2001; Plouffe, Vandenbosch, and Hulland 2001). These intentional outcomes have been regularly used as an approximation of actual adoption behavior (Van Ittersum and Feinberg 2010). However, recent research reports that intentions and actual behavior may differ greatly. Extant literature suggests three main reasons: First, consumers' reported intentions to purchase an innovation may change over time (Morrison 1979). Second, consumers are not able to incorporate unexpected events in their intention predictions, leading to inconsistencies (Morrison 1979; Morwitz, Steckel, and Gupta 2007). Third, the intention measurements used in studies are often incomplete and therefore lead to biased estimates (Van Ittersum and Feinberg 2010). Thus, intentions do not necessarily predict behavior (Arts et al. 2011; Jamieson and Bass 1989; Morwitz et al. 2007; Sun and Morwitz 2010). Surprisingly, actual consumer behavior has received only limited attention in the innovation adoption literature (e.g. Manchanda et al. 2008; Meuter et al. 2005; Nam et al. 2010; Prins and Verhoef 2007; Steenkamp and Gielens 2003). As such, there remains ample room for further research on innovation adoption behavior, and this study contributes to extant literature by investigating the effect of free trials on actual innovation adoption instead of merely examining behavioral intentions.

\subsubsection{Adoption of Products versus Contractual Services}

Notably, the studies that have considered actual consumer behavior are primarily concerned with products (Manchanda et al. 2008; Steenkamp and Gielens 2003). Only a few studies have examined actual adoption behavior of innovative services (Meuter et al. 2005; Nam et al. 2010; Prins and Verhoef 2007), and to the best of our knowledge, only two have included subscription services (Nam et al. 2010; Prins and Verhoef 2007). The majority of studies on service innovation adoption focus on self-service technologies (SSTs), such as automated teller machines and automated hotel check-outs or airport check-ins (Curran et al. 2003; Meuter et al. 2005; Meuter et al. 2000). However, SSTs, as well as new products, are not usually sold on a contractual basis and thus bear lower risks than subscription services. The acceptance of a contract typically involves a long-term financial commitment, which cannot easily be terminated. Thus, the adoption of innovative contractual services is a much more complex task than trying a new SST or product and eventually requires distinct efforts from the selling firms. This study contributes to academic literature by investigating consumers' adoption behavior in the context of a contractual innovative 
service. In the following subsections, we develop a framework for the effects of trial promotions for subscription services on consumers' adoption behavior.

\subsection{Conceptual Framework for the Effects of Free Trials}

To better understand the impact of free trials on adoption, we need to account for two consumer decisions: (1) the decision to accept the trial promotion, rather than either directly choosing the regular offer or remaining a nonuser, and (2) the decision to adopt the regular offer after experiencing the trial. Both decisions likely depend on different "sources" of utility, such as acquisition utility, transaction utility (Thaler 1985), and a set of utility premiums. Acquisition utility is the difference between the expected benefits of purchasing and using a service and the monetary outlay to purchase the service. For a subscription service, acquisition costs include periodic costs, such as monthly payments, and non-periodic setup costs, such as activation and installation fees (Grewal, Monroe, and Krishnan 1998). Transaction utility captures the psychological satisfaction "from taking advantage of the financial terms of the price deal" (Grewal et al. 1998, p. 48; Thaler 1985). Consumers determine a deal's attractiveness by comparing their internal reference price with the actual purchase price. Consumers' internal reference prices result from previously paid prices and expected future fees (Briesch et al. 1997; Mazumdar, Raj, and Sinha 2005). A reference price below the actual purchase price decreases the attractiveness of the deal, and a reference price above the actual purchase price increases the attractiveness. Utility premiums are the remaining utility components that exist from the intertemporal nature of the decision context. This study examines an inertia premium and an option premium, which we explain subsequently.

In what follows, we discuss how a free trial affects these utility components. Specifically, we compare the utility of accepting the free trial and then adopting the regular offer after the free trial with the utility of directly adopting the regular offer without prior trial. Table 3.2 summarizes the expected effects.

\subsubsection{Utility of Free-Trial Acceptance}

The utility of accepting the free trial differs from the utility of directly adopting the regular offer. In the following subsections, we discuss the mechanisms that drive this difference in utilities-in particular, in acquisition utility, transaction utility, and the utility premiums. 


\subsubsection{Acquisition Utility}

In general, compared with the regular offer, a free trial is likely to have a higher acquisition utility. During the free trial, the service is available at zero monthly cost and without the usual setup cost and thus entails lower acquisition cost. At the same time, a free trier receives all the benefits of the service, such that acquisition utility is higher than that for the regular offer.

\subsubsection{Transaction Utility}

A consumer's reference price results from prior and current purchase experiences (Briesch et al. 1997; Mazumdar et al. 2005). Consumers' internal reference prices are the same no matter whether they adopt the regular offer right away or choose the free trial. For free trials, however, consumers' internal reference prices exceed the actual costs because the free trial includes no setup costs or monthly fees. Consequently, transaction utility should be positively influenced.

\subsubsection{Utility Premiums}

The free trial offers consumers the opportunity to postpone their actual adoption decision by three months. Consumers value the option to decide only after the trial whether they want to opt out of the contract without further cost or become regular subscribers (Haenlein, Kaplan, and Schoder 2006; Kridel, Lehman, and Weisman 1993). An innovation involves unpredictable risks, such as financial, performance, social, psychological, security, and time/convenience losses (Allenby and Rossi 1999; Dowling 1986; Lee and Allaway 2002; Prins and Verhoef 2007), which makes the adoption decision particularly difficult. A trial with an opt-out option gives consumers the chance to experience the service without fear of large losses. Thus, this option premium affects utility positively.

\subsubsection{Utility of Regular Offer Adoption After Trial}

The second consumer decision of interest is whether to adopt the regular paid service after using a free trial. Again, this choice alternative's utility is affected by acquisition utility, transaction utility, and a set of utility premiums, compared with direct adoption without prior trial.

\subsubsection{Acquisition Utility}

In contrast with the decision to directly adopt the service without prior trial, acquisition utility is affected in two ways. First, after using a trial promotion, consumers do not need to incur additional setup costs to continue the contract. 
All necessary actions have already been taken, such that the cost of subscribing after trial is lower than the cost of subscribing without prior trial.

Second, a trial enables the consumer to use the service. Prior research has identified usage as an important antecedent of perceived payment equity, which refers to the consumer's perceived fairness of the deal (Bolton and Lemon 1999; Curran et al. 2003). In particular, consumers compare the benefits of usage with the costs they must incur. For services with fixed fees, independent of usage (as is often the case for subscription services), perceived payment equity increases. As a result, compared with the utility of directly adopting the regular offer without prior trial, the utility of adopting after trial will be higher if actual usage exceeds expected usage but lower if actual usage stays below expectations.

\subsubsection{Transaction Utility}

Transaction utility of adopting the regular offer after having used a free trial differs from that of direct adoption. After using a free trial, consumers may correct their internal reference prices downward. Thus, negative reference price effects, which decrease transaction utility of adopting the regular offer after using a free trial, should occur.

\subsubsection{Utility Premiums}

Free trials offer consumers the chance to opt out after the trial period. However, in consumer behavior, inertia plays an important role. Often, consumers avoid variety and simply choose the same product or service they have chosen before (Bawa 1990). That is, the consumer is not necessarily loyal (Jeuland 1979) but rather unmotivated or not dissatisfied enough to search for an alternative. The opt-out characteristic requires consumers to actively finish the contract after the free-trial period. The inertia effect will be active in this case, and thus consumers, if they are not completely dissatisfied, rather passively adopt the regular offer than actively opt out. Thus, compared with the utility of adopting the regular offer without prior trial, the utility of adoption after trial can benefit from an inertia premium. 
Table 3.2 Expected Effects

\begin{tabular}{llrcc}
\hline & Free-Trial Acceptance & $\begin{array}{l}\text { Effect } \\
\text { Paid Service Adoption } \\
\text { After Trial }\end{array}$ & Effect \\
\hline $\begin{array}{l}\text { Acquisition } \\
\text { utility }\end{array}$ & $\begin{array}{l}\text { No installation/activation } \\
\text { and no periodic fees during } \\
\text { trial }\end{array}$ & + & $\begin{array}{l}\text { Comparison of actual and } \\
\text { expected usage }\end{array}$ & $+/-$ \\
& & & No installation/activation fee & + \\
\hline $\begin{array}{l}\text { Transaction } \\
\text { utility }\end{array}$ & $\begin{array}{l}\text { No installation/activation } \\
\text { and no periodic fees during } \\
\text { trial }\end{array}$ & + & $\begin{array}{l}\text { Decrease in reference price } \\
\text { after free trial }\end{array}$ & - \\
\hline Utility premiums & Option premium & + & Inertia premium & + \\
\hline
\end{tabular}

\subsection{Empirical Study}

\subsubsection{Study Context}

To investigate the effects of free-trial promotions, we use data from a European telecom operator that provides telephone, Internet, and television services. The data describe consumers' adoption behavior and the company's marketing efforts for interactive digital television (IDTV) during the first two years after the service's launch. ${ }^{8}$ The company is the only player in the studied country to offer IDTV via digital subscriber line (DSL). Its main competitor provides IDTV via cable. To use the focal company's IDTV service, customers need a DSL modem and a set-top box that decodes the digital signal and allows interaction with the television content. The service provides access to a wide selection of television channels in digital quality, an electronic program guide, and videoon-demand (including movies, concerts, shows, and newscasts). Under regular conditions, new IDTV customers sign a 12-month contract with automatic renewal. They also pay a one-time installation/activation fee and a monthly flat rate for the basic channel package and set-top box, but the wireless DSL modem is free.

Especially in the first years after product launch, many consumers were uncertain about the nature and benefits of DSL-based IDTV. In an attempt to accelerate adoption, the company made extensive use of free-trial promotions: between months 10 and 19 of the two-year observation period, consumers could subscribe to a three-month free trial of the IDTV offer, without any purchase obligation. Subscribers either received the necessary hardware by mail and installed everything themselves or were visited by a technician who han-

\footnotetext{
${ }^{8}$ Because in the studied country most television channels still also broadcast an analog signal, the adoption of IDTV involves a truly free choice.
} 
dled the installation. After the trial, customers could cancel the contract and return the set-top box to one of the operator's many shops or do nothing and thus continue the contract as regular users, paying the full price. Thus, similar to many free-trial offers, the contract was extended as long as the customer did not opt out. Between months 20 and 23, the company changed its promotion from a free trial to a paid trial, which allowed consumers to try the product for three months at the regular price without further purchase obligations. This paid trial enables us to isolate specific mechanisms in our analysis, such as possible reference price effects of the free trial.

Parallel to the trial promotions, the operator continued offering the regular 12-month subscription, typically at a price discount. Whether consumers decided to adopt the regular offer at a discount or the trial was largely dependent on their awareness of both deals.

\subsubsection{Specific Data Set}

From our initial sample of more than 170,000 customers, we selected a subset of 10,040 customers on the basis of several criteria. First, because the IDTV service was initially only available to households with a sufficiently fast DSL connection (from the focal company ${ }^{9}$ ), we selected only customers who already had an adequate Internet connection before the company's launch of IDTV. That is, we do not separately model consumers' Internet adoption or upgrading decisions. Second, we removed households that were too far away from the nearest DSL hub to receive the IDTV signal (even when they had an adequate Internet connection). ${ }^{10}$ Third, we retained only households for which we had detailed socio-demographic information.

Our data set indicates for each customer if and in which month he or she subscribed to the free trial or adopted the regular service. Furthermore, we know how extensively each free-trial subscriber used the service. In particular, we have information on IDTV users' monthly number of channel zaps. The data set also describes the marketing efforts of the focal company during the observation period. Apart from the exact timing of the free trial, it contains pricing information for the paid IDTV service, the monthly number of direct marketing contacts per consumer (through telephone, e-mail, or regular mail), and monthly region-specific advertising expenditures. The latter information is also avail-

\footnotetext{
${ }^{9}$ In the studied period, the company's market share of the DSL market was more than 75\%.

${ }^{10}$ As the company continuously added hubs, it regularly updated its database, flagging those customers that were within reach of the IDTV signal. We selected only households that were already flagged on the first few updates, though we recognized that some of these households may not have had access to IDTV before these updates.
} 
able to the company's main competitor. We discuss the few variables not explicitly mentioned here when introducing them in the model.

Table 3.3 contains descriptive statistics of the data. As panel A shows, the focal company makes extensive use of direct marketing and, on average, invests more than twice as much in advertising than its main competitor. However, all variables vary greatly over time or across consumers. Panel B provides a tentative indication of adoption behavior and free-trial effectiveness. In general, $22.27 \%$ of the customers adopted the regular (i.e., paid) IDTV service at some point during the observation period. Of all the customers who took advantage of the free trial, $61.01 \%$ became paying IDTV users after the trial. In comparison, of the customers who did not accept the free-trial offer, only $14.56 \%$ adopted IDTV. Although these numbers summarize general behavior, they do not indicate the underlying mechanisms. That is, do consumers choose a trial because of the opt-out option or because it is free? Does a free trial merely have positive effects on the decision to adopt the regular offer, or does the negative reference price effect play a role as well? Evidently, a systematic approach is necessary to identify these mechanisms.

Table 3.3 Data Descriptives

A. Basic Statistics

\begin{tabular}{lll}
\hline Variable & Average & Standard Deviation \\
\hline $\begin{array}{l}\text { Monthly number of direct marketing contacts per } \\
\text { consumer }\end{array}$ & .23 & .64 \\
$\begin{array}{l}\text { Monthly advertising expenditures of focal company } \\
\text { (in thousands of euros) }\end{array}$ & $2,066.78$ & $1,519.37$ \\
$\begin{array}{l}\text { Monthly advertising expenditures of main competitor } \\
\text { (in thousands of euros) }\end{array}$ & 917.36 & 463.12 \\
\begin{tabular}{l} 
Monthly number of channel zaps per trial subscriber \\
\hline
\end{tabular} & 162.44 & 166.23 \\
\hline
\end{tabular}

B. Tentative Indicators of Adoption Behavior and Free-Trial Effectiveness

\begin{tabular}{lrl}
\hline Group & $\mathrm{N}$ & $\begin{array}{l}\text { Adopters of Paid IDTV } \\
\text { Service (\% of N) }\end{array}$ \\
\hline Complete sample & & $2,236(22.27 \%)$ \\
Free triers & 10,040 & $1,017(61.01 \%)$ \\
Non-free triers & 1,667 & $1,219(14.56 \%)$ \\
\hline
\end{tabular}

\subsection{Model and Variable Description}

We model consumers' decisions over time using the multinomial logit model. There are three choice alternatives: (1) no adoption, (2) acceptance of the trial 
promotion, and (3) adoption of the regular offer. The availability of these choice alternatives varied over time. Figure 3.4 illustrates when each alternative was available to consumers. From months 1 to 9 , the free trial was not available, and consumers could either do nothing or adopt the regular offer. The company introduced the promotion in month 10 . If a consumer accepts a free trial (month 11), he or she continues using the free trial during the three-month trial period (months 11-13). After the free trial (3 months +1 , see month 14), the consumer can either adopt the regular offer or stop using the service.

Table 3.4 An Example of Alternative Availability

\begin{tabular}{lccccccc}
\hline Month & 8 & 9 & 10 & 11 & 12 & 13 & 14 \\
\hline No purchase & $\mathrm{x}$ & $\mathrm{x}$ & $\mathrm{X}$ & $\mathrm{x}$ & & & $\mathrm{x}$ \\
Free trial & & & $\mathrm{X}$ & $\mathrm{A}^{1}$ & $\mathrm{x}$ & $\mathrm{x}$ & \\
Adopt regular offer & $\mathrm{x}$ & $\mathrm{x}$ & $\mathrm{X}$ & $\mathrm{x}$ & & & $\mathrm{x}$ \\
\hline${ }^{1}$ Consumer accepts free trial. & & & & &
\end{tabular}

${ }^{1}$ Consumer accepts free trial.

The utility $Z_{\text {hit }}$ that a consumer $h$ derives from a particular choice $i$ at time $t$ is divided into an observed part $V_{\text {hit }}$ and an unobserved portion $\varepsilon_{\text {hit. }}$.

$$
\mathrm{Z}_{\text {hit }}=\mathrm{V}_{\text {hit }}+\varepsilon_{\text {hit. }}
$$

The $\varepsilon_{\text {hit }}$ are independent and type I extreme value distributed. As a result, we can write the probability that consumer h chooses option i at time t $P_{h t}(i)$ as follows:

$$
\mathrm{P}_{\mathrm{ht}}(\mathrm{i})=\frac{\exp \left(\mathrm{V}_{\mathrm{hit}}\right)}{\sum_{\mathrm{j}} \exp \left(\mathrm{v}_{\mathrm{hjt}}\right)} .
$$

The observed choice utility $V_{\text {hit }}$ is:

$$
\begin{aligned}
& \mathrm{V}_{\text {hit }}=\beta_{\mathrm{RO}} * \mathrm{RO}_{\mathrm{i}}+\beta_{\mathrm{TO}} * \mathrm{TO}_{\mathrm{i}}+\beta_{\mathrm{FT}} * \mathrm{FT}_{\mathrm{i}}+\beta_{\mathrm{USAGE}} * \mathrm{USAGE}_{\text {hit }}+\beta_{\mathrm{FBT}} * \mathrm{FBT}_{\text {hit }}+ \\
& \beta_{\mathrm{FBFT}} * \mathrm{FBFT}_{\text {hit }}+\beta \mathrm{C} * \mathrm{C}_{\text {hit. }}
\end{aligned}
$$

\subsubsection{Alternative Specific Intercepts}

We include alternative specific intercepts in the model to capture the intrinsic differences in choice utility. We set the utility of the "no-purchase" alternative to zero and use it as the benchmark. RO equals 1 for the regular offer and for a trial promotion (both free and paid) and 0 otherwise. TO is a dummy that equals 1 for a trial promotion (both free and paid). FT also is a dummy and equals 1 for a free trial and 0 otherwise.

The inclusion of all three variables leads to the following interpretation of the coefficients: The coefficient of RO corresponds to the intrinsic utility con- 
sumers attach to the regular offer. The coefficients of TO and FT capture incremental effects: The coefficient of TO captures the utility of a paid trial, and the coefficient of FT is the incremental effect if a trial is free rather than paid. Although we do not directly examine the effects of paid trials, the inclusion helps isolate certain mechanisms. The significance of the coefficient of TO determines whether consumers value the option premium, which is the utility they attach to postponing the adoption decision. If a significant incremental effect emerges, the option premium increases the attractiveness of the paid trial compared with the regular offer. The coefficient of FT represents the incremental effect of paying less (no monthly fees and no installation and activation fees) for a free trial. If this coefficient is significant, consumers value the fact that the free trial is provided free. Table 3.5 summarizes the coefficients and the mechanisms they represent.

Table 3.5 Mechanisms and Related Coefficients

\begin{tabular}{ll}
\hline Mechanisms & Coefficients \\
\hline Intrinsic utility of regular offer & $\beta_{\mathrm{RO}}$ \\
Option premium & $\beta_{\mathrm{TO}}$ \\
No installation/activation fee; no subscription fee during the free-trial period & $\beta_{\mathrm{FT}}$ \\
Actual usage-expected usage & $\beta_{\mathrm{USAGE}}$ \\
Inertia premium; no installation/activation fee & $\beta_{\mathrm{FBT}}$ \\
Negative reference price effect & $\beta_{\mathrm{FBFT}}$ \\
\hline
\end{tabular}

\subsubsection{Feedback Variables}

Three variables describe the feedback effect of trial promotions on adoption probability. Again, we include paid-trial effects to isolate the underlying mechanisms. FBT is a dummy variable that equals 1 when a consumer finished using either a free or a paid trial. FBFT also is a dummy variable that equals 1 when the consumer took advantage of the free trial. The coefficient of FBT captures the effect of a paid trial on adoption of the regular offer, and the coefficient of FBFT indicates the incremental effect if a consumer used a free trial rather than a paid trial. The third feedback variable is the variable USAGE, which is a cumulative measure of a consumer's channel zaps during the trial period. We meancenter the variable to capture the extent to which consumers' actual usage deviates from average expected usage. We calculate expects to use the service before the trial. Its coefficient represents the the mean of the USAGE variable as a proxy for the intensity with which the average customer effect of actual usage compared with the average consumer's expected usage on adoption probability of the regular offer. 
The three variables help in differentiating the three mechanisms that influence the adoption decision after trial. First, the coefficient of FBT represents the inertia premium and the absence of installation and activation fees. Second, the coefficient of USAGE captures the difference between actual and expected usage. According to our expectation, the less negative or more positive this difference, the higher is the acquisition utility. Third, the coefficient of FBFT captures the change in transaction utility due to possible negative reference price effects.

\subsubsection{Control Variables}

In line with extant literature on innovation adoption, we include several control variables. The first set of controls includes marketing variables and remaining fluctuations. The variable CONTACT represents the number of direct contacts through mail, e-mail, or telephone. A positive impact on adoption should emerge because consumers are individually targeted and thus might pay particular attention to the marketing message (Manchanda et al. 2008; Prins and Verhoef 2007). The coefficients of ADV and CADV capture the impact of the firm's and the main competitor's mass advertising. The values of advertising spending vary depending on time and the consumer's living area: We know when, where, and how much the firms spend on their IDTV advertising campaigns. In line with extant literature, a positive impact of ADV and a negative impact of CADV on adoption should emerge (Prins and Verhoef 2007; Steenkamp and Gielens 2003). We also include the impact of the discount, DISC, which the focal firm offers on the monthly fees and installation costs of the regular offer. In general, a discount should influence adoption likelihood positively. Finally, we incorporate the trend variables Month, Month' ${ }^{2}$, and Month ${ }^{3}$, which form a third-degree polynomial that captures any remaining effects, such as social contagion/word of mouth.

The second set of control variables are consumer-specific variables. The variable INC, the average yearly income before taxes within the consumer's statistical tract, should have an influence. The direction is not certain, however: On the one hand, a higher income enables consumers to invest in new technologies (Meuter et al. 2005). On the other hand, the innovative technology studied is an advancement of traditional television. Television is a widely accepted medium, particularly across lower-income groups (O'Guinn and Shrum 1997), such that there may be an increased likelihood of these lower-income groups to adopt IDTV. We also include AGE in the model (i.e. the consumer's age at the beginning of the observation period); we expect that younger consumers are more likely to adopt because they are more receptive to innovations than older consumers. HHsize, a consumer's household's size, should also have a positive effect because the service's value increases when more people use it. As a 
measure of relationship length, we include the variable LENGTH, which measures the period a consumer has been using ADSL. The longer a consumer has been with a company, the more receptive he or she is to new offers (Prins and Verhoef 2007).

\subsubsection{Estimation}

We estimated the multinomial logit model with the PROC MDC tool of SAS 9.2; PROC MDC can incorporate various choice alternatives. Because the different choice alternatives were not always available at the same time, we needed to accommodate a changing choice set. We use maximum likelihood estimation based on the Newton-Raphson method.

\subsection{Results and Discussion}

Table 3.6 summarizes the results of the analysis. We first address the mechanisms that determine the decision to accept the free trial, then focus on the decision to adopt the regular offer after trial, and finally consider the control variables.

Table 3.6 Estimation Results

\begin{tabular}{lll}
\hline Variable & Coefficient (standard error) & $p$-Value \\
\hline RO & $-5.085(.197)$ & $<.001$ \\
TO & $-.009(.187)$ & .962 \\
FT & $2.536(.141)$ & $<.001$ \\
\hline Usage & $.287(.018)$ & $<.001$ \\
FBT & $8.331(.539)$ & $<.001$ \\
FBFT & $-1.39(.521)$ & $<.01$ \\
\hline Month & $-.438(.051)$ & $<.001$ \\
Month2 & $.037(.004)$ & $<.001$ \\
Month3 & $-.001(.000)$ & $<.001$ \\
\hline ADV & $.584(.117)$ & $<.001$ \\
CADV & $.478(.197)$ & $<.05$ \\
DISC & $.006(.001)$ & $<.001$ \\
CONTACT & $.6(.016)$ & $<.001$ \\
\hline INC & $-.013(.003)$ & $<.001$ \\
AGE & $-.01(.002)$ & $<.001$ \\
HHsize & $.018(.012)$ & .142 \\
LENGTH & $.003(.015)$ & .849 \\
\hline Likelihood & $-16,023$ & \\
Likelihood ratio & 356,659 & \\
\hline
\end{tabular}




\subsubsection{Decision to Accept the Free Trial}

The coefficient of RO, the general paid offer, is negative and highly significant $\left(\beta_{\mathrm{GI}}=-5.085, p<.001\right)$. A priori, a consumer is more likely not to adopt the regular paid offer. The coefficient of TO is non-significant $\left(\beta_{\mathrm{TO}}=-.009, p=.962\right.$ ) and implies that the intrinsic utility of a paid trial does not differ from the regular offer's intrinsic utility. Thus, consumers do not value the option of postponing the adoption decision through use of the trial period. The positive and significant coefficient of FT $\left(\beta_{\mathrm{FT}}=2.536, p<.001\right)$ indicates that consumers value a free trial more than a paid trial. Apparently, consumers predominantly value the ability to use the service free of charge. The absence of installation/activation and subscription fees leads to increased acquisition and transaction utility. However, we cannot further differentiate the effect of either acquisition or transaction utility.

\subsubsection{Decision to Adopt Regular Offer}

The two trial feedback variables, FBT and FBFT, have significant coefficients $\left(\beta_{\mathrm{FBT}}=8.331, p<.001 ; \beta_{\mathrm{FBFT}}=-1.390, p<.01\right)$. From the positive coefficient of FBT, using a trial (paid or free) indeed increases a consumer's probability of adopting the regular offer. The coefficient of FBT combines the effects of two mechanisms: First, in contrast with directly adopting the regular offer, consumers do not need to pay any installation/activation fees after using the trial because the service is already installed and activated. This positively influences acquisition utility. Second, a possible inertia premium may also increase consumers' utility to adopt the regular offer after using free trial compared with the paid trial. Consumers who receive the trial free of charge seem to adjust their internal reference price downward, which decreases transaction utility of the paid offer and, thus, their probability of adopting the regular paid offer.

The feedback variable USAGE is positive and highly significant ( $\beta_{\text {USAGE }}=$ $.287, p<.001$ ), which implies that the less negative/more positive the deviation of actual usage from (average) expected usage, the the trial because they are either unmotivated or not dissatisfied enough to actively opt out. Instead, consumers are likely to continue the service after the trial. Although we are not able to assess the two mechanisms individually, on average they exert a strong positive effect on adoption of the regular offer. However, the negative coefficient of FBFT, the free-trial feedback variable, indicates that using a free trial is less effective than using a paid trial. This confirms our expectation of negative reference price effects of the more likely consumers adopt the regular offer after the trial. In contrast with directly adopting the regular offer without prior trial, an actual usage level below average expected usage decreases acquisition 
utility. Yet, to obtain a negative net trial impact, the deviation of actual usage from (average) expected usage must be strongly negative. Figure 3.2 shows that the deviation needs to be -2415.31 channel zaps for a negative net trial effect, which implies that given an average expected usage of 552.31 zaps, actual usage must be strongly negative at -1863 zaps. Because negative actual usage is impossible, the results indicate that total trial feedback effects remain positive regardless of the usage level. However, there may be situations in which expectations exceed actual usage so far that the deviation in the end is extremely negative.

Figure 3.2 Net Effects of a Trial Promotion

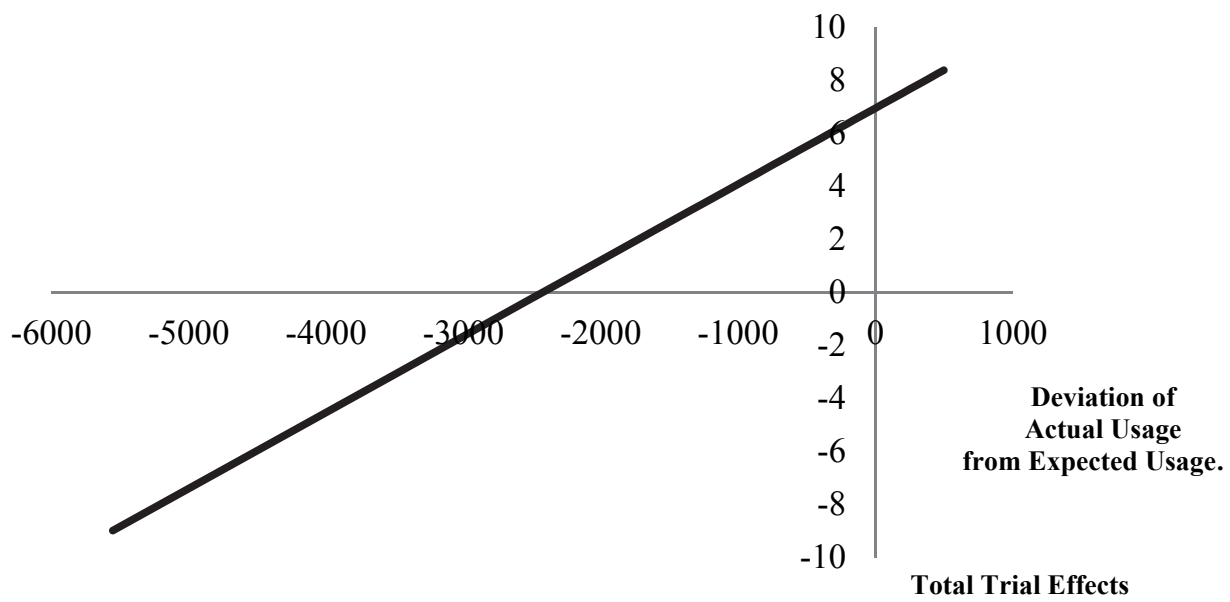

\subsubsection{Covariates}

The first group of controls, the marketing related variables, shows the expected signs; they all have a positive impact on adoption probability. In line with extant literature, the coefficient of DISC is positive and significant $\left(\beta_{\mathrm{DISC}}=.006, p<\right.$ $.001)$ (Anderson and Simester 2004), as is the coefficient of ADV $\left(\beta_{\mathrm{ADV}}=.584, p\right.$ $<$.001) (Steenkamp and Gielens 2003). Mass advertising creates awareness among consumers and proves important in spurring the diffusion of innovative services. CADV also has a positive coefficient $\left(\beta_{\mathrm{CADV}}=.478, p<.01\right)$, indicating that the competitor's advertising leads to primary demand effects. In line with our findings, Prins and Verhoef (2007) find positive effects of a competitor's mass marketing if the service rather than the brand is advertised. Moreover, in our specific case, consumers with ADSL connections are rather unlikely to switch to a company that provides IDTV via cable. The direct consumer contacts through mail, e-mail, or telephone also positively influence adoption 
probability $\left(\beta_{\text {CONTACT }}=.600, p<.001\right)$. Thus, the more often consumers are contacted about the service, the more likely they adopt (Prins and Verhoef 2007; Steenkamp and Gielens 2003; Verhoef, Franses, and Hoekstra 2001). The variables of the third-degree polynomial (Month, Month ${ }^{2}$, and Month ${ }^{3}$ ) all have significant coefficients $\left(\beta_{\text {month }}=-.438, p<.001 ; \beta_{\text {month } 2}=.037, p<.001 ; \beta_{\text {month } 3}=-\right.$ $.001, p<.001$ ), indicating that other factors, which we do not explicitly model (e.g. word of mouth), drive consumers' adoption decisions.

Finally, with regard to the consumer-specific control variables, the coefficient of INC is slightly negative $\left(\beta_{\mathrm{INC}}=-.013, p<.001\right)$; the higher a consumer's yearly income, the less likely he or she adopts. This is unexpected, because prior studies have found positive effects (Gatignon and Robertson 1991; Meuter et al. 2005; Rogers 2003). However, in our context, consumers with lower income may be particularly interested because the innovation pertains to television. For example, O'Guinn and Shrum (1997) find that television viewing times and income are negatively related. The variable AGE has a negative effect on adoption probability $\left(\beta_{\mathrm{AGE}}=-.01, p<.001\right)$, which is in line with other innovation adoption research (Meuter et al. 2005). The variable HHsize $\left(\beta_{\mathrm{HHsize}}=\right.$ $.018, p<.05$ ) has a significant, positive impact; that is, the more people in a household, the more likely adoption takes place. Finally, relationship length, as captured by the variable LENGTH, is non-significant ( $\left.\beta_{\mathrm{LENGTH}}=.003, p=.849\right)$ and thus does not influence the adoption decision.

\subsection{Conclusion and Managerial Implications}

This study investigates the influence of a free-trial promotion on consumers' decisions to adopt a new contractual service. To better understand the underlying mechanisms driving adoption in response to free trials, we focus on two consumer decisions: the decision to accept the free trial and the decision to adopt the regular paid offer after trial. In addition to variables related to trial, we include consumer demographics and other marketing communication variables in the model. We add to promotional and innovation adoption literature in three ways: First, the impact of marketing variables and particularly of sales promotions on innovation adoption is limited, and thus we address this gap by examining the effect of a free trial on adoption. Second, we consider actual adoption behavior, which has been neglected in extant literature, though the link between intentions and behavior is especially uncertain for innovations. Third, the innovation adoption literature has mainly focused on products. We investigate an innovative contractual service, which is perceived as more risky than a product because it involves a long-term financial commitment. By focusing on a contractual service, we need to account for a fixed consumption period 
and usage behavior during this period rather than a fixed consumption amount (as for product sampling). Thus, we investigate (1) the effects of a free trial on (2) consumers' actual adoption decision of (3) an innovative contractual service. In what follows, we first summarize our main findings and then discuss the managerial implications.

\subsubsection{Main Findings}

Our findings imply that consumers highly value the chance to try a new service free of charge. Consumers prefer the free trial to both a paid trial and the regular paid offer. Both acquisition and transaction utility increase because costs are reduced. However, the fact that a free trial offers an "option premium" in that consumers can postpone the adoption decision does not add value. Consumers seem to concentrate on the costs of the free trial as they receive the service free of charge for a limited time.

Furthermore, the results show that acceptance of a free trial increases the probability of adopting the paid offer afterward. In contrast with direct adoption without prior trial, consumers do not need to pay setup costs after trial. In addition, the trial may trigger inertia effects, meaning that consumers simply continue the service because cancelling the contract requires taking action. Moreover, consumers may discover during the trial that they actually use the service more frequently than expected, which increases the perceived benefits. However, the free trial seems to suffer from negative reference price effects. In addition, the notion that consumers rely on their usage intensity to judge the value of the service may also backfire: Consumers who realize they use the service less frequently than expected may be less likely to adopt the paid offer, compared with the situation in which they did not accept the trial. However, for the net trial impact to become negative, the deviation of actual usage from expected usage must be strongly negative.

\subsubsection{Managerial Implications}

Contrary to the general belief that a free trial does not hurt unit sales, our analysis suggests that it may reduce the number of subscribers. This negative impact is further reinforced by the data, which show that consumers who decide not to adopt after the trial do so for good. ${ }^{11}$ To avoid negative outcomes, managers should control expectations of usage up front and keep track of usage levels during the free-trial period. To avoid large negative deviations of actual usage from expected usage, managers need to inform and teach consumers

${ }^{11}$ This permanent customer defection is not abnormal in a setting where, due to the opt-out clause, disadoption requires explicit - and therefore thought-through - action from the customer. 
before they accept the trial through use of, for example, marketing communications that highlight the benefits of the service. They should also encourage customers to use the service frequently by actively teaching them the benefits of the service and by eliminating malfunctions, especially during the free-trial period. Particularly in the introduction phase, innovative high-tech services may indeed show deficiencies.

In combination with the previously discussed finding that consumers do not value the opt-out opportunity, the negative effects at the end of the trial period suggest that managers should offer the first months of the regular contract for free without giving consumers the chance to opt out. Doing so would avoid the negative post-trial effects: After the free period, all customers would become paying users.

To reduce the reference price effect, managers could also charge a modest amount for the trial. Although doing so would lower the initial attractiveness of the promotion, the less detrimental reference price effect may lead to a more favorable net impact. This is in line with Scott (1976), who finds that a free sample is not the most effective trial promotion to increase adoption: On the contrary, a sample for which consumers must pay a small amount seems more effective than a free sample.

Finally, managers should compare the effectiveness of their free trials with that of other marketing instruments. Direct contacts are important tools to increase adoption likelihood, even for newly introduced services (Prins and Verhoef 2007). Eventually, a firm can inform consumers with specific and focused messages. According to our findings, 10 contacts are needed before these marketing instruments increase adoption likelihood to the same degree as a free trial with an average usage level. We also find a positive impact of mass advertising, which creates awareness among consumers and proves important to spur the diffusion of innovative services. Yet a firm must spend approximately 10,000,000 € per month to influence adoption likelihood to the same extent as a free trial with average usage levels. In general, discounts also exert a positive influence on adoption likelihood, but they do not reach the same effectiveness as a free trial. That is, the discount on a 12-month contract must be almost two and a half times as large as total costs of that contract. Thus, our data imply that, assuming average usage, the net feedback effect of a free trial on adoption likelihood is stronger than the impact of other marketing instruments, such as direct contacts, discounts, and mass advertising.

A trial promotion can be a successful tool to increase adoption likelihood, if actual and expected usage levels are carefully managed and controlled and if service malfunctions are prevented. The results also suggest that the effects of a trial promotion can be optimized, if negative reference price effects are mini- 
mized, by eventually charging customers a small amount and if the opt-out opportunity is eliminated.

\subsubsection{Limitations and Further Research}

This study has several limitations that lead to suggestions for further research. First, the data are restricted to one contractual innovative service, one industry, and one company. To test the generalizability of the findings, it would be valuable to consider a wider range of services, industries, and/or companies.

Second, the trial period the focal company used lasted three months. Further research on service trials could investigate different trial lengths to determine their effects on the adoption of innovations. For examples, it might be that for longer trial periods, the option premium becomes significant after all.

Third, we did not consider consumer learning during the free-trial period. However, incorporating usage-based learning about service quality would be a valuable extension to this research.

Fourth, further research could investigate whether customer behavior after the adoption decision differs depending on the acquisition method. Lewis (2006) reports that acquisition types influence customers' lifetime values; for example, customers acquired with large discounts are less likely to repurchase. Consequently, future studies could examine the impact of free trials on consumers' lifetime value. 

Chapter 4

\section{Conclusion}




\subsection{Introduction}

The two empirical studies of this dissertation investigate the effects of promotions that involve a free offer, namely premium and free-trial promotions, on consumers' purchase behavior. The first study - Chapter 2 - studies the effects of premium promotions on consumers' purchase decisions, incidence, choice, and quantity for fast-moving-consumer-goods, compares the premium effects with those of price cuts, and investigates three crucial moderators - namely the category's degree of utilitarianism and hedonism, whether the promoted brand is a private label or a national brand, and the degree of premium-product relatedness - of this relationship. The second study - Chapter 3 - examines the impact of free trials on consumers' adoption of new contractual services. This chapter concludes this dissertation by discussing the findings and their practical implications, and giving suggestions for further research.

\subsection{Discussion}

This dissertation contributes to promotional literature by investigating the effectiveness of two promotions that involve a free offer. Although there exists research on the effectiveness of promotions that come with a free offer, we notice that there is ample room for further research. This is particularly true for premium promotions and free trials, whose effects we study in this dissertation.

Research on the effects of premiums on consumers' purchase decisions was limited to studies on choice, while effects on incidence and quantity had not been studied. However, extant research proposes that promotions perform differently across the different purchase levels (e.g. Foubert and Gijsbrechts 2007). The analysis of Chapter 2 finds this to be true also for premium promotions and indicates that the selection of promotions must be carefully matched with marketing goals.

The study on free-trial promotions contributes to promotional literature by investigating on the basis of panel data how a free service trial affects consumers' adoption decisions. Because a free trial enables consumers to use the service freely during a consumption period, we include usage to understand its effect on a trial's effectiveness. We also contribute to innovation adoption literature in that we are among the first to study a sales promotion's effects on adoption of an innovative contractual service. The results of our study reveal that, although a free trial may lead to an increase in adoption likelihood, this is not always the case. 
In the subsequent section, the findings and their managerial implications of the two empirical studies are discussed in detail.

\subsubsection{Premium Promotions}

Premiums have different effects across the three purchase levels. They exert positive effects on incidence and choice, but do not affect purchase quantity. Although the analysis reveals that price cuts in general perform better than premiums because of their strong effect on quantity, we find that there are moderators that can improve a premium's performance relative to an equivalent price cut. In particular, we examine three moderators - premium-product relatedness, national brand versus private label, and the product category's degree of utilitarianism/hedonism. At the incidence and choice level, offering a premium with a private label rather than a national brand enhances a premium promotion's relative effectiveness. This effect is intensified, if the brand belongs to a hedonic rather than to a utilitarian product category. This confirms the principle of benefit congruency (Chandon et al. 2000), which predicts that a promotion with hedonic benefits - a premium - performs better in hedonic than in utilitarian categories.

Interestingly, the expected moderating effect of premium-product relatedness could not be confirmed. Eventually, consumers value the premium itself and consider the functional compatibility with the category to be rather unimportant. Furthermore, premiums that are attached to fast-moving consumer goods are usually simple items whose functionality is apparent even without a clear link with the category.

We conduct a simulation study, in which we take the promotions' costs into account. Very often, price cuts cost manufacturers more than the final discount offered to consumers, whereas the premium's cost may be significantly below the value perceived by consumers. Manufacturers pay more than the final discount, because retailers keep a certain amount of the reduction, depending on the pass-through rate. We vary this rate to understand how the comparison of the two promotions is affected and find that premiums have the potential to outperform price cuts for hedonic brands and utilitarian private labels. However, premiums should not be offered with utilitarian national brands.

This study illustrates that managers must understand promotional effects to align strategic objectives and promotional choice. Our analysis shows that premiums increase brand line sales (secondary demand) because they induce brand switching. For example, manufacturers, who aim at promoting a new product and are not interested in increasing total category sales, may consider a premium. However, premiums do not affect the quantity decision and are 
therefore less appropriate if managers aim at increasing category sales among current buyers. Here, price cuts are the preferred alternative.

\subsubsection{Free Trial Promotions}

The results of the Multinomial Logit Model demonstrate that consumers highly value using a service free of charge: the fact that a free trial enables consumers to postpone their adoption decision has no influence on a trial's attractiveness. The acceptance of the free trial has the potential to increase a consumer's probability to accept the regular paid offer. Consumers, who have accepted the free trial, do not need to make any additional effort to adopt the regular offer after trial. Trial users who do not want to adopt the regular offer, must explicitly opt out after trial. This increases adoption likelihood because consumers may avoid the hassle of opting out (inertial effects). Another favorable effect is that consumers may discover they use the service more frequently than expected, which leads to higher perceived benefits. However, a free trial may also trigger negative effects. Our results indicate that a free trial is subject to negative reference price effects. Also, some users may realize that they use the service far less frequently than expected, which leads to a decrease in adoption likelihood. However, for the net trial impact to become negative, the usage intensity should be much lower than expected.

Even when, on average, the free trial has a positive effect on adoption probability, a free trial may eventually hurt sales: as is common in a contractual context (and as suggested by our data), consumers that have decided not to adopt after a trial are very unlikely to consider adopting at a later moment and are thus lost for good. Managers must control consumers' expectations and beliefs regarding their usage intensity before and during the free trial to avoid negative effects. A possible strategy is to inform consumers via marketing communication about the service's benefits and continue to teach the functionality of the service during trial.

\subsection{Directions for Further Research}

We have reported several limitations and suggestions for further research for each empirical study. Here, we formulate some general suggestions.

Research on free should study long-term effects. Extant research finds that a customer's behavior differs in the longer-term depending on the acquisition method. Lewis (2006) reports that acquisition types influence customers' lifetime values: customers acquired via large discounts are less likely to repurchase. Thus, how will a free offer affect customers' lifetime value and will they 
repurchase in the future? Will the effects be visible only in the short, medium, or even long-term? The two promotions we examined in this dissertation may have different effects in the long-term. That is, a premium is conditional, because consumers need to purchase the underlying product in order to receive the premium. A free trial, however, is unconditional. This difference may cause free-trial promotions to be more susceptible to reference price changes, because the entire service can be unconditionally used for free. However, the conditional premium promotion may cause more reactance among consumers, because to receive the premium the product has to be bought or if the product is bought, the premium is an obligatory add on. Another intriguing question is whether the performance of free offers relative to price cuts improves once we also account for effects across time. For example, free offers deemphasize the product's price (Darke and Chung 2005) and might thus have a less detrimental effect on consumers' reference prices than price cuts do (Lattin and Bucklin 1989).

In Chapter 2 we compare premiums and price cuts to identify situations in which one outperforms the other. However, for premium promotions, bonus packs, samples, and free trials alike, further research should compare free offers with other promotions that do not involve a free offer. Although several authors have compared different sales promotions (e.g. Arora and Henderson 2007; Kumar and Leone 1988), systematic comparisons at different purchase levels have still not been conducted for the majority of sales promotions.

Similarly, promotions that involve a free offer should be compared to each other. Although free triggers some general mechanisms, the effects of the free offers seem to also depend on the characteristics of the free offer. Thus, it is particularly interesting to understand how the specific characteristics of the free offers influence the promotions' effects. 


\section{Appendix Pre-Purchase Questionnaire}

1. Socio-Demographic Information

\begin{tabular}{|c|c|c|c|}
\hline & Question & Answer Possibilities & Purpose \\
\hline 1. & $\begin{array}{l}\text { Who is mainly responsible for grocery } \\
\text { shopping in your family? }\end{array}$ & $\begin{array}{l}\text { I am responsible. } \\
\text { My partner is responsible. } \\
\text { My partner and I are both responsi- } \\
\text { ble. } \\
\text { Somebody else is responsible. }\end{array}$ & $\begin{array}{l}\text { Selection of } \\
\text { Sample }\end{array}$ \\
\hline 2. & $\begin{array}{l}\text { Do you or another member of your family } \\
\text { regularly consume milk/orange } \\
\text { juice/margarine/cereals? }\end{array}$ & $\begin{array}{l}\text { Yes } \\
\text { No }\end{array}$ & $\begin{array}{l}\text { Selection of } \\
\text { categories to } \\
\text { purchase in }\end{array}$ \\
\hline 3. & What is your gender? & $\begin{array}{l}\text { Male } \\
\text { Female }\end{array}$ & Control \\
\hline 4. & What is your age? & $\begin{array}{l}18 \text { years or younger } \\
19-25 \text { years } \\
26-35 \text { years } \\
36-45 \text { years } \\
46-55 \text { years } \\
56-65 \text { years } \\
66 \text { years or older }\end{array}$ & Control \\
\hline 5. & $\begin{array}{l}\text { How can your family situation best be } \\
\text { described? }\end{array}$ & $\begin{array}{l}\text { Living with parents } \\
\text { Living alone } \\
\text { Widowed } \\
\text { Married } \\
\text { Living together with unmarried } \\
\text { partner } \\
\text { Divorced } \\
\text { Other }\end{array}$ & Control \\
\hline 6. & $\begin{array}{l}\text { How many children do you have that still } \\
\text { live at home? (Please indicate the number } \\
\text { of children of a certain age group in the } \\
\text { boxes.) }\end{array}$ & $\begin{array}{l}\text { None } \\
\text { Younger than } 3 \text { years } \\
\text { Between } 3 \text { and } 6 \text { years } \\
\text { Between } 7 \text { and } 14 \text { years } \\
\text { Between } 15 \text { and } 18 \text { years } \\
\text { Older than } 18 \text { years }\end{array}$ & $\begin{array}{l}\text { Control } \\
\begin{array}{|l} \\
\\
\end{array} \\
\end{array}$ \\
\hline 7. & What is your highest attained diploma? & $\begin{array}{l}\text { Elementary school } \\
\text { Lower secondary school } \\
\text { Higher secondary school } \\
\text { College, short type } \\
\text { College, long type } \\
\text { University } \\
\text { Other }\end{array}$ & Control \\
\hline 8. & What is your work situation? & $\begin{array}{l}\text { Student } \\
\text { Homemaker } \\
\text { Part-time employed } \\
\text { Full-time employed } \\
\text { Work seeking } \\
\text { Retired } \\
\text { Other }\end{array}$ & Control \\
\hline
\end{tabular}




\section{Usual Shopping Behavior}

\begin{tabular}{|c|c|c|c|}
\hline & Question & Answer Possibilities & Purpose \\
\hline 1. & $\begin{array}{l}\text { How often do you buy on average in } \\
\text { this category? }\end{array}$ & $\begin{array}{l}\text { Less than once a week }{ }^{a} \\
\text { More than once a weekb }\end{array}$ & $\begin{array}{l}\text { Purchase frequency } \\
\text { (FREQ) }\end{array}$ \\
\hline 2. & $\begin{array}{l}\text { How many weeks are between two } \\
\text { shopping trips in this category? }\end{array}$ & & \\
\hline 3. & $\begin{array}{l}\text { How often per week do you buy on } \\
\text { average in this category? }\end{array}$ & & \\
\hline 4. & $\begin{array}{l}\text { If you buy, how many packages do you } \\
\text { purchase? }\end{array}$ & & $\begin{array}{l}\text { Indicated purchase } \\
\text { quantity }\end{array}$ \\
\hline 5. & $\begin{array}{l}\text { Please indicate which products you } \\
\text { have bought during the last } 12 \text { months. } \\
\text { If the product you usually purchase is } \\
\text { not listed, please fill in the box at the } \\
\text { end. }\end{array}$ & $\begin{array}{l}\text { [A list of products in the } \\
\text { category including name and } \\
\text { a picture] }\end{array}$ & Loyalty indicator (LOY) \\
\hline 6. & $\begin{array}{l}\text { Please indicate how often you purchase } \\
\text { the under } 5 \text {. selected products. If you } \\
\text { purchase e.g. three different products, } \\
\text { please indicate their shares. For exam- } \\
\text { ple: } \\
\text { Milk 1:70\% } \\
\text { Milk } 2: 20 \% \\
\text { Milk 3:10\% }\end{array}$ & & \\
\hline
\end{tabular}

a If a consumer buys less than once a week, go to 2 , skip 3, and continue directly with 4 .

b If a consumer buys more than once a week, go directly to 3 .

\section{Consumption Behavior}

\begin{tabular}{|c|c|c|c|}
\hline & Question & Answer Possibilities & Purpose \\
\hline 1. & $\begin{array}{l}\text { Which product size do you usually } \\
\text { purchase? }\end{array}$ & $\begin{array}{l}\text { Normal sizes } \\
\text { Big sizes }^{\mathrm{a}}\end{array}$ & \multirow{4}{*}{$\begin{array}{l}\text { Calculation of usual } \\
\text { consumption for the } \\
\text {-inventory calculation } \\
\text { ic }\end{array}$} \\
\hline 2. & $\begin{array}{l}\text { How many packages do you and your } \\
\text { family consume per week? }\end{array}$ & $\begin{array}{l}\text { Less than one unit per week }{ }^{b} \\
\text { More than one unit per week }\end{array}$ & \\
\hline 3. & \multicolumn{2}{|l|}{$\begin{array}{l}\text { How many weeks do you do on average } \\
\text { with one package? }\end{array}$} & \\
\hline 4. & \multicolumn{2}{|l|}{$\begin{array}{l}\text { How many packages do you consume } \\
\text { on average per week? }\end{array}$} & \\
\hline 5. & \multicolumn{2}{|l|}{$\begin{array}{l}\text { How many open packages do you have } \\
\text { at home at the moment? }\end{array}$} & \multirow{2}{*}{$\begin{array}{l}\text { Current inventory at the } \\
\text { beginning of the shop- } \\
\text {-ping experiment }\end{array}$} \\
\hline 6. & \multicolumn{2}{|l|}{$\begin{array}{l}\text { How many closed packages do you } \\
\text { have at home at the moment? }\end{array}$} & \\
\hline
\end{tabular}

a In the questionnaire, to clarify normal and large, sizes, depending on the category, are in either grams or liters.

${ }^{b}$ If a consumer consumes less than one unit per week, go to 3, skip 4, and continue with 5 .

c If a consumer consumes more than one unit per week, continue with 4 . 



\section{References}

Aaker, David A. and Kevin Lane Keller (1990), "Consumer Evaluations of Brand Extensions," Journal of Marketing, 54 (1), 27-41.

Adams, Dennis A., R. Ryan Nelson, and Peter A. Todd (1992), "Perceived Usefulness, Ease of Use, and Usage of Information Technology: A Replication," MIS Quarterly, 16 (2), 227-47.

Ailawadi, Kusum L., Karen Gedenk, Christian Lutzky, and Scott A. Neslin (2007), "Decomposition of the Sales Impact of Promotion-Induced Stockpiling," Journal of Marketing Research, 44 (3), 45067.

Ailawadi, Kusum L. and Bari A. Harlam (2009), "Retailer Promotion Pass-Through: A Measure, Its Magnitude, and Its Determinants," Marketing Science, 28 (4), 782-91.

Ailawadi, Kusum L., Scott A. Neslin, and Karen Gedenk (2001), "Pursuing the Value-Conscious Consumer: Store Brands Versus National Brand Promotions," Journal of Marketing, 65 (1), 7189.

Ajzen, Icek and B. L. Driver (1992), "Contingent Value Measurement: On the Nature and Meaning of Willingness to Pay," Journal of Consumer Psychology, 1 (4), 297.

Allenby, Greg M. and Peter E. Rossi (1999), "Marketing Models of Consumer Heterogeneity," Journal of Econometrics, 89 (1/2), 57-78.

Anderson, Eric T. and Duncan I. Simester (2004), "Long-Run Effects of Promotion Depth on New Versus Established Customers: Three Field Studies," Marketing Science, 23 (1), 4-20.

Arora, Neeraj and Ty Henderson (2007), "Embedded Premium Promotion: Why It Works and How to Make It More Effective," Marketing Science, 26 (4), 514-31.

Arts, Joep W. C., Ruud T. Frambach, and Tammo H. A. Bijmolt (2011), "Generalizations on Consumer Innovation Adoption: A Meta-Analysis on Drivers of Intention and Behavior," International Journal of Research in Marketing, 28 (2), 134-44.

\section{$\underline{B}$}

Bawa, Kapil (1990), "Modeling Inertia and Variety Seeking Tendencies in Brand Choice Behavior," Marketing Science, 9 (3), 263-78.

Bawa, Kapil and Robert Shoemaker (2004), "The Effects of Free Sample Promotions on Incremental Brand Sales," Marketing Science, 23 (3), 345-63.

Bayus, Barry L., Gary Erickson, and Robert Jacobson (2003), "The Financial Rewards of New Product Introductions in the Personal Computer Industry," Management Science, 49 (2), 197 210.

Belk, Russell W. and Gregory S. Coon (1993), "Gift Giving as Agapic Love: An Alternative to the Exchange Paradigm Based on Dating Experiences," Journal of Consumer Research, 20 (3), 393417.

Bell, David R., Jeongwen Chiang, and V. Padmanabhan (1999), "The Decomposition of Promotional Response: An Empirical Generalization," Marketing Science, 18 (4), 504-26.

Besanko, David, Jean-Pierre Dubé, and Sachin Gupta (2005), "Own-Brand and Cross-Brand Retail Pass-Through," Marketing Science, 24 (1), 123-37. 
Bettinger, Charles O., Lyndon E. Dawson, and Hugh G. Wales (1979), "The Impact of Free-Sample Advertising," Journal of Advertising Research, 19 (3), 35-39.

Bhat, Chandra R. (2001), "Quasi-Random Maximum Simulated Likelihood Estimation of the Mixed Multinomial Logit Model," Transportation Research Part B: Methodological, 35 (7), 677-93.

Blattberg, Robert C. and Scott A. Neslin (1990), Sales Promotion: Concepts, Methods, and Strategies, Englewood Cliffs, NJ: Prentice Hall.

Blattberg, Robert C. and Kenneth J. Wisniewski (1989), "Price-Induced Patterns of Competition," Marketing Science, 8 (4), 291.

Bolton, Ruth N. and Katherine N. Lemon (1999), "A Dynamic Model of Customers' Usage of Services: Usage as an Antecedent and Consequence of Satisfaction," Journal of Marketing Research, 36 (2), 171-86.

Brehm, Jack W. (1966), A Theory of Psychological Reactance, New York: Academic Press.

--- (1989), "Psychological Reactance: Theory and Applications," Advances in Consumer Research, 16 (1), 72-75.

Breugelmans, Els, Katia Campo, and Els Gijsbrechts (2006), "Opportunities for Active Stock-out Management in Online Stores: The Impact of the Stock-out Policy on Online Stock-out Reactions," Journal of Retailing, 82 (3), 215-28.

--- (2007), "Shelf Sequence and Proximity Effects on Online Grocery Choices," Marketing Letters, 18 (1/2), 117-33.

Briesch, Richard A., Lakshman Krishnamurthi, Tridib Mazumdar, and S. P. Raj (1997), "A Comparative Analysis of Reference Price Models," Journal of Consumer Research, 24 (2), 202-14.

Brown, Christina L. and Gregrory S. Carpenter (2000), "Why Is the Trivial Important? A ReasonsBased Account for the Effects of Trivial Attributes on Choice," Journal of Consumer Research, 26 (4), 372-85.

Bucklin, Randolph E. and Sunil Gupta (1992), "Brand Choice, Purchase Incidence, and Segmentation: An Integrated Modeling Approach," Journal of Marketing Research, 29 (2), 201 15.

Bucklin, Randolph E. and James M. Lattin (1992), "A Model Product Category Competition among Grocery Retailers," Journal of Retailing, 68 (3), 271.

Burke, Raymond R., Bari A. Harlam, Barbara E. Kahn, and Leonard M. Lodish (1992), "Comparing Dynamic Consumer Choice in Real and Computer-Simulated Environments," Journal of Consumer Research, 19 (1), 71-82.

\section{$\underline{\mathrm{C}}$}

Campo, Katia (1997), "Variety Seeking and the Sensitivity to in-Store Promotions," Unpublished doctoral thesis, UFSIA (University of Antwerp), Antwerp.

Chandon, Pierre, Brian Wansink, and Gilles Laurent (2000), "A Benefit Congruency Framework of Sales Promotion Effectiveness," Journal of Marketing, 64 (4), 65-81.

Chandran, Sucharita and Vicki G. Morwitz (2006), "The Price Of "Free"-Dom: Consumer Sensitivity to Promotions with Negative Contextual Influences," Journal of Consumer Research, 33 (3), 38492.

Chen, Haipeng, Howard Marmorstein, Michael Tsiros, and Akshay R. Rao (2012), "When More Is Less: The Impact of Base Value Neglect on Consumer Preferences for Bonus Packs over Price Discounts," Journal of Marketing, 76 (4), 64-77.

Chiang, Jeongwen (1991), "A Simultaneous Approach to the Whether, What and How Much to Buy Questions," Marketing Science, 10 (4), 297.

Curran, James M. and Matthew L. Meuter (2007), "Encouraging Existing Customers to Switch to Self-Service Technologies: Put a Little Fun in Their Lives," Journal of Marketing Theory \& Practice, 15 (4), 283-98. 
Curran, James M., Matthew L. Meuter, and Carol F. Surprenant (2003), "Intentions to Use SelfService Technologies: A Confluence of Multiple Attitudes," Journal of Service Research, 5 (3), 209-24.

\section{D}

D'Astous, Alain and Isabelle Jacob (2002), "Understanding Consumer Reactions to Premium-Based Promotional Offers," European Journal of Marketing, 36 (11/12), 1270-86.

D'Astous, Alain and Valérie Landreville (2003), "An Experimental Investigation of Factors Affecting Consumers' Perceptions of Sales Promotions," European Journal of Marketing, 37 (11/12), 1746-61.

Dabholkar, Pratibha and Richard Bagozzi (2002), "An Attitudinal Model of Technology-Based SelfService: Moderating Effects of Consumer Traits and Situational Factors," Journal of the Academy of Marketing Science, 30 (3), 184-201.

Darke, Peter R. and Cindy M.Y. Chung (2005), "Effects of Pricing and Promotion on Consumer Perceptions: It Depends on How You Frame It," Journal of Retailing, 81 (1), 35-47.

Davis, Fred D. (1989), "Perceived Usefulness, Perceived Ease of Use, and User Acceptance of Information Technology," MIS Quarterly, 13 (3), 319-40.

Deci, Edward L., Richard Koestner, and Richard M. Ryan (1999), "A Meta-Analytic Review of Experiments Examining the Effects of Extrinsic Rewards on Intrinsic Motivation," Psychological Bulletin, 125 (6), 627-68.

Delhaize Group (2009), "Annual Report 2008," http://www.delhaizegroup.com/Portals/0/html/AnnualReport/2008/html\%20nl/index.htm.

Dhar, Ravi and Klaus Wertenbroch (2000), "Consumer Choice between Hedonic and Utilitarian Goods," Journal of Marketing Research, 37 (1), 60-71.

Diamond, William D. (1992), "Just What Is a 'Dollar's Worth'? Consumer Reactions to Price Discounts Vs. Extra Product Promotions," Journal of Retailing, 68 (3), 254.

Dickerson, Mary Dee and James W. Gentry (1983), "Characteristics of Adopters and Non-Adopters of Home Computers," Journal of Consumer Research, 10 (2), 225-35.

Dowling, G. R. (1986), "Perceived Risk: The Concept and Its Measurement," Psychology \& Marketing, 3 (3), 193-210.

\section{$\underline{E}$}

Esteban-Bravo, Mercedes, José M. Múgica, and Jose M. Vidal-Sanz (2009), "Magazine Sales Promotion," Journal of Advertising, 38 (1), 137-46.

\section{F}

Foubert, Bram and Els Gijsbrechts (2007), "Shopper Response to Bundle Promotions for Packaged Goods," Journal of Marketing Research, 44 (4), 647-62.

\section{$\underline{\mathbf{G}}$}

Gaeth, Gary J., Irwin P. Levin, Goutam Chakraborty, and Aron M. Levin (1991), "Consumer Evaluation of Multi-Product Bundles: An Information Integration Analysis," Marketing Letters, 2 (1), 47-57.

Gatignon, H. and T.S. Robertson (1991), "Innovative Decision Processes," in Handbook of Consumer Behavior, ed. Englewood Cliffs, NJ: Prentice-Hall.

Gedenk, Karen, Sönke Hartmann, and Tim Schulze (2000), "Die Wirkung Von Produktzugabe -Ein Conjoint-Experiment-," Zeitschrift für Betriebswirtschaft, 12, 1311-30.

Gedenk, Karen, Sascha Hoffmann, and Claudia Fantapié Altobelli (2008), "Premium Promotions: Do They Work, and What Drives Their Effectiveness?," Working Paper. 
--- (2010), "Premium Promotions: Do They Work, and What Drives Their Effectiveness?," working Paper, Universität Hamburg, Hamburg, Germany.

Gedenk, Karen and Scott A. Neslin (1999), "The Role of Retail Promotion in Determining Future Brand Loyalty: Its Effect on Purchase Event Feedback," Journal of Retailing, 75 (4), 433.

Gielens, Katrijn and Jan-Benedict E.M. Steenkamp (2007), "Drivers of Consumer Acceptance of New Packaged Goods: An Investigation across Products and Countries," International Journal of Research in Marketing, 24 (2), 97-111.

Gneezy, Uri and Aldo Rustichini (2000a), "A Fine Is a Price," The Journal of Legal Studies, 29 (1), 117.

--- (2000b), "Pay Enough or Don't Pay at All," Quarterly Journal of Economics, 115 (3), 791-810.

Goldenberg, Jacob, Sangman Han, Donald R. Lehmann, and Jae Weon Hong (2009), "The Role of Hubs in the Adoption Process," Journal of Marketing, 73 (2), 1-13.

Grewal, Dhruv, Kent B. Monroe, and R. Krishnan (1998), "The Effects of Price-Comparison Advertising on Buyers' Perceptions of Acquisition Value, Transaction Value, and Behavioral Intentions," The Journal of Marketing, 62 (2), 46-59.

Gupta, Sunil (1988), "Impact of Sales Promotions on When, What, and How Much to Buy," Journal of Marketing Research, 25 (4), 342-55.

$\underline{\mathbf{H}}$

Haenlein, Michael, Andreas M. Kaplan, and Detlef Schoder (2006), "Valuing the Real Option of Abandoning Unprofitable Customers When Calculating Customer Lifetime Value," Journal of Marketing, 70 (3), 5-20.

Hamm, B. Curtis, Michael Perry, and Hugh F. Wynn (1969), "The Effect of Free Samples on Image and Attitude," Journal of Advertising Research, 9 (4), 35-38.

Hardesty, David M. and William O. Bearden (2003), "Consumer Evaluations of Different Promotion Types and Price Presentations: The Moderating Role of Promotional Benefit Level," Journal of Retailing, 79 (1), 17-25.

Heiman, Amir, Bruce McWilliams, Zhihua Shen, and David Zilberman (2001), "Learning and Forgetting: Modeling Optimal Product Sampling over Time," Management Science, 47 (4), 532 46.

Heyman, James and Dan Ariely (2004), "Effort for Payment," Psychological Science, 15 (11), 787-93.

Hoeffler, Steve (2003), "Measuring Preferences for Really New Products," Journal of Marketing Research, 40 (4), 406-20.

\section{$\underline{I}$}

Im, Subin, Barry L. Bayus, and Charlotte H. Mason (2003), "An Empirical Study of Innate Consumer Innovativeness, Personal Characteristics, and New-Product Adoption Behavior," Journal of the Academy of Marketing Science, 31 (1), 61-73.

Iyengar, Raghuram, Christophe Van den Bulte, and Thomas W. Valente (2011), "Opinion Leadership and Social Contagion in New Product Diffusion," Marketing Science, 30 (2), 195-212.

\section{$\perp$}

Jain, Dipak, Vijay Mahajan, and Eitan Muller (1995), "An Approach for Determining Optimal Product Sampling for the Diffusion of a New Product," Journal of Product Innovation Management, 12 (2), 124-35.

Jamieson, Linda F. and Frank M. Bass (1989), "Adjusting Stated Intention Measures to Predict Trial Purchase of New Products: A Comparison of Models and Methods," Journal of Marketing Research, 26 (3), 336-45. 
Jeuland, Abel P. (1979), "Brand Choice Inertia as One Aspect of the Notion of Brand Loyalty," Management Science, 25 (7), 671-82.

\section{$\underline{\mathbf{K}}$}

Kahneman, Daniel and Amos Tversky (1979), "Prospect Theory: An Analysis of Decision under Risk," Econometrica, 47 (2), 263-91.

Kempf, Deanne S. and Robert E. Smith (1998), "Consumer Processing of Product Trial and the Influence of Prior Advertising: A Structural Modeling Approach," Journal of Marketing Research, 35 (3), 325-38.

Kivetz, Ran (2005), "Promotion Reactance: The Role of Effort-Reward Congruity," Journal of Consumer Research, 31 (4), 725-36.

Kridel, Donald J., Dale E. Lehman, and Dennis L. Weisman (1993), "Option Value, Telecommunications Demand, and Policy," Information Economics and Policy, 5 (2), 125-44.

Kumar, V. and Robert P. Leone (1988), "Measuring the Effect of Retail Store Promotions on Brand and Store Substitution," Journal of Marketing Research, 25 (2), 178-85.

$\underline{\mathbf{L}}$

Laochumnanvanit, Krongjit and David H. B. Bednall (2005), "Consumers' Evaluation of Free Service Trial Offers," Academy of Marketing Science Review, 2005 (11), 1-13.

Lattin, James M. and Randolf E. Bucklin (1989), "Reference Effects of Price and Promotion on Brand Choice Behavior," Journal of Marketing Research, 26 (3), 299-310.

Lee, Jungki and Arthur Allaway (2002), "Effects of Personal Control on Adoption of Self-Service Technology Innovations," Journal of Services Marketing, 16 (6), 553.

Lewis, Michael (2006), "Customer Acquisition Promotions and Customer Asset Value," Journal of Marketing Research, 43 (2), 195-203.

Low, George S. and Donald Jr. Lichtenstein (1993), "Technical Research Note: The Effect of Double Deals on Consumer Attitudes," Journal of Retailing, 69 (4), 453-66.

\section{$\underline{\text { M }}$}

Manchanda, Puneet, Xie Ying, and Nara Youn (2008), "The Role of Targeted Communication and Contagion in Product Adoption," Marketing Science, 27 (6), 961-76.

Manning, Kenneth C., William O. Bearden, and Thomas J. Madden (1995), "Consumer Innovativeness and the Adoption Process," Journal of Consumer Psychology (Lawrence Erlbaum Associates), 4 (4), 329.

Marks, Lawrence J. and Michael A. Kamins (1988), "The Use of Product Sampling and Advertising: Effects of Sequence of Exposure and Degree of Advertising Claim Exaggeration on Consumers' Belief Strength, Belief Confidence, and Attitudes," Journal of Marketing Research, 25 (3), 266.

Martin, Ingrid M. and David W. Stewart (2001), "The Differential Impact of Goal Congruency on Attitudes, Intentions, and the Transfer of Brand Equity," Journal of Marketing Research, 38 (4), 471-84.

Mazumdar, Tridib, S. P. Raj, and Indrajit Sinha (2005), "Reference Price Research: Review and Propositions," The Journal of Marketing, 69 (4), 84-102.

McFadden, Daniel and Kenneth Train (2000), "Mixed Mnl Models for Discrete Response," Journal of Applied Econometrics, 15 (5), 447-70.

Meuter, Matthew L., Mary Jo Bitner, Amy L. Ostrom, and Stephen W. Brown (2005), "Choosing among Alternative Service Delivery Modes: An Investigation of Customer Trial of Self-Service Technologies," Journal of Marketing, 69 (2), 61-83. 
Meuter, Matthew L., Amy L. Ostrom, Robert I. Roundtree, and Mary Jo Bitner (2000), "Self-Service Technologies: Understanding Customer Satisfaction with Technology-Based Service Encounters," Journal of Marketing, 64 (3), 50-64.

Mishra, Arul and Himanshu Mishra (2011), "The Influence of Price Discount Versus Bonus Pack on the Preference for Virtue and Vice Foods," Journal of Marketing Research, 48 (1), 196-206.

Moreau, C. Page, Donald R. Lehmann, and Arthur B. Markman (2001), "Entrenched Knowledge Structures and Consumer Response to New Products," Journal of Marketing Research, 38 (1), 14-29.

Morrison, Donald G. (1979), "Purchase Intentions and Purchase Behavior," The Journal of Marketing, 43 (2), 65-74.

Morwitz, Vicki G., Joel H. Steckel, and Alok Gupta (2007), "When Do Purchase Intentions Predict Sales?," International Journal of Forecasting, 23 (3), 347-64.

Murphy, Kevin R. and Brett Myors (1998), Statistical Power Analysis: A Simple and General Model for Traditional and Modern Hypothesis Tests, Mahwah, NJ: Lawrence Erlbaum Associates.

$\underline{\mathbf{N}}$

Nam, Sungjoon, Puneet Manchanda, and Pradeep K. Chintagunta (2010), "The Effect of Signal Quality and Contiguous Word of Mouth on Customer Acquisition for a Video-on-Demand Service," Marketing Science, 29 (4), 690-700.

Neslin, Scott A., Caroline Henderson, and John Quelch (1985), "Consumer Promotions and the Acceleration of Product Purchases," Marketing Science, 4 (2), 147.

Nunes, Joseph C. and C. Whan Park (2003), "Incommensurate Resources: Not Just More of the Same," Journal of Marketing Research, 40 (1), 26-38.

0

O'Guinn, Thomas C. and L. J. Shrum (1997), "The Role of Television in the Construction of Consumer Reality," Journal of Consumer Research, 23 (4), 278-94.

Okada, Erica Mina (2005), "Justification Effects on Consumer Choice of Hedonic and Utilitarian Goods," Journal of Marketing Research, 42 (1), 43-53.

Ong, Beng Soo, Foo Nin Ho, and Carolyn Tripp (1997), "Consumer Perceptions of Bonus Packs: An Exploratory Analysis," Journal of Consumer Marketing, 14 (2), 102-12.

Ostlund, Lyman E. (1974), "Perceived Innovation Attributes as Predictors of Innovativeness," Journal of Consumer Research, 1 (2), 23-29.

\section{P}

Palazón-Vidal, Mariola and Elena Delgado-Ballester (2005), "Sales Promotions Effects on Consumer-Based Brand Equity," International Journal of Market Research, 47 (2), 179-204.

Parasuraman, A. (2000), "Technology Readiness Index (Tri): A Multiple-Item Scale to Measure Readiness to Embrace New Technologies," Journal of Service Research, 2 (4), 307-20.

Park, Sojin and John C. Mowen (2007), "Replacement Purchase Decisions: On the Effects of TradeIns, Hedonic Versus Utilitarian Usage Goal, and Tightwadism," Journal of Consumer Behaviour, 6 (2/3), 123-31.

Park, Sungho and Sachin Gupta (2009), "Simulated Maximum Likelihood Estimator for the Random Coefficient Logit Model Using Aggregate Data," Journal of Marketing Research, 46 (4), 531-42.

Pauwels, Koen, Jorge Silva-Risso, Shuba Srinivasan, and Dominique M. Hanssens (2004), "New Products, Sales Promotions, and Firm Value: The Case of the Automobile Industry," Journal of Marketing, 68 (4), 142-56.

Plouffe, Christopher R., Mark Vandenbosch, and John Hulland (2001), "Intermediating Technologies and Multi-Group Adoption: A Comparison of Consumer and Merchant Adoption Intentions 
toward a New Electronic Payment System," Journal of Product Innovation Management, 18 (2), 65-81.

Preston, Robert H., Robert F. Dwyer, and William Rudelius (1978), "The Effectiveness of Bank Premiums," Journal of Marketing, 42 (3), 96-101.

Prins, Remco and Peter C. Verhoef (2007), "Marketing Communication Drivers of Adoption Timing of a New E-Service among Existing Customers," Journal of Marketing, 71 (2), 169-83.

$\underline{\mathbf{R}}$

Raghubir, Priya (2004), "Free Gift with Purchase: Promoting or Discounting the Brand?," Journal of Consumer Psychology, 14 (1/2), 181-86.

Raghubir, Priya and Kim Corfman (1999), "When Do Price Promotions Affect Pretrial Brand Evaluations?," Journal of Marketing Research, 36 (2), 211-22.

Revelt, David and Kenneth Train (1998), "Mixed Logit with Repeated Choices: Households' Choices of Appliance Efficiency Level," Review of Economics \& Statistics, 80 (4), 647-57.

Rogers, ed. (2003), Diffusion of Innovations New York: The Free Press.

Roy, Rishin, Pradeep K. Chintagunta, and Sudeep Haldar (1996), "A Framework for Investigating Habits, "The Hand of the Past," And Heterogeneity in Dynamic Brand Choice," Marketing Science, 15 (3), 280-99.

\section{$\underline{S}$}

Sándor, Zsolt and Kenneth Train (2004), "Quasi-Random Simulation of Discrete Choice Models," Transportation Research: Part B, 38 (4), 313.

Schary, Philip B. and Martin Christopher (1979), "The Anatomy of a Stock-Out," Journal of Retailing, $55(2), 59-71$.

Scott, Carol A. (1976), "The Effects of Trial and Incentives on Repeat Purchase Behavior," Journal of Marketing Research, 13 (3), 263-69.

Sethuraman, Raj, V. Srinivasan, and Doyle Kim (1999), "Asymmetric and Neighborhood Cross-Price Effects: Some Empirical Generalizations," Marketing Science, 18 (1), 23-41.

Shampanier, Kristina, Nina Mazar, and Dan Ariely (2007), "Zero as a Special Price: The True Value of Free Products," Marketing Science, 26 (6), 742-57.

Shimp, Terence A., Robert F. Dyer, and Salvatore F. Divita (1976), "An Experimental Test of the Harmful Effects of Premium-Oriented Commercials on Children," Journal of Consumer Research, 3 (1), 1-47.

Simonson, Itamar (1999), "The Effect of Product Assortment on Buyer Preferences," Journal of Retailing, 75 (3), 347.

Simonson, Itamar, Ziv Carmon, and Suzanne O'Curry (1994), "Experimental Evidence on the Negative Effect of Product Features and Sales Promotions on Brand Choice," Marketing Science, 13 (1), 23-40.

Sinha, Indrajit and Michael F. Smith (2000), "Consumers' Preferences of Promotional Framing of Price," Psychology \& Marketing, 17 (3), 257-75.

Sivakumar, K. and S.P. Raj (1997), "Quality Tier Competition: How Price Change Influences Brand Choice and Category Choice," Journal of Marketing, 61 (3), 71-84.

Sloot, Laurens M., Peter C. Verhoef, and Philip Hans Franses (2005), "The Impact of Brand Equity and the Hedonic Level of Products on Consumer Stock-out Reactions," Journal of Retailing, 81 (1), 15-34.

Smith, Robert E. and William R. Swinyard (1983), "Attitude-Behavior Consistency: The Impact of Product Trial Versus Advertising," Journal of Marketing Research, 20 (3), 257-67.

Sprott, David E. and Terence A. Shimp (2004), "Using Product Sampling to Augment the Perceived Quality of Store Brands," Journal of Retailing, 80 (4), 305-15. 
Steenkamp, Jan-Benedict E. M. and Steven M. Burgess (2002), "Optimum Stimulation Level and Exploratory Consumer Behavior in an Emerging Consumer Market," International Journal of Research in Marketing, 19 (2), 131-50.

Steenkamp, Jan-Benedict E. M. and Katrijn Gielens (2003), "Consumer and Market Drivers of the Trial Probability of New Consumer Packaged Goods," Journal of Consumer Research, 30 (3), 368-84.

Sun, Baohong and Vicki G. Morwitz (2010), "Stated Intentions and Purchase Behavior: A Unified Model," International Journal of Research in Marketing, 27 (4), 356-66.

\section{$\underline{T}$}

Thaler, Richard (1985), "Mental Accounting and Consumer Choice," Marketing Science, 4 (3), 199.

Thaler, Richard H. (2008), "Mental Accounting and Consumer Choice," Marketing Science, 27 (1), 15-25.

Train, Kenneth E. (2002), Discrete Choice Methods with Simulation, Cambridge, MA: Cambridge University Press.

--- (2003), Discrete Choice Methods with Simulation, Cambridge, MA: Cambridge University Press.

Tyagi, Rajeev K. (1999), "A Characterization of Retailer Response to Manufacturer Trade Deals," Journal of Marketing Research, 36 (4), 510-16.

$\underline{\mathrm{V}}$

Van Heerde, Harald J. , Sachin Gupta, and Dick R. Wittink (2003), "Is 75\% of the Sales Promotion Bump Due to Brand Switching? No, Only 33\% Is," Journal of Marketing Research, 40 (4), 481-91.

Van Ittersum, Koert and Fred M. Feinberg (2010), "Cumulative Timed Intent: A New Predictive Tool for Technology Adoption," Journal of Marketing Research, 47 (5), 808-22.

Venkatesh, R. and Wagner Kamakura (2003), "Optimal Bundling and Pricing under a Monopoly: Contrasting Complements and Substitutes from Independently Valued Products," Journal of Business, 76 (2), 211-31.

Verhoef, Peter C., Philip Hans Franses, and Janny C. Hoekstra (2001), "The Impact of Satisfaction and Payment Equity on Cross-Buying: A Dynamic Model for a Multi-Service Provider," Journal of Retailing, 77 (3), 359.

\section{$\underline{\mathbf{W}}$}

Walters, Rockney G. and Heikki J. Rinne (1986), "An Empirical Investigation into the Impact of Price Promotions on Retail Store Performance," Journal of Retailing, 62 (3), 237.

Wertenbroch, Klaus and Bernd Skiera (2002), "Measuring Consumers' Willingness to Pay at the Point of Purchase," Journal of Marketing Research, 39 (2), 228-41.

\section{$\underline{\mathbf{Z}}$}

Zhang, Jie and Lakshman Krishnamurthi (2004), "Customizing Promotions in Online Stores," Marketing Science, 23 (4), 561-78.

Zhang, Jie and Michel Wedel (2009), "The Effectiveness of Customized Promotions in Online and Offline Stores," Journal of Marketing Research, 46 (2), 190-206. 


\section{Curriculum Vitae}

Charlotte Rolef was born on the $12^{\text {th }}$ of May 1982 in Euskirchen, Germany. In 2001, she completed her secondary studies at the Emil-Fischer-Gymnasium in Euskirchen, Germany and started studying International Management at the Faculty of Economics and Business Administration at Maastricht University, the Netherlands. During her studies, she spent one semester in Gothenburg, Sweden at the University of Gothenburg. In April 2006, she received her Master's degree and became employed as a junior lecturer at the Department of Marketing and Supply Chain Management at Maastricht University. In September 2006, she started her PhD position at the same department.

Since January 2010 Charlotte Rolef is working as a marketing manager at IAL in Engelskirchen, Germany. 